San Jose State University

SJSU ScholarWorks

Dissertations

Master's Theses and Graduate Research

Fall 2017

\title{
Latino Male College Students' Identities, Psychological Stress, and Coping Mechanisms
}

Ana E. Ramirez

San Jose State University

Follow this and additional works at: https://scholarworks.sjsu.edu/etd_dissertations

\section{Recommended Citation}

Ramirez, Ana E., "Latino Male College Students' Identities, Psychological Stress, and Coping Mechanisms" (2017). Dissertations. 12.

DOI: https://doi.org/10.31979/etd.7vax-8zc2

https://scholarworks.sjsu.edu/etd_dissertations/12

This Dissertation is brought to you for free and open access by the Master's Theses and Graduate Research at SJSU ScholarWorks. It has been accepted for inclusion in Dissertations by an authorized administrator of SJSU ScholarWorks. For more information, please contact scholarworks@sjsu.edu. 


\title{
LATINO MALE COLLEGE STUDENTS' IDENTITIES, PSYCHOLOGICAL STRESS, AND COPING MECHANISMS
}

\author{
A Dissertation \\ Presented to \\ The Faculty of the Educational Doctoral Program in Educational Leadership \\ San José State University \\ In Partial Fulfillment \\ of the Requirements for the Degree \\ Doctor of Education
}

by

Ana E. Ramírez

December 2017 
(C) 2017

Ana E. Ramírez

ALL RIGHTS RESERVED 
The Designated Dissertation Committee Approves the Dissertation Titled

LATINO MALE COLLEGE STUDENTS' IDENTITIES, PSYCHOLOGICAL STRESS, AND COPING MECHANISMS

by

Ana E. Ramírez

APPROVED FOR THE EDUCATIONAL DOCTORAL PROGRAM IN EDUCATIONAL LEADERSHIP

SAN JOSÉ STATE UNIVERSITY

December 2017

\author{
Megan Thiele, Ph.D. Department of Social Sciences \\ Marcos Pizarro, Ph.D. Department of Mexican American Studies \\ Shelly Viramontez, Ed.D. $\quad$ Superintendent of Schools, Campbell \\ Union School District
}




\title{
ABSTRACT \\ LATINO MALE COLLEGE STUDENTS’ IDENTITIES, PSYCHOLOGICAL STRESS, AND COPING MECHANISMS
}

\author{
by Ana E. Ramírez
}

Latino male college students' identities impact their personal experiences, academic achievement, and well-being. This qualitative study uses a narrative inquiry approach to research Latino male college students' racial and ethnic, gender, and academic identities and to investigate how these identities impact their psychological stress and the coping mechanisms they implement to manage their stress. Latino males undergo an identity development in which they engage in negotiating their gender identities in order to prioritize higher education academic requirements. When Latino males are determined to achieve a college degree, they are able to adjust their familism gender role expectations and shift their ethnic masculinity principles to fulfill their academic identities. Adjusting familism gender role expectations and shifting ethnic masculinity principles position these males to endure stress. Simultaneously, certain outcomes, such as racial profiling and microaggressions brought on by their racial and ethnic identities, impact their academic achievement and well-being. Some, but not all, Latino males seek professional counseling to manage their stress. More research must be done to investigate why some Latino males shift their ethnic masculinity principles to overcome academic challenges and why some are able to adjust their familism gender role expectations to function independently in order to focus on academics. 


\section{DEDICATION}

I dedicate this personal accomplishment to Uno's Pack, my husband, my parents, the 22 participants, the dissertation committee, and Club América.

Uno's Pack, my four loving German shepherds--life is great because of you! We have had enough adventures to write a few books. Uno, at times I wondered if you could read my mind, but then I realized that you just know me too well (my pack leader!). Amarilla, my nose work girl, you have made me proud (find it!). Estrella, my agility girl, we became the invincible team, but what I cherish the most is the time we spent together learning, training, and bounding (touch!). Maestra, my playful, energetic girl and Uno's best friend, for you every second of they day is playtime unless you are asleep (life is good!). My four-legged companions, you stole my heart. It has been an honor to hold your leashes and to walk through life right next to you... Love you always.

Jesus, my beloved husband, thank you for your unconditional love and support, not just during this journey, but every time I want to do something. Sharing my life with you has been a blessing. Hemos disfrutado la vida al máximo (mi Nicoya, ijeepones!).

Papá eres mi ídolo siempre haz luchado por darnos lo mejor. Desde dejar Tizapan y aventurarte a buscar un mejor futuro al otro lado para tu familia, traernos a este país y hacerte ciudadano. Gracias por tus sacrificios y por enseñarme que todo en la vida es posible con dedicación, trabajo y humildad. Mamá eres la luz de mis ojos. No hay palabras para agradecerte todo lo que haz hecho por nosotros, crecí viéndote trabajar para darnos de comer y pagar la educación de tus hijos. Te admiro por tu fortaleza, dedicación 
a tu familia y por tu gran corazón. Gracias por inculcarnos la importancia de estudiar. Mamá y papá este doctorado es de ustedes.

To my 22 Latino male participants in this study, thank you for your time and sharing your stories. Los admiro como estudiantes e hijos y los felicito por su dedicación a su educación.

To my committee members--Dr. Megan Thiele, Dr. Shelly Viramontez, and Dr. Pizarro--thank you for your time, support, and patience. You are the best dissertation committee a student could wish for. Thank you for believing in me. Together, we did it, five research questions and 22 participants!

Club de Fútbol América, aparte de Doctora Americanista. 12 títulos de liga, 5 Copas México y 5 veces Campeón de Campeones. 100 años de grandeza te amaré otro siglo (¡ódiame más!).

\section{ACKNOWLEDGEMENTS}

Rosa, Carlos, and Benjamin, being your sister is a privilege. Thank you for your love and support. Rosa, me encanta que vives la vida al máximo nunca cambies. Carlos, gracias por cuidarme cuando era una niña, que gratos recuerdos. Benjamin, eres un gran hijo, estoy muy orgullosa de ti. Gracias por toda tu ayuda. Frida my favorite niece, keep going because very soon you will be a veterinarian (I already have plenty of customers for you), Love you! Abuelas, mamá Pina y mamá María gracias por ser mis madres cuando mamá fue en busca de un mejor futuro. Tía Carmen gracias por enseñarme la 
importancia de siempre ayudar al prójimo. América Latina, porque la vida nos brindé la oportunidad de reunirnos.

Donna Tonry, thank you for all your help, time, and friendship. You have been part of this journey since I applied to the program. Peggy Bryan, thank you for hiring me as a teacher 13 years ago. Deanna Peck, thank you! And, to my former and current students, thank you, and I am looking forward to attending your college graduations.

There are multiple people that must be acknowledged, as they have helped me to get where I am today: Clara Fernández, Betsy Fitch, Pam Cheng, Dayan Flores, Alma Sánchez, Yvette Licea, Erika Contreras, Carol Villalta, Rafaela Guitron, Dr. Patricia Swanson, Dr. Ferdie Rivera, Dr. Emily Slusser, Dr. Joyce Osland, Marie Kochevar, Itza Sánchez, Adriana Poo, and Maria Muñoz.

\author{
Thank you, \\ San José State University \\ Go Spartans! \\ Uno’s Pack: Amarilla, Estrella, Maestra, Jesus, and Ana \\ I'M DONE! \\ Dr. Ana Ramírez
}




\section{TABLE OF CONTENTS}

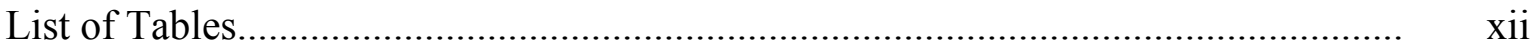

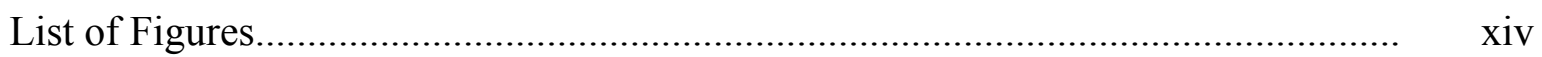

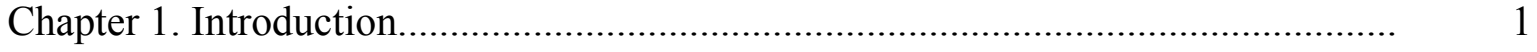

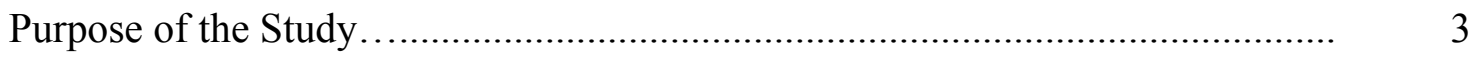

Research Questions.....................................................................................

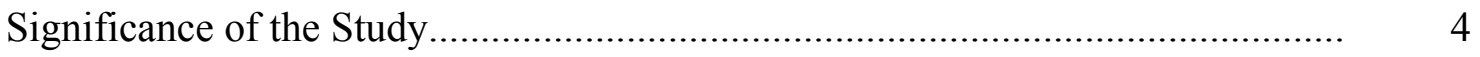

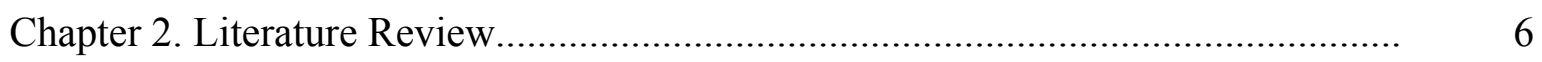

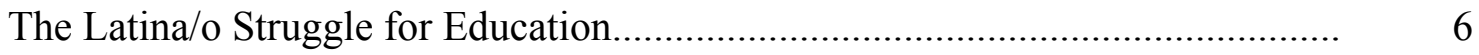

Latino Male Education................................................... 7

Race and Ethnicity..................................................... 9

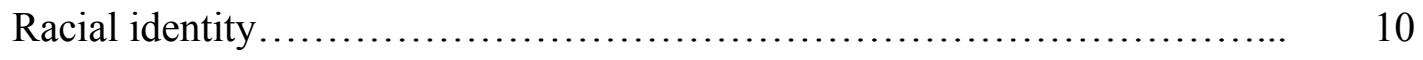

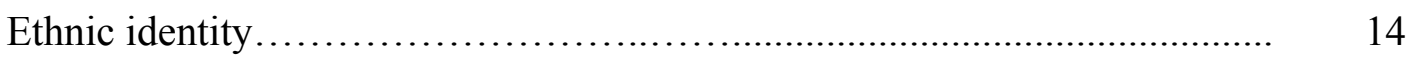

Gender Role Socialization.................................................. 19

Latino Male Gender Role Socialization........................................................ 20

Familism Expectations Impacting Gender Identity........................... 23

Latino Masculinity Constructs........................................... 24

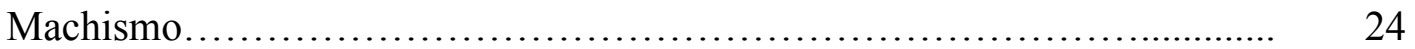

Caballerismo..................................................................... 25

Latino Male College Students' Gender Identity ................................ 26

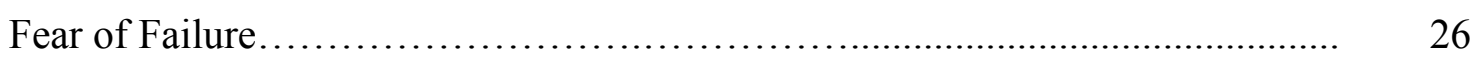

Latino Male Academic Identities and Stereotypes.......................................... 27

Latino Male College Students' Psychological Stressors..................................... $\quad 30$

Racial Battle Fatigue............................................................ 35

Latino Male College Students' Coping Responses to Stress..................... 37

Conceptual Framework................................................................ 41

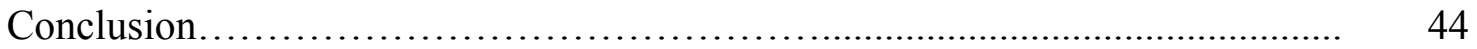

Chapter 3. Methodology ............................................................. 45

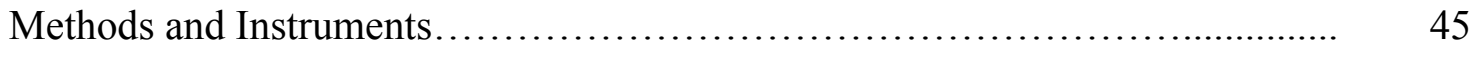

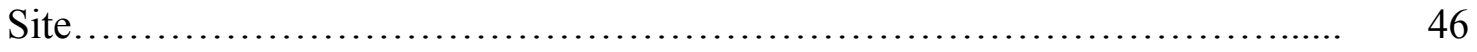

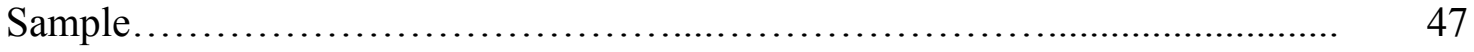


Data Collection............................................................... 48

Data Analysis......................................................................... 50

Ethical Considerations....................................................... 51

Limitations of the Study .................................................................. 52

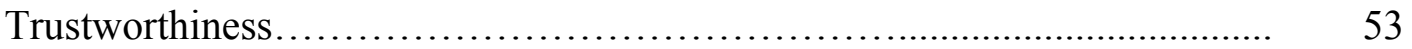

Background and role of the researcher.................................................. 53

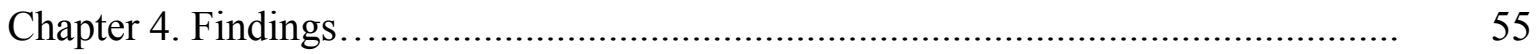

Research Question Number 1 Racial and Ethnic Identities............................. 57

Participants' ethnic identification .............................................................. $\quad 57$

Racial and ethnic identity as a motivation............................................. $\quad 62$

Research question number 1 overview of key findings............................. 65

Research Question Number 2 Participants’ Masculinity Constructs.................... 65

Un hombre de familia (a family man) familism values.............................. 67

Future provider..................................................... 69

Research question number 2 overview of key findings............................. $\quad 70$

Research Question Number 3 Ethnic Gender Identities and Academic Identities. 71

Struggling to reshape Latino masculinity principles............................ $\quad 72$

Reshaping Latino masculinity principles................................................. $\quad 76$

Research question number 3 overview of key findings .............................. $\quad 79$

Research Question Number 4 Latino Males’ Racial and Ethnic Identity

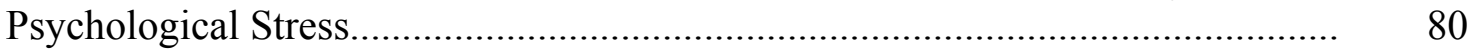

Racial profiles and microaggressions...................................................... $\quad 82$

Racial profiling from classmates............................................................ 83

Microaggressions from professors and classmates....................................... $\quad 88$

Microaggressions and racial profiling outside the classrooms...................... 91

Acceptability and being treated with respect by faculty............................. 99

Acceptability and being treated with respect by classmates......................... 101

Nonverbal indirect singling out by classmates............................ 102

Latino Males' Gender Identity Psychological Stress........................................... 104

Latino Males' Academic Identity Psychological Stress First-Generation College Student Status...........................................................

Balancing academics and finances..................................... 119

Major academic demands.......................................... 120 
Research question number 4 overview of key findings.................. 121

Research Question Number 5 Latino Males' Coping Mechanisms............... 124

Various informal coping mechanisms................................ 124

Formal coping mechanisms.......................................... 128

Opposed to formal coping mechanisms................................ 129

Formal coping mechanisms counseling .............................. 130

Seeking professional help, a difficult decision.......................... 130

Seeking professional help, an uncomplicated decision................... 131

Emotional Stress Symptoms......................................... 133

Research Question Number 5 Overview of Key Findings..................... 135

Latino Males' Identity Development, Negotiation, and the Impacts on

Academics............................................................ 136

Participants' Ethnicities and Academic Majors Overview of Key Findings....... 142

Conclusion....................................................... 146

Chapter 5. Key Findings, Conclusions, Discussions, and Recommendations......... 150

Ethnic and Racial Identity, Academic Achievement, and Participants' Wellbeing

Academic achievement

Academic achievement doubt....................................... 157

Participants' well-being............................................... 159

Ethnic Gender Identity, Academic Achievement, and Participants' Well-being... 162

Ethnic Masculinity Principles Academic Achievement......................... 163

Recommendations for Further Research.................................. 168

Implications for Policy and Practice................................... 170

Administration....................................................... 171

Health center................................................. 171

Admissions............................................................ 172

Faculty....................................................... 172

Latino organizations.............................................. 173

Conclusion.......................................................... 174

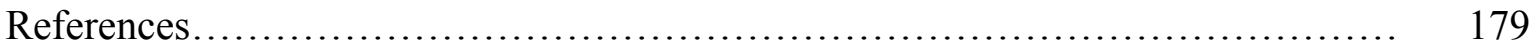

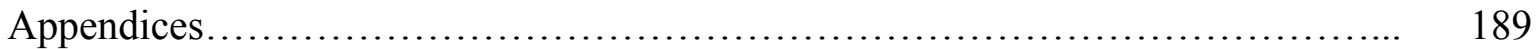

Appendix A: Potential Participant Questionnaire............................ 189 
Appendix B: Demographic Survey Profile Consent Form.................... 190

Appendix C: Demographic Survey Profile................................. 192

Appendix D: Individual Interview Consent Form.......................... 193

Appendix E: Individual Interview Protocol................................ 195

Appendix F: Recruitment Email to Stakeholders.......................... 198

Appendix G: Recruitment Flyer......................................... 199

Appendix H: Participants Demographic Survey Profiles.................... 200 


\section{LIST OF TABLES}

Table 1. Latina Females, Latino Males, White Males and White Females' Higher Education Enrollment 1900 - 2008......................................... 8

Table 2. Participants' Information..................................... 56

Table 3. Participants' Ethnic Identification............................. 57

Table 4. Participants' Ethnic Identification and Birthplace................... 60

Table 5. Participants' Ethnic Identification by Parents' Heritage and Birthplace.. 61

Table 6. Participants' Masculinity Constructs............................ 69

Table 7. Stage 1: Ethnically Masculinity Principles Restricting Academic Identities................................................... 73

Table 8. Stage 2: Academic Identities Reshaping Ethnic Masculinity Principles.. 75

Table 9. Racial and Ethnic Identity Participants' Experiences.................. 81

Table 10. Fourteen Participants' Racial and Ethnic Identity Experiences.......... 81

Table 11. Fourteen Participants' Positive and Negative Racial and Ethnic Identity Experiences.................................................

Table 12. Struggling to Balance Academic Responsibilities and Familism Values. 105

Table 13. Negotiating Detachment Period................................ 108

Table 14. Causes of Academic Stress.................................... 114

Table 15. Types of Informal Coping Mechanisms......................... 124

Table 16. Formal Counseling Participation............................... 130

Table 17. Formal Counseling Psychological Stress Symptoms................ 133

Table 18. Impacts of Racial Profiling, Microaggressions, and Nonverbal Indirect Singling Out............................................... 147

Table 19. Racial Profiling, Microaggressions, and Nonverbal Indirect Singling Out Stereotypes 
Table 20. Racial Profiling and Microaggressions: Participants' Ethnic Identities and Major........................................................ 153

Table 21. Nonverbal Singling Out by Classmates: Participants' Ethnic Identities and Major................................................................. 


\section{LIST OF FIGURES}

Figure 1. Latino male college students' identities conceptual framework............ 43

Figure 2. Latino male college students' findings conceptual model............. 175 


\section{Chapter 1}

\section{Introduction}

From elementary school to university, Latina/o students are the fastest growing group within our public educational settings (Chapa \& De La Rosa, 2004). According to Fry and Gonzales (2008), the U.S. Census Bureau estimates that by 2050 the Latina/o population will grow to 28 million school-aged students. The school-aged Latina/o population is predicted to continue to grow at higher rates than non-Latina/o school age students (Chapa \& De La Rosa, 2004; Fry \& Gonzales, 2008). This demographic transformation requires educators, educational researchers, and policymakers to understand the educational experiences of these students. Equally important, by understanding these students' educational experiences, learning institutions can take a proactive approach towards acknowledging and figuring out how to meet their specific needs.

In the educational arena, the pipeline metaphor explains how students travel through primary, secondary, and postsecondary education (Huber, Huidor, Malagón, Sanchez, \& Solorzano, 2006; Pérez Huber et al., 2015). The Latina/o educational pipeline highlights the academic underachievement of these students, as they struggle to travel successfully from primary through postsecondary stages (Huber et al., 2006; Pérez Huber et al., 2015). Researchers concur that lack of academic preparation is the biggest obstacle to Latina/o students' secondary and postsecondary achievement (Hernandez \& Lopez, 2004; Pino, Martinez-Ramos, \& Smith, 2012; Zalaquett, 2005). The ACT College Readiness Benchmarks evaluate if high school students have learned the essential skills to be 
academically successful in college. As Excelencia in Education and ACT (2015) reported in "The Conditions of College and Career Readiness 2014: Hispanic Students" in 2014, just 57\% of Latina/o high school graduating students undertook the ACT College Readiness exams and only 14\% successfully passed all four subjects: English, reading, mathematics, and science. This illustrates how Latina/o students, in particular, disappear in the educational pipeline as they move towards postsecondary education, whereas their White counterparts are much more successful at arriving at that stage and achieving postsecondary degrees (Huber et al., 2006; Pérez Huber et al., 2015). In contrast to other groups, Latina/o students are less likely to attend four-year colleges or selective colleges, or even to enroll full time in either (Fry \& Taylor, 2013). However, Latina/o students are overrepresented at community colleges in comparison to other ethnic groups (Fry \& Taylor, 2013). Postsecondary enrollment numbers from 2014 reflect that trend: $48 \%$ of Latina/o students attended community colleges as opposed to 36\% Blacks, 32\% Asians, and 30\% Whites (Krogstand, 2016).

Furthermore, the numbers demonstrate that when it comes to gender, Latino males are more likely than Latina females to be underrepresented in postsecondary education (Sáenz \& Ponjuan, 2009). For example, for every 100 Latina/o elementary students, 63 females and 60 males will earn a high school diploma, whereas for every 100 White students, 92 females and 91 males will earn that diploma (Pérez Huber et al., 2015). Ultimately, only 13 Latina females and 11 Latino males will graduate from college in comparison to 32 White females and 33 White males (Pérez Huber et al., 2015). Graduate school numbers are similar: 4 Latina females and 3 Latino males will earn 
higher degrees, as compared to 12 White females and 13 White males (Pérez Huber et al., 2015). This data, especially when extrapolated, is significant in that it reveals Latino males' education attainment struggles in comparison to Latina females at the different sectors of the pipeline (Pérez Huber et al., 2015).

Latino males' secondary and postsecondary enrollment rates are of great concern (Sáenz \& Ponjuan, 2009). For example, in 2004, 28.4\% of Latino males between the ages of 16 and 24 were high school dropouts in comparison to $18.5 \%$ Latina females (Sáenz \& Ponjuan, 2009). Similarly, from 1975 to 2006, Latino males' enrollment in relation to Latina females' enrollment in four-year institutions declined from $57.4 \%$ to 39.0\% (Sáenz \& Ponjuan, 2009). Consequently, there is an overall enrollment gap that speaks to the low percentages of Latino males attending four-year institutions and a disturbing gender gap that reflects lower percentages of Latinos attending four-year institutions (Sáenz \& Ponjuan, 2009). So far, this gender gap has been largely understudied (Sáenz \& Ponjuan, 2011).

\section{Purpose of the Study}

The purpose of this study is to investigate the underachievement among Latino male students in a public university setting. In so doing, it seeks to show how these students understand their racial and ethnic, gender, and academic identities while at university. Arguably, these identities and the relationships between these identities shape how Latino male college students fare and position themselves within higher education (Torres, 2003). Moreover, in order to present a complete portrayal of Latino males, this study investigates not only how Latino male college students' various identities impact their 
psychological stress, but also the coping mechanisms these students employ to manage their psychological stress. The study addresses a significant research gap in regard to Latino male college students. It sheds light on the impact that both identities and psychological stress have on the academic and personal experiences Latino male college students face within the college setting.

\section{Research Questions}

The following research questions guide this study:

1. How do Latino male college students understand their racial and ethnic identity?

2. How do Latino male college students understand their gender identity?

3. How do Latino male college students understand their academic identity?

4. How do Latino male college students' various identities impact their psychological stress?

5. What coping mechanisms do Latino male college students employ to manage their various identities' psychological stress?

\section{Significance of the Study}

This study is significant as it recognizes that the intersections of race, ethnicity, and gender identities frame Latino males' educational experiences and outcomes (Cammarota, 2004; Figueroa, Pérez, \& Vega, 2016). As Sáenz and Ponjuan (2011) articulate, "The issues of how and why Latino males are struggling to access and succeed in college are complex" (p. 4). For that reason, this qualitative study seeks to bring to light the particular experiences of Latino male college students within higher education. Edwards (2006) emphasizes that, "Within the frame of masculinity studies, few scholars 
have incorporated race and ethnicity in their analyses" (as cited in Figueroa et al., 2016, p. 64). Prior masculinity investigations have documented the significance of gender in education; however, only slight attention has been paid to Latino males' gender identity and their masculinity expectations as they attend higher education (Figueroa et al., 2016). Previous studies illustrate the significance of gender on Latino male students (Arciniega, Anderson, Tovar-Blank, \& Tracey, 2008; Figueroa et al., 2016; Liang, Salcedo, \& Miller, 2011; Lu \& Wong, 2014; Saez, Casado, \& Wade, 2010), whereas only a single study has focused on investigating gender on current Latino male college students (PeñaTalamantes, 2013). Utilizing male gender conflict framework, the Sáenz, Bukoski, Lu, and Rodriguez (2013) community college phenomenological study found that restraining emotions, emphasizing strength, and cultural and familial responsibilities impact Latino male students' experiences.

Additionally, this study is significant as it provides a new lens that uncovers how these students' various identities impact their psychological stress and, at the same time, investigates the coping mechanisms these students employ to manage stress. It does so by providing participants with an opportunity to voice their experiences. In sum, it is imperative to understand how Latino male college students' racial, ethnic, gender, and academic identities not only impact their psychological well-being, but also how these students cope with related stresses. Students' responses will allow this study to inform policy related to how learning institutions can better meet the needs of these students. 


\section{Chapter 2}

\section{Literature Review}

\section{The Latina/o Struggle for Education}

As history illustrates, Latinas/os have encountered different educational barriers in their efforts to safeguard equitable educational practices within public learning institutions (MacDonald, 2013). Oftentimes they experience inequities based on the vast cultural differences (including ethnicity and native languages) between their home life and the culture that is dominant within public education (MacDonald, 2013). Latinas/os have responded to the unfavorable educational practices by exercising their constitutional rights. ${ }^{1}$

Conceivably, the most notable case that challenged lawful segregation was Brown v. Board of Education of Topeka, Kansas (1954) (Gonzalez, 2007). Under Brown v. Board of Education of Topeka, Kansas (1954), the Supreme Court collectively concluded that Plessey v. Ferguson (1896) procedures of "separate but equal" were unconstitutional (Gonzalez, 2007, p. 340). One decisive outcome from the Brown v. Board of Education ruling was that it changed Latinas/os lawsuit practices in that it allowed Latinas/os to be recognized as a cultural "minority group" by ending their classification as "other White" (San Miguel, 2005, p. 221). As Gonzalez (2007) concludes, the Brown and the Cisneros v. Corpus Christi Independent School District (1970) court cases brought to light

\footnotetext{
${ }^{1}$ List of different cases that have challenged separate but equal education practices: Romo v Laird (1925), Independent School District v. Salvatierra (1930), Alvarez v. Lemon Grove (1931), Mendez v. Westminister School District (1946), Delgado v. Bastrop Independent School District (1948), and Gonzalez v. Sheely (1951) (Aguirre, 2005; Contreras \& Valverde, 1994; Gonzalez, 2007; Muñoz, 2001).
} 
practices that perpetuated legal poor quality education under separate but equal rulings for Latina/o students.

These historical cases represent a fight against "institutional racism" (Gonzalez, 2007, p. 332). Institutional racism refers to the covert and/or hidden racist practices within the educational system that continue to be unchallenged and accepted as educational norms (Carroll Massey, Vaughn Scott, \& Dornbusch, 1975). An example of this paradigm is the deficit model, which articulates that students and parents are responsible for the low academic achievement of minority students, not the school system (Carroll Massey et al., 1975). Since 1975, Carroll Massey et al. advocated for changing institutional racism educational practices. However, 41 years later minority students continue to underperform academically. As mentioned in Chapter 1, Latina/o students underperform academically at primary, secondary, and postsecondary levels. Thus, one can only wonder how our educational system would react under opposite circumstances. "If the achievement picture were reversed, with white students doing the poorest work, major changes would probably be instituted within the schools to improve their achievement" (Carroll Massey et al., 1975, p. 17). In fact, Sáenz and Ponjuan (2011) refer to Latino males" low levels of bachelor-degree completion rates as "vanishing from postsecondary education" (p. 54).

\section{Latino Male Education}

Our nation faces an "educational and civil rights crisis" due to the insufficient educational completion rates of low socioeconomic students, English learners, and ethnic minority students (Orfield, Losen, Wald, \& Swanson, 2004, p. 2). Such situations 
become complicated when it comes to Latino male students' postsecondary enrollment.

Lee and Ransom's (2011) report illustrates Latino male students' low postsecondary enrollment percentages in comparison with their Latina, White male, and White female counterparts (see Table 1).

Table 1. Latina Females, Latino Males, White Males and White Females' Higher Education Enrollment 1900 - 2008

\begin{tabular}{|l|l|l|l|l|}
\hline Year & Latina Females & Latino Males & White Males & White Females \\
\hline 1990 & $16.4 \%$ & $15.4 \%$ & $35.6 \%$ & $34.7 \%$ \\
\hline 1995 & $23.0 \%$ & $18.7 \%$ & $37.0 \%$ & $38.8 \%$ \\
\hline 2000 & $25.4 \%$ & $18.5 \%$ & $36.2 \%$ & $41.3 \%$ \\
\hline 2005 & $29.5 \%$ & $20.7 \%$ & $39.4 \%$ & $46.1 \%$ \\
\hline 2006 & $27.6 \%$ & $20.0 \%$ & $37.9 \%$ & $44.1 \%$ \\
\hline 2007 & $33.0 \%$ & $20.7 \%$ & $39.6 \%$ & $45.7 \%$ \\
\hline 2008 & $28.9 \%$ & $23.0 \%$ & $41.7 \%$ & $46.9 \%$ \\
\hline
\end{tabular}

Note. The table is adapted from The Educational Experience of Young Men of Color: A Review of Research, Pathways and Progress (p. 53), by J. M. Lee Jr. and T. Ransom, 2011 (https://www.luminafoundation.org/files/resources/educational-experienceymc.pdf). Copyright 2011 by The College Board.

Latino male college students encounter different challenges as they strive to graduate from postsecondary institutions. It is well documented that they arrive at higher education settings academically underprepared (Cammarota, 2004; Cerezo, Lyda, Beristianos, Enrique, \& Connor, 2013). Additionally, since higher education institutions mainly focus on academics "access, retention and graduation rates" (Franklin, 2016, p. 44), Franklin, Smith, and Hung (2014) contend that those institutions must compromise to take into consideration the health consequences that Latina/o college students endure in exchange for attending their institutions. Therefore, an area that needs to be addressed within the literature is how Latino males' racial, ethnic, gender, and academic identities shape their higher education experiences. Furthermore, it is important to understand how 
these identities impact Latino males' psychological stressors and how these students manage their stress. This study leaves out academic performance, as this topic is beyond the scope of this research agenda; this is not a longitudinal study. As Franklin vents, "Sometimes, higher education scholarship operates in a vacuum without considering that students live complex lives that are not only concerned with academics" (2016, p. 48). In that this study focuses on understanding Latino males' nonacademic constructs, we can begin to value how racial identity, ethnic identity, gender role expectations, and masculinity constructs impact Latino males' academic identities.

\section{Race and Ethnicity}

According to Quintana (2007), definitions and implication of race and ethnicity vary depending on the circumstances for which they are being used. In the past, race was basically employed solely for "biological and genetic dimensions" (Quintana, 2007, p. 259). Nowadays, the meaning of race has shifted to describe "the social distance between different racial groups" (as cited in Quintana, 2007, p. 259). In other words, race is no longer just a demographic (Quintana, 2007), phenotypic category; instead, it highlights "its presence in both the smallest and the largest features of social relationships, institutions, and identities" (Winant, 2000, p. 181). Likewise, ethnicity overall entails demographic stipulations such as language and culture (Quintana, 2007). And ethnicity, just like race, involves "socially constructed meanings" (Quintana, 2007, p. 260).

It is important to point out that researchers are divided in regards to how race and ethnicity should be used for classification purposes. On one hand, Helm and Cook (1999) have contemplated reclassifying ethnic groups as racial groups because usually a 
person's color and visible characteristics are employed to distinguish them as specific ethnic group members (as cited in Quintana, 2007). Quintana (2007) counteracts such a method by emphasizing that Latinos face prejudgments due to their ethnicity and cultural traits. On the other hand, reclassifying racial groups as ethnic groups leaves out "the racial basis of the social distance among sociocultural groups" (Quintana, 2007, p. 260). Some researchers assert that race and ethnicity constructs are interchangeable. Actually, the American Anthropological Association (1997) officially stated its disapproval of handling ethnicity and race as unlike social groups (as cited in Quintana, 2007). Hence, Cross and Cross (in press) advocated for categorizing groups as racial-ethnic in order to address the social range amongst groups, leading Latinas/os to be regarded within the constructs of race and ethnicity (as cited in Quintana, 2007). Furthermore, Cross and Cross maintain that sociocultural identities must be regarded as racial-ethnic cultural identities, as the experiences of people of color emerge from their race, ethnic, and cultural identities (as cited in Quintana, 2007). As a result, it is important for this literature review to clarify how racial and ethnic constructs influence Latinas/os' identity formation.

Racial identity. In the United States, race is perceived mainly as someone's skin color and understood within the parameters of biological ancestry (Rodriguez, 2000). Thus, color categories are employed to classify different races (Borrell, 2005; Rodriguez, 2000). As Omi and Winant (1994) affirmed, "In the United States, the black/white color line has historically been rigidly defined and enforced" (p. 11). Even though scholars, scientists, and journalists have disputed the notion of a pure race concept (Rodriguez, 
2000), "the presence of a system of racial meaning and stereotypes, of racial ideology, seems to be a permanent feature of US culture" (Omi \& Winant, 1994, p. 13). The Pew Hispanic Center indicates that Latinas/os evaluate race according to their understanding of belongingness within U.S. society and whiteness as the scale that weights integration or perceived integration (Tafoya, 2007). Borrell (2005) emphasizes that Latinas/os racial classification as Black or White draws geographic lines as to where people can live, in addition to regulating one's social structures that institutionalize "segregation, educational equity, racism and discrimination" (p. 381). Since racial acknowledgement plays a major role in this country, it is important to investigate how Latino male college students understand their racial identity.

According to Fergus (2016), "racial/ethnic minority students develop dispositions about school and opportunity based on how they experienced racialization" (p. 461). To this point, Pizarro's (2005) investigation focused on understanding how race shapes Chicana/o students' school experiences. By allowing Chicana/o high school, community college, and university students to describe their school experiences, Pizarro (2005) affirms that these students' racial/ethnic identities unfold "as political in response to discrimination (racial identity) and as cultural (ethnic identity)" (p. 51).

In the interest of examining how Latino male college students understand their racial identity, this part of the literature review focuses on what Pizarro (2005) describes as the racial political aspects of identity. Pizarro (2005) concludes that racial identity development is the central factor that influences these students' accomplishments and failures within the school setting. The participants acknowledged that race plays a major 
role in regards to how they are treated, in addition to staging their racial discrimination experiences (Pizarro, 2005). In essence, the students developed an accomplished racial identity through racial encounters with people from the dominant culture while experiencing lower ranking stances and strengths (Pizarro, 2005). Therefore, it is essential to understand how race serves to profile and stereotype Latino male students' educational experiences.

One's race is ascribed, whereas social status or class can be modified (Pizarro, 2005). In other words, as one participant describes it, "[Race is] really the basis of who I am. You're basically born into it" (Pizarro, 2005, p. 48). Race is perceived as incorporating class, religion, family, community, and gender (Pizarro, 2005). Still, Pizarro’s participants described it this way: language, immigrant status and skin color are unrelated to identity development, but they play a main role in shaping the racial discrimination experiences they endured at the hands of the dominant group (Pizarro, 2005). Therefore, within the school setting, Latino male students are profiled according to their skin color, language skills, and socioeconomic status (Pizarro, 2005). Such profiling guides educational authority figures into negatively stereotyping Latino male students (Pizarro, 2005). It is worth noting that profiling is a common practice employed by teachers as they categorize students by skill abilities and needs in order to differentiate instruction, and such ingrained practice leads teachers to unconsciously profile Latino male students due to their race (Pizarro, 2005). Drawing on Pizarro’s investigation, the following examples highlight how school personnel utilize racial profiles to negatively stereotype and impact Latino male students' educational experiences. 
Ernesto explains that, when he was a sixth grader, a substitute teacher corrected students" behavior by telling them to "Shut up, shut up!" (Pizarro, 2005, p. 52). As one of the only two Mexican students in class, though, his behavior was corrected by "If you don't like it, you can go back to where you came from" and "Go back to Mexico!" (Pizarro, 2005, p. 52). As a high school student, he also experienced differential treatment from a teacher who refused to acknowledge him as a student by letting him know that "I'll never ever listen to you or call on you if you raise your hand" (Pizarro, 2005, p. 68). Similarly, Diego, a high school student, narrates how his White teacher instructed everyone to read and framed him as a non-English reader since he felt like not reading anymore. The teacher reacted by announcing, "What? You don't know how to read English," and as the student questioned "What do you mean by that?" the teacher simply replied, "You know" (p. 59). This student's racial encounter shows how the language of power was utilized as an instrument to harm and humiliate him for his maternal language and to undervalue his linguistic abilities, as well as to reminded him of his inferior status, since he was profiled as an English language learner just because of his race. By the same token, Santiago explains how difficult it was to attend junior high school in an upper middle class White neighborhood as a minority student: "What I didn't like was that students and teachers treat you different. Cause they know you were the bused kid. You come from [the barrio]" (Pizarro, 2005, p. 76). Rather than defeat these Latino male students, such experiences of racial prejudice and lack of power within learning institutions served to fortify their racial identities (Pizarro, 2005). 
Stereotypes are common obstacles Latino male students encounter. To counteract them, one male student attempted to close the distance that existed between him and the school by trying to blend in by playing basketball. Nevertheless, in the eyes of the assistant principal, every Latino student is a gang member. He explains:

All the white boys out there, wearing baseball caps, and everything, and they're cupped and everything, and they're wearin' big old shirts and big old pants, but that's basic, that's style. You see a Hispanic wearin' em [then it's] "Oh no, uh-uh. Search him. Frisk him.” (Pizarro, 2005, p. 128)

Another male high school student gives details about how teachers handled Latino male actions differently in comparison to their White peers. For example, if White students wore bandannas, that was considered normal and, besides, those students were football players. Conversely, Latino males wearing bandanas were profiled as being gang-related (Pizarro, 2005). As a result, Latino male students struggle psychologically to understand how race generates specific discipline rules that apply only to them (Pizarro, 2005).

In sum, the aforementioned racial interactions caused those Latino male students to internalize that they are "racially and socioeconomic distinct (and inferior) from the authority figures" (and perhaps their White peers). Further, "this racial-political climate can be linked to feeling a lack of ownership of the school process and to feeling distance between self and school" (Pizarro, 2005, p. 61). So, because Latino male students' racial experiences impact how they understand their racial identity, it is crucial to investigate how they understand their ethnic identity.

Ethnic identity. Currently, limited attention has been placed on differentiating amongst racial and ethnic identity in Latinas/os and in figuring out their associations (Pizarro \& Vera, 2001). As previously mentioned, Latino male students' race influences 
educational authority figures to negatively treat, stereotype, and profile these students (Pizarro, 2005). Similarly, "the particular form that one's ethnic identity takes is likely to reflect an interaction of cultural socialization, experience in society, the way one is perceived by others, and one's own construction of these experiences" (Phinney, 1996, p. 925). Consequently, is important to comprehend how Latino male college students understand their ethnic identity.

Ethnic identity is mainly accredited to one's heritage, decided during nativity, or appointed to individuals according to their ethnic upbringing (Phinney \& Ong, 2007; Syed, Azmitia, \& Phinney, 2007). Ethnic identity is not static (Phinney \& Ong, 2007). Rather, it is manufactured along the way, and it varies according to the environment (Phinney \& Ong, 2007). This allows individuals to choose how to identify (Phinney \& Ong, 2007). Ashmore et al. (2004) maintains that self-identification, which entails individually labeling oneself as part of a specific group, is treated as a key aspect of group identity (as cited in Phinney \& Ong, 2007). Pizarro and Vera (2001) specified that Latina/o " [...] ethnic identity refers to the individual and group meanings attached to membership in an ethnic group" (p. 95). Knight, Bernal, Cota, Garza, and Ocampo (1993) created the most advanced model for understanding Latina/o youth ethnic identity development (as cited in Pizarro \& Vera, 2001). That model reveals that enculturation and acculturation collectively structure ethnic identity and ethnic behaviors. Essentially, enculturation helps Latinas/os to internalize precise ethnic role behaviors, such as traditional customs, which contribute to embracing ethnic tendencies (as cited in Pizarro \& Vera, 2001). Simultaneously, acculturation leads them to take on cultural aspects and 
norms from the culture of power (as cited in Pizarro \& Vera, 2001). Along these lines, Torres' (2003) grounded theory study found that Latina/o college students' ethnic identification and cultural positioning develop from within the environment in which they grew up. Actually, every single participant attributed their ethnic identification and its function in their life to their parents. The findings illustrate that ethnic identification intensifies as a result of parents' greater involvement within cultural related activities. Further, the utmost distinct dimension that surfaced was that participants identified themselves by employing their parents' terminology, such as Mexican, Mexican American, Cuban, or Hispanic.

Once in college, the environment impacts Latina/o students' ethnic identity. As Latina/o college students function within the college environment their ethnic identity is altered (Torres, 2003). For example, the participants who previously experienced diverse educational settings identified themselves as having a bicultural or Latino orientation. Torres (2003) stresses that such election stems from how these participants internalized diversity prior to arriving to college. When they encountered campus climates that failed to acknowledge diversity, they furthered their Latino identity by relating with those that valued diversity (Torres, 2003). Similar to Torres' findings, Santos, Ortiz, Morales and Rosales' (2007) qualitative study about the relationship between campus diversity, students' ethnic identity, and college adjustment found that a diverse college setting can strengthen some students' ethnic identity. One student who identifies as a Mexican American explains, "I feel I can explore my ethnicity, my cultural feelings, and traditions on this campus" (Santos et al., 2007, p. 108). But participants from Torres' study who 
had an absence of campus diversity and downplayed the importance of such environment self-identified as having bicultural orientations. Torres (2003) determined that, even though these participants were highly inclined to relate to the culture of power, they nonetheless were able to maintain their cultural values. Furthermore, the participants continued to hold confident perspectives in regard to their Latino identity. Relevant to this point, Santos et al. (2007) determined that "students' commentaries highlight how the college environment can serve as a catalyst for examining and exploring one's identity as an ethnic individual" (p. 108). Therefore, it is important to research how Latina/o college students manage their ethnic identity at predominately Anglo campuses.

The Ethier and Deaux (1994) longitudinal study illustrates how Latina/o college students manage social identity while attending predominately Anglo campuses. The study focused on documenting how context change impacts students' ethnic identification, maintenance, and responses to threat. To accomplish this, students were interviewed three times during their first college year. Identity was measured via qualitative and quantitative methods. The findings indicated that those students who entered college possessing a fragile ethnic identity decreased in ethnic group identification. Furthermore, the results of owning a weaker ethnic identity produced a reduction in self-esteem connected with group affiliation, in addition to a heightened sense of threat on campus. Ethier and Deaux (1994) explained that "it seems quite likely that these students felt conflict about being categorized as Hispanic by the university when they themselves did not strongly identify with their ethnic group" (p. 250). 
Meanwhile, students who entered college with a solid Latina/o ethnic identity were able to foster and reinforce their group identification.

It is important to note that, at the start of the college year, the significance of the participants' ethnic identity was in essence associated solely with family background. However, during "the second and third interviews, the link between cultural background and the strength of ethnic identification was no longer significant, suggesting that ethnic identity had been detached from its previous cultural context" (Ethier \& Deaux, 1994, p. 248). At the college setting, ethnic identity was sustained by ethnic group connections (Ethier \& Deaux, 1994). Basically, the findings illustrate that Latina/o students maintain their ethnic identity in the new context by participating and associating themselves within their ethnic group.

Ethier and Deaux (1994) characterize "remooring" as a phase individuals experience in order to sustain identity while being exposed to a new setting (p. 249). During this phase of remooring, Latino/a college students "who wished to maintain a strong ethnic identity need to develop a new base of support for that identity" (Ethier \& Deaux, 1994, p. 249). Prior to college, these students' ethnic identity was fortified by their primary language at home, their family upbringing, the ethnic makeup of the neighborhood, and high school friends (Ethier \& Deaux, 1994). Within the college setting, the conditions for supporting ethnic identity drastically alter (Ethier \& Deaux, 1994). These new networks do not function "as a supplement to cultural background, but actually replaced the earlier basis of support" (Ethier \& Deaux, 1994, p. 249). The investigation by Ethier and Deaux (1994) reveals how Latina/o students' backgrounds impact their ethnic 
identity within the context of postsecondary education, in addition to drawing attention to the advantages of holding a solid ethnic identification. Since race and ethnicity shape Latino male college students' identities, it is important to learn about their gender role socialization.

\section{Gender Role Socialization}

Latina/o culture greatly shapes the gender role socialization (Raffaelli \& Ontai, 2004) that has a major influence on Latino males' gender identity. Consequently, it is important to analyze how Latina/o culture shapes gender role socialization (Raffaelli \& Ontai, 2004). Gender schema theory incorporates components of social cognitive theory, which posits that individuals learn via observation and by replicating the actions of others (Rosenstock, Strecher, \& Becker, 1988). Gender schema theory also merges components of social learning theory, which says that "social behavior is acquired both through direct conditioning and through imitation or modeling of others' behaviors" (Akers, Krohn, Lanza-Kaduce, \& Radosevich, 1979, p. 638). At their core, psychological theories of development concentrate on explaining exactly how youngsters acquire appropriate male and female principles (Bem, 1981). One, Mischel's (1970) social learning theory, illustrates the exact praising and disproval for conducting oneself within proper gender standards (as cited in Bem, 1981). Another, Kohlberg's (1966) cognitive development theory, focuses on explaining how youngsters interact as they formally identify themselves as either males or females (as cited in Bem, 1981). Bem (1981), concluding that the aforementioned theories illustrate how youngsters gain precise gender knowledge, introduces gender schema theory as "a cognitive account of sex typing by 
which schemas are developed through the combination of social and cognitive learning process" (as cited in Perle \& Waguespack, 2011, p. 690). Therefore, gender functions as a management system in which cultural gender qualities are arranged into gender role values (Bem, 1981; Piña-Watson, Lorenzo-Blanco, Dornhecker, Martinez, \& Nagoshi, 2016). Overall, gender schema theory asserts that children acquire corresponding cultural gender roles based on their gender classification (Bem, 1981; Piña-Watson et al., 2016; Raffaelli \& Ontai, 2004). Therefore, Latino males are socialized to obtain appropriate cultural gender role attributes (Piña-Watson et al., 2016; Raffaelli \& Ontai, 2004).

Within Latino culture, male and female roles are precisely defined (Raffaelli \& Ontai, 2004). The researchers conducted two studies: study one entailed in-depth interviews with a total of 22 Latinas, and study two included 166 Latina/o college students from which data was gathered via self-report surveys (Raffaelli \& Ontai, 2004). The results point out that Latina/o parents play a fundamental role in teaching their children specific gender role standards. Raffaelli and Ontai's (2004) research illustrates that Latina/o families' gender role socialization is built upon traditional cultural practices. Given that finding, it is important to address how Latino male gender role values shape their gender identities (Piña-Watson et al., 2016; Raffaelli \& Ontai, 2004).

\section{Latino Male Gender Role Socialization}

To understand Latino male gender identity, it is important to recognize that culture generates masculinity norms (Mahalik, Locke, Theodore, Cournoyer, \& Lloyd, 2001). Familism, a central cultural value within Latino culture, forms family customs, 
principles, and members' actions (Ojeda \& Piña-Watson, 2014; Stein, Gonzalez, Cupito, Kiang, \& Supple, 2015). According to Fuligni, Tseng and Lam (1999), Latino families socialize their children under familism values by transferring the importance of collectivism across generations. Thus, familism requires Latino males to function as part of a collective unit in order to fulfill their gender role (Fuligni et al., 1999; Sabogal, Marín, Otero-Sabogal, Marín, \& Perez-Stable, 1987). Latino males are expected to sacrifice personal needs and desires and to suffer adversity for the sake of the family, as family is more important than individual family members (Fuligni et al., 1999; GarciaPreto, 1996). Beyond collectivism, Latino male gender roles are based on the following familism values: "family as referents," "familial obligations," and "perceived support from the family" (Sabogal et al., 1987, p. 397). ${ }^{2}$

Within "family as referents," Latino males' personalities and actions must be in accordance with family values, as these males exemplify their families (Sabogal et al., 1987, p. 408). Since respect is a core value within familism practices, Latino males are responsible for respecting elders, others, and themselves (Garcia-Preto, 1996). Under "familial obligations," they are raised to feel accountable for helping economically and providing emotional assistance to the family (Sabogal et al., 1987, p. 401). And in the role of "perceived support from the family," Latino males are expected to watch over their families by being willing to help and safeguard family unification (Sabogal et al., 1987, p. 401). As Galanti (2003) points out, familism standards focus on the importance

\footnotetext{
${ }^{2}$ It is important to mention that familism standards apply to Latino males and Latina females (Germán, Gonzales, \& Dumka, 2009; Sabogal et al., 1987). However, for this study, familism distinctive standards are utilized to solely understand Latino male gender role values (Germán et al., 2009; Sabogal et al., 1987; Wester, 2008).
} 
of family members' dependence on each other and collaboration as a unit. Therefore, perceived support from the family counts on Latino males' responsiveness to assure family prosperity (Arciniega et al., 2008; Sabogal et al., 1987; Wester, 2008). These two familism standards direct Latino male college students toward functioning as achievers and providers (Lu \& Wong, 2014). So, these students authenticate their gender identity to their family, society, and themselves by successfully achieving and providing (Lu \& Wong, 2014). If they fail to achieve, though, their gender identity is threatened (Lu \& Wong, 2014). Figueroa's (2007) investigation shows that factors of familism guide students' insights and inform their "academic outlook, practice, and discourse" (p. 3). The case study illustrates how certain gender identities, such as achievers and providers, are extremely hard to overcome. The participants corroborated this when making it clear that, as Latino males, their main role is to be a provider and that needing help or even seeking help devitalizes masculinity (Figueroa, 2007).

Since Latino male college students are expected to function as achievers and providers, postsecondary education settings serve to measure Latino males' gender identities (Sáenz, Bukoski, Lu, \& Rodriguez, 2013). Sáenz et al. (2013) found that Latino male college students declined to seek help even when they experienced academic failure. Essentially, because the participants saw themselves as maneuvering college "alone," it made sense to them to continue their higher education journey as individuals (Sáenz et al., 2013, p. 90). When Latino male students implement such strategies consciously or unconsciously, they create obstacles instead of accessing institutional assistance (Sáenz et al., 2013). In the process of fulfilling their gender identity and 
participating in higher education institutions that mainstream hegemonic masculinity, these students struggle academically and psychologically (Cerezo et al., 2013; Lu \& Wong, 2014; Sáenz et al., 2013).

\section{Familism Expectations Impacting Gender Identity}

Considering Latino males' strong sense of family centeredness, it is critical to dissect how familism expectations challenge Latino male college students' racial, ethnic, gender, and academic identities (Cerezo et al., 2013; Lu \& Wong, 2014; Sáenz et al., 2013; Torres, Solberg, \& Carlstrom, 2002). These students struggle to fulfill the following gendered responsibilities: (1) providing economic support, (2) nurturing family, and (3) achieving academic success (Cerezo et al., 2013; Lu \& Wong, 2014; Sáenz et al., 2013; Torres et al., 2002). Latino male college students cannot afford to just focus on their academic identity; therefore, they endure constant pressure and stress (Cerezo et al., 2013; Figueroa et al., 2016; Liang et al., 2011; Lu \& Wong, 2014; Sáenz et al., 2013; Torres et al., 2002). For example, due to their first-generation college student status, Latino families perceive college attendance as the path to becoming "someone in life," whereas failure to achieve a college degree corresponds to "being a nobody" (Figueroa et al., 2016, p. 66). Under the concept of "man of the house," Latino male college students are perceived as leaders within their families, but that is not the case once they arrive at college, as college operates under a very individualistic setting which challenges these students' gender identities (Figueroa et al., 2016, p. 66). At this point, Latino males are in a double blind. Their gender identities contradict the traditional college student identity, yet failure to achieve a college degree is also detrimental to their identity 
(Figueroa et al., 2016). In order to develop a complete understanding of Latino male gender identity, it is vital to acknowledge Latino masculinity constructs (Liang et al., 2011; Saez et al., 2010; Torres et al., 2002).

\section{Latino Masculinity Constructs}

Latino males are socialized under traditional cultural familism values, so it is important to note that researchers analyzed Latino masculinity under the concept of machismo and caballerismo. A considerable amount of literature has been published on these two Latino masculinity constructs. Much of the literature focuses solely on the machismo phenomenon, while less focuses on the concept of caballerismo (Arciniega et al., 2008; Liang et al., 2011; Lu \& Wong, 2014; Peña-Talamantes, 2013; Sáenz et al., 2013; Torres et al., 2002). Fundamentally, machismo "focuses on individual power and hypermasculinity," while caballerismo "focuses on social responsibility and emotional connectedness" (Arciniega et al., 2008, p. 29). It is important to clarify that both constructs, machismo and caballerismo, establish Latino masculinity (Arciniega et al., 2008).

Machismo. Researchers have attached the concept of machismo as a central component of Latino male gender roles (Arciniega et al., 2008; Fuligni et al., 1999; Liang et al., 2011). Machismo frames Latino masculinity as being authoritarian, emotionally restrictive, and controlling (Arciniega et al., 2008; Hurtado \& Sinha, 2008; Mirandé, 1997; Peña-Talamantes, 2013). Lu and Wong (2014) explained that machismo characteristics describe Latino males as violent, self-centered, rude, and irresponsible. Popular media represents Latino males as forceful, fearless, inexpressive, and intolerant 
(Mirandé, 1997; Torres et al., 2002). However, since Latino males are socialized to value collectivism (Fuligni et al., 1999) and familism values such as family as referents, familial obligation, and perceived support from the family (Sabogal et al., 1987), these values contradict the aforementioned machismo constructs. Addressing this issue, $\mathrm{Lu}$ and Wong (2014) warned that Latino males' personalities invalidate hegemonic masculinity characteristics. Since machismo fails to capture a complete understanding of Latino masculinity constructs, it is essential to analyze how caballerismo defines Latino masculinity.

Caballerismo. According to to Arciniega et al. (2008), machismo encompasses two aspects: (1) traditional machismo, which entails negative characteristics of Latino masculinity, and (2) caballerismo, which involves positive characteristics of Latino masculinity. Arciniega et al. (2008) describes caballerismo as "nurturing, family centered, and chivalrous" (p. 29). This is consistent with Marandé's (1997) Latino male description: "Despite the popular macho stereotype of Latino men as cold, hard, aggressive, and insensitive, it is more culturally acceptable for Latino men to cry, to be emotional and demonstrate their feelings" (p. 85). Along these lines, in Hurtado and Sinha's (2008) qualitative study, male participants align manhood with cultural values such as behaving respectfully and expressing feelings. Likewise, participants in PeñaTalamantes's (2013) study countered machismo traits such as ferocity and chronic intoxication by articulating achievement and integrity as Latino male characteristics. Overall, Latino masculinity constructs are derived from the relationship between machismo and caballerismo constructs, which are two opposing ideologies (Arciniega et 
al., 2008). The fact that current research on machismo and caballerismo limits our understanding of Latino males' gender roles makes it important to investigate how Latino male college students understand their gender identity, as these two identities, machismo and caballersimo, can be burdensome to a college student.

\section{Latino Male College Students' Gender Identity}

The overwhelming majority of literature on Latino male college students presents documented failures, unsuccessful narratives, and these students' disappearance from secondary and postsecondary institutions (Castellanos \& Gloria 2007; Sáenz \& Ponjuan, 2009). Researchers contend that Latino males' cultural beliefs and lack of intellectual skills are the main reasons they vanish from educational settings (Castellanos \& Gloria 2007; Sáenz \& Ponjuan, 2009). In light of such reasoning, it is evident that those researchers lack a complete understanding of Latino male college students' gender identities (Arciniega et al., 2008; Liang et al., 2011; Lu \& Wong, 2014; Peña-Talamantes, 2013; Sáenz et al., 2013). In the interest of furthering that understanding, this literature review posits that Latino masculinity constructs and gender roles guide Latino male college students' decisions, attitudes, and responsibilities (Liang et al., 2011; Lu \& Wong, 2014; Sáenz et al., 2013; Saez et al., 2010; Torres et al., 2002).

\section{Fear of Failure}

Latino male college students experience constant fear of failure (Lu \& Wong, 2014; Sáenz et al., 2013). Their dilemma is that cultural masculinity demands academic and achievement success, yet they are still responsible for fulfilling gendered identities within their family unit (Lu \& Wong, 2014; Sáenz et al., 2013). Fear of failure negatively 
impacts them by forcing them to employ a "fight or flight response" (Sáenz et al., 2013, p. 90). Beyond university, there are alternate pathways that offer them identity role fulfillment (Lu \& Wong, 2014; Sáenz et al., 2013). Many Latino males who exit university seek other situations that grant this success (Lu \& Wong, 2014; Sáenz et al., 2013). Research suggests that when students drop out of college they are often more successful at achieving and exercising their gender identities (Lu \& Wong, 2014; Sáenz et al., 2013). Many do so by having access to and being motivated to seek military entrance, attend vocational schools, or perform unlawful activities (Cerezo et al., 2013). Sáenz et al.'s (2013) study pinpoints a critical understanding in regard to Latino males' higher education attrition rates:

In essence, they began college with an escape plan, which includes not accepting help so they can maintain a clear focus on their knowable future (working and supporting a family), rather than working towards an intimidating and unknown future (education and social mobility). (p. 91)

Because Latino cultural masculinity constructs consider failure a male deficiency, it encourages males to embrace alternate pathways to establishing themselves as providers in order to fulfill their gender role identities (Cerezo et al., 2013; Liang et al., 2011; Lu \& Wong, 2014; Sáenz et al., 2013).

\section{Latino Male Academic Identities and Stereotypes}

Steele (1997) contends that students' academic identities deteriorate when students are the targets of negative stereotypes. Social biases from school staff, police, and the media expose Latino male students to negative impressions about themselves (Cammarota, 2004; Ginorio \& Huston, 2001; López, 2002; Suárez-Orozco \& Qin, 2006). According to Steele's (1997) theory of domain identification, "to sustain school success one must be 
identified with school achievement in the sense of its being a part of one's self-definition, a personal identity to which one is self-evaluatively accountable" (p. 613). As Latino male students stumble upon "imposed identities" from negative stereotypes, such circumstances constrain their academic identities (Cammarota, 2004; Ginorio \& Huston, 2001; López, 2002; Suárez-Orozco \& Qin, 2006, p. 178; Steele, 1997). Steele (1997) refers to a greater degree of harm to identification as stereotype threat.

The event of a negative stereotype about a group to which one belongs becoming self-relevant, usually as a plausible interpretation for something one is doing, for an experience one is having, or for a situation one is in, that has relevance to one's self-definition. (p. 616)

The most predominant stereotype threat for Latino male students is machismo (described above), which affects how educational institutions perceive and care about Latino male students (Cammarota, 2004). For example, Cammarota's (2004) ethnographic study focused on how high school Latino students handled dominant conditions that arise from the intersections of gender and race. Cammarota's (2004) study of a high school documents a heavy police presence which continuously targeted Latino male students. One male participant stated that, although socializing around the high school with his friends was considered a threat to school police, White students socializing just like the Latino male students were not considered dangerous to school police. Clearly, Latino males' gender, racial, and ethnic identities automatically classified them as a danger (Cammarota, 2004; López, 2002). Ginorio and Huston (2001) also found that teachers and counselors stereotype Latina/o students and categorize them as criminals and as academically deficient. Such stereotypes support teachers' low 
academic expectations for Latina/o students (Niemman, 2001). Furthermore, Latina/o students indicated that teachers characterized them as gang members and future lowwage workers (Ginorio \& Huston, 2001). Latino male students are harmed because, in order to identify themselves as academically successful, theory of domain identification requires "that one has the interest, skills, resources, and opportunities to prosper there, as well as that one belongs there, in the sense of being accepted and valued in the domain" (Steele, 1997, p. 613).

The stereotypes discussed above prevent Latino male students from identifying themselves as students, which affects their academic achievement. Along these lines, the following statistical illustrations show how gender, racial, and ethnic perceptions about Latino males negatively impact their academic identities (Sáenz, Ponjuan, \& Figueroa, 2016). To begin with, male students "are twice as likely as girls to be labeled 'learning disabled' and they are seven times more likely to be diagnosed with attention deficit disorder or attention deficit/hyperactivity disorder" (Sáenz et al., 2016, p. 13). Similarly, Entman's (2006) report about how society perceives minority males based on media images highlights the vivid stereotypes our society constructs. For instance, the University of Chicago conducted a General Social Survey to figure out negative stereotypes associated with males' ethnicity and race and determined that the general public holds the following perceptions about Latino males: $37.4 \%$ said they are prone to violence, $23.9 \%$ that they are unintelligent, and $21.9 \%$ that they are lazy (Entman, 2006). In addition, opinion questionnaires demonstrated that half of White Americans accept widespread stereotypes about Blacks and Latinos, even those that characterize them as 
unintelligent (Smith, 1990). It has been well documented that stereotypes, the images in the brain that facilitate our "thinking" in regard to other individuals, yield assumptions that frame individuals' behaviors and actions (Aronson, 2004). In essence, these trends provide the racist context in which these students are striving for educational success. Unfortunately, as they seek to overcome these stereotypes their academic identity diminishes (Fergus, Noguera, \& Martin, 2014).

\section{Latino Male College Students' Psychological Stressors}

Higher education institutions present specific stressors to some students as they adjust to unknown educational and social settings (Castillo, Cano, Chen, Blucker, \& Olds, 2008). College stressors include economic difficulties, peer interactions, and academic achievement (Castillo et al., 2008). Lazarus and Folkman (1984) define stress as "a particular relationship between the person and the environment that is appraised by the person as taxing or exceeding his or her resources and endangering his or her well-being" (p. 284). This literature review establishes that racial and ethnic identity, gender identity, and academic identity all affect Latino male college students' psychological stress. However, since Latino male students' academic experiences are coupled with negative stereotypes and racial profiling (Fergus, 2016; Pizarro, 2005; Suárez-Orozco \& Qin, 2006), the following sections focus on documenting specifically how racial and ethnic constructs impact these students' psychological stress (Schmader \& Johns, 2003). In the interest of understanding Latino male college students' racial and ethnic psychological stressors, it is essential to understand their personal experiences within racial microaggressions (Franklin et al., 2014). 
Sue et al. (2007) defined racial microaggressions as follows: "Racial microaggressions are brief and commonplace daily verbal, behavioral, or environmental indignities, whether intentional or unintentional, that communicate hostile, derogatory, or negative racial slights and insults toward people of color" (p. 271). In other words, microaggressions operate on a daily basis and are short interactions that deliver demeaning attitudes to people of color due to their affiliations as racial minority members (Sue et al., 2007). Yosso, Smith, Ceja and Solórzano’s (2009) qualitative study investigated how Latina/o college students experienced higher education's racial settings while the participants attended White, elite institutions. Like Pizarro's (2005) participants' experiences, Yosso et al.'s (2009) findings reveal that participants experienced the following kinds of microaggressions: (1) "interpersonal microagressions" and (2) "racial jokes" (p. 667).

Interpersonal microaggressions are verbal and nonverbal racial insults which drive Latina/o college students to internalize that their existence on campus poses a burden to the dominant group while, at same time, intensifying their stress as their perception of “being the racial Other” increases (Yosso et al., 2009, p. 667). Yosso et al.'s participants communicated that, as people of color, they struggled to enjoy who they are, because White people continued to refrain from associating with them just because of their looks, oral language, and how they carry themselves (Yosso et al., 2009). One participant said that White students refused to sit next to him during class. This rejection affected his concentration to the point that he kept on speculating if he was responsible for the "racialized seating arrangement" (Yosso et al., 2009, p. 668). 
Aronson (2004) explains that minority students are well aware of the different negative stereotypes that are associated with their ethnic group. To this point, a Latino male participant's awareness that his racial ethnic identity might drive professors to perceive him as academically incompetent found himself paralyzed from asking questions (Yosso et al., 2009). Such anecdotes make it obvious that interpersonal microaggresssions have the power to restrict students' learning opportunities. Another male university participant, from Pizarro's (2005) investigation, shared that during a class lecture his high school French teacher had drawn a connection to a character that was bribing a police officer in México by stating, "And I think you will generally find that true of all Mexicans, that they're easily bought off and cheap and all you ever see them at is like K-Mart and Wal-Mart" (p. 190). Another university male disclosed that when he was a high school student his history teacher assigned the class an essay about Texas and the Alamo. His essay, that integrated the Mexican point of view, earned him an F, and he was told aloud that he "was gonna go to hell because [he] was racially mixed" (Pizarro, 2005, p. 142). Yosso et al. (2009) acknowledges that interpersonal microaggressions generate anxiety, as Latina/o students are conscious that their words and behaviors have the potential to confirm negative stereotypes about them.

Latina/o students also face psychological stressors from experiencing microaggressions that originate as racial jokes (Yosso et al., 2009). The majority of the time, racial jokes as microaggresions emerge as insulting rhetorical assertions "with questionably humorous intentions" communicated in social situations when Latina/o students are present or explicitly pointing to Latina/o students (Yosso et al., 2009, p. 
669). Racial joke-telling, or laughing about it, originates from individuals possessing racial stereotypical views about the target group. A major struggle Latina/o students encounter when facing racial jokes is that the narrator is frequently somebody the students regularly or occasionally associate with. The microaggressor might even be perceived as a colleague, "friend or close acquaintance" (Yosso et al., 2009, p. 670). As a result, the stress that derives from experiencing racial microaggresions remains with the victims as they try to determine if the aggressor envisioned causing damage. Adding to the distressing experience is the victims' battle to figure out if they should react and in what ways (Yosso et al., 2009). For instance, a Latino male explains how difficult it is to ask White classmates to abstain from joking:

When you don't call them on these racial jokes and remarks and things, then it just, of course it's going to stick with them and they'll think, "Oh it's okay I might be making a crack about his grades or whatever, but if he didn't tell me anything that'll be fine. I'll keep on with what I'm doing." (Yosso et al., 2009, p. 670)

White students conveying racial jokes about Latina/o students produces stress that results in dampening Latina/a students' feelings of campus inclusion to the point that they abstain from engaging in college extracurricular activities (Yosso et al., 2009). For example, a Latino male soccer athlete recalls experiencing racial jokes from the university soccer team. Although he acknowledges that they were just joking, he also recognizes the aggressors' underlying negative intentions and recalls his inability to do something about it, as he was one out of 27 others, including the coaching staff (Yosso et al., 2009). After tolerating racial jokes for two years in a row, he decided not to re-join the team (Yosso et al., 2009). Similarly, a university student from Pizarro's (2005) 
investigation recalls that as a high school student his White friends identified him as "beaner." At first, he perceived that as a "good-hearted" joke, but eventually he realized the negative racial intentions such a nickname prompted (p. 55). Yosso et al. (2009) emphasizes that hiding behind racial jokes are the intentional biases that perpetuate countless Whites to function in a false color-blind society. Dangerously disturbing, racial jokes exhibit society's endorsement of negative stereotypes and racial labels, chronically persistent within the portrayal of Latinas/os in the media with labels like "beaner, wetback, violent, sexually promiscuous, unintelligent, and morally depraved" (Yosso et al., 2009 p. 672). Such stereotypes and racial labels play a major role in framing society's viewpoints, attitudes, and political campaigns that trap Latinas/os with continuous indication of their inferior establishment within the "social/racial hierarchy of the university" (Yosso et al., 2009, p. 672).

The interpersonal microaggressions and racial jokes that Latina/o students face within academic settings cause massive stress (Yosso et al., 2009). Furthermore, these aggressions trigger Latina/o students' self-perception as insignificant to the university environment (Yosso et al., 2009). And these microaggressions corroborate Latina/o students' intruder perceptions while increasing their psychological stress levels (Yosso et al., 2009). As Franklin (2016) states, “These instances of racial microaggressions put a burden on students of color to justify their identity and presence on college campuses" (p. 45). Therefore, these microaggressions push Latina/o students into a war zone in which they strive to offset, overcome, and survive such invasions (Yosso et al., 2009). Fighting 
the battle--disputing racial microaggressions--debilitates Latina/o students physically and mentally, inducing Racial Battle Fatigue (RBF) (Franklin et al., 2014).

\section{Racial Battle Fatigue}

Various studies point out that Latina/o college students keep on enduring racial microaggressions, which negatively impacts their psychological stress (Franklin et al., 2014; Yosso et al., 2009). Eventually, stress instigated by aggressions has the power to produce "mental, emotional and physical problems" (Palmer \& Maramba, 2015, p. 707). Smith's (2004, 2009a, 2009b) Racial Battle Fatigue (RBF) framework addresses the wellbeing ramifications of recurrent "racialized stress" (as cited in Franklin et al., 2014, p. 304). The RBF framework identifies the following three types of stress as a result of racial microaggression: (1) physiological stress, (2) psychological stress, and (3) behavioral stress (Franklin et al., 2014; Smith, Allen, \& Danley, 2007). Some of the physiological stress reactions include "tension headaches and backaches, elevated heartbeat, rapid breathing in anticipation of racial conflict, an upset stomach or butterflies, extreme fatigue, loss of appetite and elevated blood pressure" (Smith et al., 2007, p. 556). Certain psychological stress reactions are "constant anxiety and worrying, inability to sleep, loss of self-confidence, difficulty thinking coherently or being able to articulate (confirming stereotype), hypervigilance, and frustration" (Smith et al., 2007, p. 556). Part of behavioral stress reactions consists of "stereotype threat, impatience, and poor school performance" (Franklin et al., 2014, p. 306). The combination of stress that derives from simply being a student and acquiring a postsecondary degree intensifies due to "racialized stress" for Latina/o students (Franklin et al., 2014, p. 307). Racial 
microaggressions and RBF bring about the detrimental actualities that higher education Latina/o students endure (Franklin et al., 2014).

Franklin et al.'s (2014) quantitative study focused on testing the RBF framework for Latina/o college students. The participant sample was composed of 176 undergraduate students and 22 others who were graduate students or out of college. The study found that racial microaggressions highly disturb Latina/os' psychological stress reactions within the RBF framework. According to the findings, "frustration, being more aware of racism, irritability mood changes, shock, disappointment and agitation" are the more salient reactions that impact Latina/os psychological stress (Franklin et al., 2014, p. 315). Lopez' (2005) longitudinal investigation about minority status stress and sociocultural orientations included 54 Latina/o freshman college students. Lopez' (2005) findings correlate to Franklin et al.'s (2014), agreeing that Latina/o racism experiences impact their psychological stress. Students reacted to this psychological stress by alienating themselves and feeling marginalized (Lopez, 2005). Franklin et al.'s (2014) findings illustrated that racial microaggressions play a similar role in physiological and behavioral stress reactions, as the path coefficients between latent variables were closely similar: physiological 0.508 and behavioral 0.407 . Latina/o students' physiological stress reactions involved "muscle aches, back pains, and the inability to sleep" (p. 315). According to Franklin et al. (2014) current literature on Latina/os physiological stress reactions is limited. Still, several studies demonstrated that experiencing racism increases the blood pressure of students of color (Blascovich, Spencer, Quinn, \& Steele, 2001; Hill, Kobayashi, \& Hughes, 2007 as cited in Franklin et al., 2014). In Franklin et 
al.'s (2014) study, Latina/o students responded to behavioral stress by “eating less, sleeping less, procrastinating and neglecting responsibilities" (p. 315). In general, RBF psychological, physiological, and behavioral stress reactions have the power to dangerously shape Latina/o students' well-being.

\section{Latino Male College Students' Coping Responses to Stress}

As Latina/o college students experience racial microaggression, which leads them to suffer racial battle fatigue stressors, they employ informal coping responses to manage stress (Chiang, Hunter, \& Yeh, 2004). Researchers emphasize that an accomplished ethnic identity increases individual well-being and decreases psychological stress (Kiang, Yip, Gonzales-Backen, Witkow, \& Fuligni, 2006; Phinney, 1992; Seaton, Scottham, \& Sellers, 2006; Yip, Seaton, \& Sellers, 2006). For example, Lopez (2005) indicates that Latina/o college students cope with racism by associating themselves with members of their racial ethnic group. Similarly, Yosso et al.'s (2009) participants coped with RBF stressors by forming communities within their racial and ethnic group: "findings demonstrate community building occurs during and after rejection, when Latina/os seek out and establish socioacademic counterspaces that position their cultural knowledge as valuable strengths" (p. 677). This approach is what Yosso (2005) calls community cultural wealth, which brings students a "sense of home and family" within postsecondary education settings so they can help one another academically, express troubles, and foster friendships with those who have faced similar experiences (Yosso et al., 2009, p. 677). Latina/o college students also cope with RBF stress by taking ethnic 
studies courses, which "fostered skills of critical navigation" and have helped them learn "to see themselves as contributing to a legacy of resistance to oppression" (Yosso et al., 2009, p. 679).

At the high school level, ethnic identity safeguards Latina/o and Chinese students' psychological well-being (Kiang et al., 2006). Kiang's et al.'s (2006) study focused on normative adolescence stress that derives from having more autonomy and responsibility. Although such stress differs from RBF, it is worth noting how ethnic identity supports adolescents' coping methods. The findings highlight that feeling positively about one's ethnic identity serves as a coping mechanism to overcome stress (Kiang et al., 2006). Furthermore, Kiang et al.'s (2006) findings revealed that ethnic regard "has a longerlasting influence in the association between daily stressors on a given day and happiness reported 1 day later" (p. 1347).

In order to support Latino males' stress management, it is imperative to understand what kinds of coping mechanisms they prefer (Aranda, Castaneda, Lee, \& Sobel, 2001; Chiang, et al., 2004; Gloria, Castellanos, Scull, \& Villegas, 2009). Chiang et al.’s (2004) exploratory study examined Black and Latina/o students' feelings about professional counseling and coping mechanisms. The most preferable "coping sources" for the Latina/o sample were talking to a friend $(80.0 \%)$ and talking to parents $(70.9 \%)$, whereas talking to a counselor $(34.5 \%)$ or to an advisor $(20 \%)$ were the least preferable (Chiang et al., 2004, p. 803). Chiang et al. (2004) concluded that, due to the important role family plays within the Latino culture, the participants preferred to talk to their parents, friends, siblings, and significant others rather than to seek professional counseling. Such 
preferences validate two of the previously mentioned familism standards, "perceived support from the family" and "family as referents" (Sabogal et al., 1987, p. 397). According to Kiang et al. (2006), "such feelings of connectedness could, in turn, serve a variety of protective functions, especially in light of coping with difficult situations (e.g., stress)" (p. 1339). When it comes to gender, Chiang et al.'s (2004) study discovered that Latino males have a much more positive attitude about counseling than do Latina females. Furthermore, Lasley and Pierce (2001) explain, "For Latino males in college settings, less positive racial, ethnic and cultural definitions of themselves may lead to coping from a more individualistic perspective" (as cited in Chiang et al. 2004, p. 809). Chiang et al. (2004) supports Lasley and Pierce's (2001) point by suggesting that once Latino males find themselves functioning within the White culture of power that emphasizes individualism, "self-actualization," and professional coping mechanisms, these Latino males might be inclined to view professional counseling as a source (p. 810).

In order to examine what coping mechanisms Latino male college students employ to manage their various identities' psychological stress, it is important to integrate literature that focuses only on Latino male college participants. Gloria et al.'s (2009) quantitative study investigated how cultural self-esteem, perceived educational barriers, cultural fit, and coping responses predicted psychological well-being among Latino male college students. In regards to coping, Latino males preferred to "find out more about the situation" and "take a positive planned action" (96.0\%) (p. 326). Such approaches correlate to the findings of $\mathrm{Lu}$ and Wong (2014) and Sáenz et al. (2013) that Latino males' gender identities prevent them from seeking help and that they prove their 
masculinity by succeeding on their own. Along these lines, Gloria et al.'s (2009) participants' second-preferred coping mechanism involved utilizing previous experiences, under the assumption that like circumstances could assist (88.7\%). Gloria and colleagues' conclusions contrast with Chiang's (2004), whose Latino males had much more positive attitudes about counseling than did the 100 participants from Gloria et al.'s (2009) study, who ranked seeking professional advice from doctors, psychologists, or counselors as the least preferred coping method (11.1\%). Although the Gloria et al.’s (2009) participants preferred to manage stress independently, a central discovery by that study's investigation is that "emotional focus coping was the largest predicting variable of psychological well-being" (p. 332). Such a discovery implies that Latino male college students can benefit from having access to an emotional avenue through which they can discuss their higher education stressors and coping methods (Gloria et al., 2009). More importantly, "Ideally, such emotion-friendly forums would provide a space and opportunity to voice or vent concerns in the company of supportive listeners, without fearing judgment based on common Latino male socialization expectations that might threaten their sense of healthy masculinity" (Gloria et al., 2009, p. 332). The following conceptual framework for this study focuses on compiling the different perspectives that impact Latino male college students' identities, psychological stressors, and coping mechanisms. 


\section{Conceptual Framework}

The conceptual framework for studying Latino male college students' identities involves the following perspectives: gender role socialization, gender identity, racial and ethnic identity, academic identity, psychological stressors, and coping responses. The Latino culture shapes their males' gender role socialization and gender identity (Mahalik et al., 2001). Therefore, familism defines Latino males' customs, principles, and actions (Ojeda \& Piña-Watson, 2014; Stein et al., 2015). As a result, Latino male college students function as achievers and providers, which, at times, guides them into experiencing fear of failure (Lu \& Wong, 2014; Sáenz et al., 2013). This literature review has determined that machismo and caballerismo masculinity constructs fail to capture a complete understanding of Latino males' gender identity (Liang et al., 2011; Lu \& Wong, 2014; Sáenz et al., 2013; Saez et al., 2010; Torres et al., 2002). Hence, Latino males are to be defined as un hombre de familia (a family man), the definition of which captures their decisions, attitudes, and responsibilities within gender role socialization and gender identity. Racial and ethnic identity impact Latino males' academic identity, as race and racial profiling shape these students' educational experiences, largely because educational authority figures play a crucial role in shaping these students' successes and failures (Pizarro, 2005). College settings impact Latino males' ethnic identification, since possessing a fragile ethnic identity results in experiencing additional stress, as opposed to owning a solid ethnic identity, which strengthens group identification (Ethier \& Deaux, 1994). Yet, while possessing a solid ethnic identity may counter stress, Latino male college students still experience psychological stress from their various identities 
and from racial microaggressions (Franklin et al., 2014; Pizarro, 2005; Sue et al., 2007; Yosso et al., 2009). While Latino male college students endure interpersonal and racial jokes and microaggressions, they are subject to racial battle fatigue (Franklin et al., 2014). The aforementioned perspectives steer Latino male college students toward employing informal coping mechanisms to manage their stress rather than seeking professional counseling (Gloria et al., 2009). The following Latino male college students' identities conceptual framework represents the different perspectives that shape their identities, psychological stressors, and coping mechanisms to stress as they work to earn a four-year college degree (see Figure 1). 


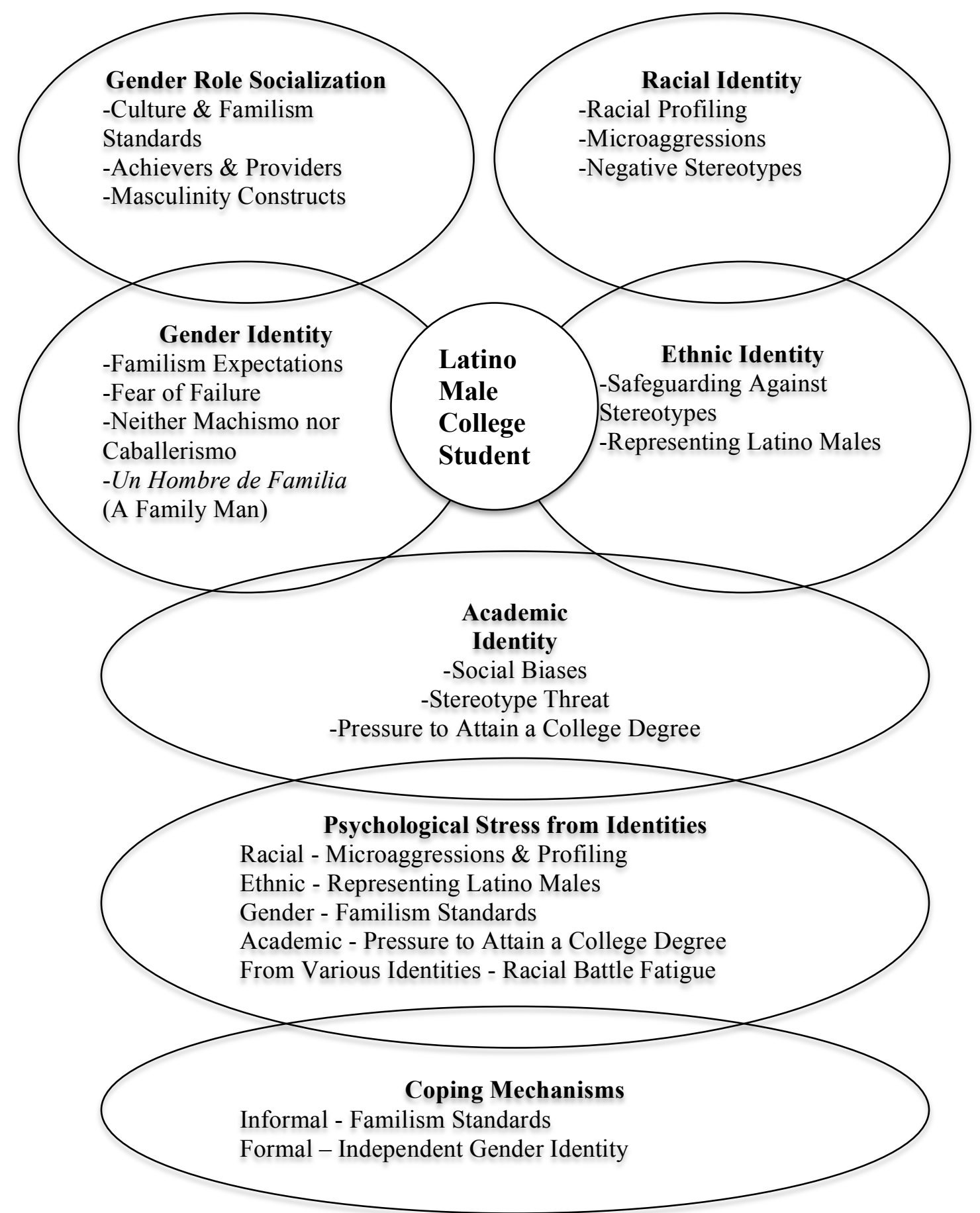

Figure 1. Latino male college students' identities conceptual framework. 


\section{Conclusion}

This literature review focuses on the important role Latino culture plays within Latino male college students' identities. In brief, Latino male college students adhere to the following familial standards: "familial obligations, perceived support from the family, and family as referents" (Sabogal et al., 1987, p. 397). Currently, their gender masculinity frames their masculinity predominantly within the machismo construct and, to a smaller extent, within the caballerismo construct (Arciniega et al., 2008; Hurtado \& Sinha, 2008; Mirandé 1997; Peña-Talamantes, 2013). However, this literature review acknowledges that Latino males function as a family man by (1) representing their families, (2) acting as achievers and providers, and (3) being responsible for protecting their families (Aranda et al., 2001; Cerezo et al., 2013; Lu \& Wong, 2014; Sáenz et al., 2013). Perhaps, as this literature review highlights, a new definition of Latino masculinity is required, one that moves away from stereotypes (machismo and caballerismo), which hinder a full understanding of Latino males' identities. Although

the current literature on caballerismo fails to pose it as the other end of the spectrum from machismo, it does challenge the very idea. Therefore, this literature review concludes that Latino males are to be defined as un hombre de famila (a family man). This definition correlates with the important role familism plays within the Latino culture and Latino males' gender role socialization, which impact their racial and ethnic identity, academic identity, psychological stress, and coping responses to stress. The following qualitative research study explores Latino male college students' identities, psychological stress, and coping mechanism by integrating a narrative inquiry approach. 


\section{Chapter 3}

\section{Methodology}

\section{Methods and Instruments}

This qualitative research integrated a narrative inquiry approach by combining surveys and interviews. The study invited Latino male college students to participate in three stages. Stage one consisted of recruitment. During this stage, potential candidates were emailed an invitation to participate in the study, accompanied by a link to an online questionnaire. The brief (approximately five-minute) potential-participant questionnaire (see Appendix A) determined if a person could be considered an "information-rich" case (Patton, 2002, p. 273), and acted as a screener for stage two of this study. In order for participants to be considered information-rich cases, they had to meet the following four requirements: (1) identified as a male, (2) identified as a Latino, (3) be an engineering or social science major, and (4) be enrolled in college for one or more years. Once information-rich cases were identified, they were asked to volunteer as participants in this study. If participants agreed to volunteer, they were asked to complete stage two, a demographic survey profile consent form (see Appendix B) and a demographic survey profile (see Appendix C). The demographic survey profile served to gather participants' background information and was used as part of the narrative inquiry data. At the end of the survey, participants were asked if they were willing to be contacted to participate in a one-on-one semi-structured interview. If they agreed, they were provided with an electronic version of the individual interview consent form (see Appendix D). Stage three was the interview (see Appendix E). Participants were invited to schedule one-on- 
one interviews. At the time of the scheduled interview, participants were provided with a printed version of the individual interview consent form (see Appendix D) and were asked to sign. The goal was to have 22 participants complete the last two stages.

\section{Site}

This study was conducted at a public coeducational university located on the West Coast. Data was collected during the 2016-2017 academic year. The undergraduate ethnic population there mainly consisted of $41.2 \%$ Asian, $26 \%$ Latina/o, $19.3 \%$ White, 3.1\% Black or African American, 0.4\% Pacific Islander, and 0.2\% Native American, while the remaining $9.8 \%$ claimed two or more races, race/ethnicity unknown, or nonresident. In regard to faculty, $46 \%$ were White, $15 \%$ Asian, $8 \%$ Latina/o, $8 \%$ American Indian, and $23 \%$ who identified as "other."

During the fall 2016 semester, the College of Engineering had the highest number of males, $77 \%$, plus $23 \%$ females. The College of Engineering was selected for this study because of its high concentration of males and, in particular, because for the past five academic years the number of Latino males graduating from that college has increased: $2011-2012=65,2012-2013=74,2013-2014=102,2014-2015=104$, and $2015-2016=$ 139. The College of Social Sciences had experienced a similar increased graduation pattern (except for the academic year 2013-2014) with regard to Latino males earning degrees: $2011-2012=114,2012-2013=127,2013-2014=125,2014-2015=132$, and 2015-2016 $=157$. In terms of gender distribution during the fall 2016, a total of $42 \%$ males and 58\% females were enrolled in the College of Social Sciences. Since the Colleges of Engineering and Social Sciences had experienced a gradual graduation 
increase in regard to Latino males, this study focused on finding participants from these Colleges to investigate Latino male college students' identities, psychological stress, and the coping mechanisms they employ to manage stress.

\section{Sample}

According to Patton (2002), the goal of purposeful sampling is to handpick "information- rich" cases (p. 273). For the purpose of this study, an "information-rich" case was defined as a Latino male, from the Colleges of either Engineering or Social Sciences, who had been enrolled at this institution for one or more years. To begin understanding Latino male college students' identities, psychological stressors, and coping mechanisms, it was important for these participants to have been exposed to a university campus for at least one year. In order to recruit Latino male college participants, different stakeholders from the College of Engineering and Social Sciences were contacted. These stakeholders were asked to help publicize this study (see Appendix F) and to distribute recruitment flyers (see Appendix G). Stakeholders were asked to allow the researcher to announce this study during their classes, if possible. In order to recruit enough participants, flyers were distributed within the Colleges of Engineering and Social Sciences in addition to Latina/o students' organizations. Snowball sampling (Palinkas et al., 2015) was also used as a strategy to identify the 22 Latino male participants by asking current participants, either via email or in person, to recommend additional participants. The search ended when eight social sciences majors and 14 engineering majors had been selected. Once potential participants were identified, they were contacted via email for the purpose of introduction and explanation of the 
purpose of this study. Furthermore, they received an explanation of the demographic survey profile and the one-on-one interview so that they would understand what to expect.

\section{Data Collection}

Data collection included 22 demographic survey profiles and 22 one-on-one semistructured and in-depth interviews (Creswell, 2013; Riessman, 2008). The participants selected for data were chosen due to their ethnicity and gender identity and because they fulfilled the aforementioned information-rich cases characteristics, all of which was critical to answer this study's research questions. The data collection site was chosen because Latina/o students represent the second highest undergraduate ethnic population group at this university. In addition, these participants were selected because for the previous four academic years, overall Latino male enrollment at this university had increased: $2012-2013=5,262,2013-2014=5,741,2014-2015=6,306$, and 2015-2016 $=6,594$.

In investigating Latino male college students' identities and educational experiences, this study utilized a narrative inquiry approach (Connelly \& Clandinin, 1990). According to Connelly and Clandinin (1990), "The main claim for the use of narrative in educational research is that humans are storytelling organisms who, individually and socially, lead storied lives" (p. 2). To elicit their stories, participants were sent, via email, the demographic survey profile consent form (see Appendix B). Once they agreed to the conditions outlined, they completed the demographic survey profile (see Appendix C). The demographic survey profile (taking less than an hour) was used to identify 
participants' background information, which was then used as data to compose students' narratives.

At the end of the demographic survey profile, participants were asked if they were willing to be contacted to participate in a one-on-one interview. If participants answered "yes," they were individually contacted via email to schedule an in-person interview on campus during their available time. Prior to the interviews, which were conducted in the engineering building, the participants were provided with a printed version of the individual interview consent form (see Appendix D). During the semi-structured and indepth interviews, participants were asked questions about their racial, ethnic, gender, and academic identities, in addition to questions about how their identities impact their psychological stress and the coping mechanisms they employed (see Appendix E). This study opted for open-ended questions to give participants the opportunity to share their individual experiences and to avoid restricting their responses (DiCicco-Bloom \& Crabtree, 2006). This approached permitted the researcher to delve much more intensely into Latino male college students' "social and personal matters" (DiCicco-Bloom \& Crabtree, 2006, p. 315). In order to understand Latino male college students' identities, it was important to question these participants about how their settings, culture, and social traits had shaped their life experiences. Interviews were the best method for gaining such knowledge, as participants were allowed to narrate, in their own words, their lived stories (Clandinin \& Connelly, 2000; Riesman, 2008). The interview data was used to develop the participants' narratives and to allow their marginalized voices to be heard (Clandinin \& Connelly, 2000; Riesman, 2008). 
To maintain the same procedure for every participant, during each interview the opening and closing statement was read aloud (see Appendix E) (Jacob \& Furgerson, 2012). In keeping with Riessman (2008) data gathering protocols, field notes were written right after data collection, allowing the interviewer to be fully present, focused, and involved during the interviews, yet have sharp recall quickly afterwards. The oneon-one interviews, which were recorded on a password-protected iPad, lasted from an hour to an hour and a half. Each participant was assigned a pseudonym in order to maintain confidentiality. At the end of each interview, the participant was reminded that the researcher would be contacting them for further clarification, additional questions, and to share the data results pertinent to them. All data gathered was kept on a passwordprotected laptop; once the study was completed, all data was deleted.

\section{Data Analysis}

The interview audio-recordings were sent to a third party transcription service for processing in order to facilitate data analysis (Creswell, 2013; DiCicco-Bloom \& Crabtree, 2006; Riessman, 2008). Every interview transcription was read, following along with the audio-recorded version, to ensure precision (DiCicco-Bloom \& Crabtree, 2006). Sandelowski (2000) reminds us "there is no mandate to re-present the data in any other terms but their own" (p. 338). The transcriptions and the research questions guiding this study were used to organize the data. After that, the transcriptions were used to color-code preliminary themes across participants (Creswell, 2013). According to Riessman (2008), "in thematic analysis, content is the exclusive focus" (p. 53). Thus, themes were developed to identify commonalities and differences across participants in 
regard to their racial, ethnic, gender, and academic identities, psychological stressors, and coping mechanisms (Riesssman, 2008). While determining and classifying Latino male college students' experiences, the goal of this data analysis was to focus on "what" participants said and not on the "how" or "why" (Riessman, 2008, p. 54). In short, the data was used to narrate Latino male colleges students' stories.

\section{Ethical Considerations}

As a safeguard for the participants, this study incorporated the following three main ethical guidelines: (1) minimizing participants' likelihood of danger, (2) shielding participants' information, and (3) efficiently notifying participants about the study's purpose and their roles (DiCicco-Bloom \& Crabtree, 2006). It is important to mention that by asking Latino male college students to share their identity experiences, this study acknowledged that they might have had experienced negative and emotional feelings. However, according to Marcos Pizarro (personal communication, 2016), a potential benefit may have been that these participants developed a clearer understanding of their own experiences through their self-reflection. Consequently, the three aforementioned guidelines were carefully followed, in addition to the specific procedures and guidelines from San José State's Institutional Review Board (IRB). Specifically, the researcher informed the participants about their rights on multiple occasions. Likewise, the participants knew that they had the right to skip any question or questions they did not wish to answer and that they were allowed to abandon the study at any time. 


\section{Limitations of the Study}

This study had several limitations. First of all, it did not focus on academic achievement. Such a topic was beyond the scope of the research agenda, as this was not a longitudinal study. Another limitation was the sample size of 22 participants that have been attending this institution for one or more years. Furthermore, this study was restricted to Latino male participants from a single setting within two of the Colleges: College of Engineering and College of Social Sciences. The majority of the participants were engineering majors $64 \%$ (14 of 22 ), and 36\% were social sciences majors ( 8 of 22 ).

Moreover, for convenience, the term "Latino" has been used to refer to these males, although the sample included 18 participants who, through various terms, incorporated their Mexican heritage as part of their identity: 45\% Mexican American (10 of 22), 6\%

Chicanos ( 2 of 22), and 27\% Mexicans (6 of 22). Three non-Mexican participants (14\%) identified through their parents' birthplace (Central América or South América) in addition to incorporating the American term of Honduran American, Salvadoran American, or Peruvian American. One participant (5\%--1 of 22) identified as Mexican Nicaraguan American.

Because the purpose of this study was to explore in depth the experiences of Latino males so as to begin to understand their attitudes, decisions, and behaviors as college students, findings from this study cannot be generalized to all Latino male college students. Equally important is that fact that only two types of data were gathered: (1) demographic survey profile and (2) one-on-one semi-structured interviews. Using a qualitative narrative inquiry approach, this study depended on participants' self-reported 
data. As a result, participants shared their own interpretations as to what they understood their experiences were.

The limitations and data results suggest the following recommendation for further research:

1. This study could be duplicated with a focus on academic achievement.

2. This study could be duplicated with a larger sample.

3. This study could be duplicated with Latino males from different Colleges.

Trustworthiness. Mishler (1990) defines validation "as the process(es) through which we make claims for and evaluate the "trustworthiness" of reported observations, interpretations, and generalizations" (p. 419). Therefore, validation focuses on how data was gathered and interpreted, instead of the motionless aspects of data instruments and calculations (Mishler, 1990). To this point, the researcher shared with the participants their individual data results, in addition to the overall interpretations and conclusions so that participants could assess the credibility of the findings (Cresswell, 2013). Cresswell (2013) delineates participants' assessing their own findings as the greatest method for constructing qualitative studies' credibility.

Background and role of the researcher. The researcher played a main role in framing the qualitative study and developing the demographic survey profile and the oneon-one semi structured interview questions. Also, the researcher was solely responsible for collecting the demographic surveys, conducting the interviews, and analyzing the data (Cresswell, 2013). Furthermore, the researcher was responsible for using the data to find themes and patterns and to draw conclusions (Cresswell, 2013). 
Cresswell (2013) recommends clarifying research bias from the beginning by articulating the researcher's "past experiences, biases, prejudice and orientations that have likely shaped the interpretations and approach to the study" (p. 251). To clarify, the researcher identifies as a Latina female who promotes the importance of achieving a higher education degree amongst underrepresented minority students. Once a year, the researcher conducts a workshop for underrepresented minority students' parents about college readiness and accessibility. 


\section{Chapter 4}

\section{Findings}

The purpose of this narrative inquiry research study is to understand Latino male college students' identities, psychological stress, and coping mechanisms. Data was collected via a demographic survey profile, and in-depth qualitative data was gathered by individually interviewing each participant. As a result, these participants had the opportunity to share how they understand and interpret their experiences. The following Table (see Table 2) displays participants' demographic survey profile findings, which set the context for understanding the unique experiences of the 22 participants in this study. The next section analyzes the themes that emerged from the one-on-one semi-structured interviews designed to answer the five research questions guiding this study.

Table 2 (below) displays further participant information, as well pseudonym, major emphasis, college level, transfer or non-transfer status, college generation, and ethnicity, while Appendix H provides even more of the participants' demographic information. The sample includes eight social science majors (two transfer students and six nontransfer students). All of the social science majors are first-generation college students. A total of 14 engineering major students participated in this study (eight transfer students and six non-transfer students). Ten engineering majors are first-generation college students, while four of them are second-generation (two of them have an older sibling who graduated from a four-year university). The other two participants reported that one of their parents graduated from college in México, but they are the first ones in their family to attend a four-year university in the United States. 
Table 2. Participants' Information

\begin{tabular}{|c|c|c|c|c|c|}
\hline Participant & $\begin{array}{l}\text { Major } \\
\text { Emphasis }\end{array}$ & $\begin{array}{l}\text { College } \\
\text { Level }\end{array}$ & Transfer & $\begin{array}{l}\text { College } \\
\text { Generation }\end{array}$ & Ethnicity \\
\hline 1. Galindo & Economics & Junior & Yes & First & Mexican \\
\hline 2. Ramos & Anthropology & Senior & Yes & First & $\begin{array}{l}\text { Mexican } \\
\text { American }\end{array}$ \\
\hline 3. Rivaldo & $\begin{array}{l}\text { Political } \\
\text { Science }\end{array}$ & Sophomore & No & First & $\begin{array}{l}\text { Honduran } \\
\text { American }\end{array}$ \\
\hline 4. Giovanni & $\begin{array}{l}\text { Political } \\
\text { Science }\end{array}$ & Junior & No & First & $\begin{array}{l}\text { Mexican } \\
\text { American }\end{array}$ \\
\hline 5. Cienfuegos & $\begin{array}{l}\text { Political } \\
\text { Science }\end{array}$ & Senior & No & First & $\begin{array}{l}\text { Salvadoran } \\
\text { American }\end{array}$ \\
\hline $\begin{array}{l}\text { 6. Luis } \\
\text { Enrique }\end{array}$ & Sociology & Senior & No & First & $\begin{array}{l}\text { Mexican } \\
\text { Nicaraguan } \\
\text { American }\end{array}$ \\
\hline 7. Neymar & Psychology & Junior & No & First & $\begin{array}{l}\text { Peruvian } \\
\text { American }\end{array}$ \\
\hline 8. Blanco & Psychology & Junior & No & First & $\begin{array}{l}\text { Mexican } \\
\text { American }\end{array}$ \\
\hline 9. Pelé & Mechanical & Junior & Yes & Second & Mexican \\
\hline 10. Luna & Electrical & Junior & Yes & Second & Mexican \\
\hline 11. James & Electrical & Senior & No & Second & $\begin{array}{l}\text { Mexican } \\
\text { American }\end{array}$ \\
\hline 12. Borgetti & Mechanical & Junior & Yes & Second & $\begin{array}{l}\text { Mexican } \\
\text { American }\end{array}$ \\
\hline 13. Guardado & Mechanical & Junior & Yes & First & $\begin{array}{l}\text { Mexican } \\
\text { American }\end{array}$ \\
\hline 14. Zague & Mechanical & Senior & Yes & First & Mexican \\
\hline $\begin{array}{l}\text { 15. Roberto } \\
\text { Carlos }\end{array}$ & Chemical & Senior & Yes & First & Chicano \\
\hline 16. Alves & Chemical & Junior & Yes & First & Chicano \\
\hline 17. Ochoa & Mechanical & Senior & Yes & First & $\begin{array}{l}\text { Mexican } \\
\text { American }\end{array}$ \\
\hline 18. Ronaldo & Electrical & Junior & No & First & Mexican \\
\hline 19. Campos & Aerospace & Sophomore & No & First & Mexican \\
\hline 20. Hermosillo & Aerospace & Junior & No & First & $\begin{array}{l}\text { Mexican } \\
\text { American }\end{array}$ \\
\hline 21. Hernandez & Aerospace & Junior & No & First & $\begin{array}{l}\text { Mexican } \\
\text { American }\end{array}$ \\
\hline 22. Wondo & $\begin{array}{l}\text { Computer } \\
\text { Engineering } \\
\end{array}$ & Senior & No & First & $\begin{array}{l}\text { Mexican } \\
\text { American }\end{array}$ \\
\hline
\end{tabular}




\section{Research Question Number 1 Racial and Ethnic Identities}

The first question guiding this research study was, How do Latino male college students understand their racial and ethnic identity? Overall, participants in this study demonstrated a clear understanding about their racial and ethnic identity and, thus, were quick to point out their ethnic identification (see Table 3).

Table 3. Participants' Ethnic Identification

\begin{tabular}{ll}
\hline Number of Participants & Ethnic Identification \\
\hline 2 & Chicano \\
1 & Honduran American \\
6 & Mexican \\
10 & Mexican American \\
1 & Mexican Nicaraguan American \\
1 & Peruvian American \\
1 & Salvadoran American
\end{tabular}

A common trend among these 22 participants is that they entered college already owning a solid ethnic identity. According to these participants, prior to attending higher education their ethnic identification was strengthened by their families, the ethnic makeup of their neighborhood, cultural socialization, birthplace, experiences in society, and their very own personal understanding of their experiences. The following sections focus on explaining participants' reported understanding of their ethnic identification.

Participants' ethnic identification. A total of six participants identified as Mexicans. From these six, five identified their ethnic identities according to their birthplace. Two of them spent their early childhood years (through 7 and 8 years old) living in México, while the other three lived in México until their adolescent years (11, 12, and 13). Campos, a sophomore aerospace engineering major, came to the United 
States when he was eight years old. His narrative best characterizes how these five participants understand their ethnic identity within the margins of their birthplace. He said, "I was born in México, so it's who I am. Being Mexican is just where I come from. It's something that I don't really forget." The sixth participant, Zague, a senior mechanical engineering major, understands his ethnic identification as Mexican because of his early years. Despite the fact that Zague was born in the United States, he identifies as Mexican because he spent part of his early childhood in Mexico. "I was born here," he explained, "but I was raised in México until I was five years old, so I am Mexican. It's a part of me that's never going to go away or change."

Essentially, then, the childhood environment of these six participants has had a longterm effect on their ethnic identification. This is consistent with Torres' (2003) grounded theory study that found that college students' ethnic identification arises from the environment in which they were raised. It is important to draw attention to the fact that these six participants still identified as Mexican regardless of how long they have lived in the United States. The six of them recounted their ethnicity from a geographical point of view, "where I come from."

Since ethnic identity is not static but is manufactured along the way (Phinney, 1996; Phinney \& Ong, 2007), some participants opted to identify as Mexican Americans. Contrary to the "where I come from" rationale of the six discussed above, the following three participants identified as Mexican Americans even though they were born in México. These three also spent part of their childhood living in Mexico. Hernández, a junior aerospace engineering major, arrived in this country when he was four years old, 
and Hermonsillo, another junior aerospace engineering major, came to this country when he was five years old. Ochoa, a senior mechanical engineering major, left México when he was nine years old. Although these three participants acknowledged and felt proud about being born in México, they identified as Mexican Americans. According to all of them, three perspectives prompted them to include the American identity term: (1) 1.5 generation status, (2) lifetime living in the United States, and (3) navigating two different cultures. Hermosillo summarized why these participants may identify as Mexican Americans:

I came here when I was very, very young. Even though I wasn't born here I say I'm Mexican American. I'm American because I feel that I've been here long enough to understand how to navigate both cultures and both ways of life.

Similar to the aforementioned participants, Alves, a junior mechanical engineering major, was born in México. He likewise identifies as a generation 1.5. However, he draws attention to fact that being born outside the United States affects one's ethnic identification.

I define my ethnicity as Chicano, even though I was born in México, but came here when I was 2 years old. I've always struggled with selfidentification because you're living in the U.S. but you're not technically American, so you're in a divide. What do you identify? I feel strongly about identifying myself as a Chicano. I have been here basically all my life. But, I wasn't born here.

The three participants identifying as Mexican American employed the American identity term, as they considered their time spent living in the United States and their adaptation to this country as qualifications for identifying themselves as Mexican Americans, whereas Alves took on the Chicano classification because he understood that being born 
in a different country influences his ethnic identity regardless of how long he has been living in the United States. His understanding that "you're not technically American" based on birthplace brings him to self-identify as a Chicano. Table 4 summarizes these participants' ethnic identification and birthplace.

Table 4. Participants' Ethnic Identification and Birthplace

\begin{tabular}{lll}
\hline Number of Participants & Ethnic Identification & Birthplace \\
\hline 5 & Mexican & México \\
1 & Mexican & United States \\
3 & Mexican American & México \\
1 & Chicano & México \\
7 & Mexican American & United States \\
1 & Chicano & United States
\end{tabular}

Similar to Alves' birthplace notion, the following seven participants identified their ethnicity as Mexican American because they were born in the United States. These seven acknowledged that, because their parents were born in México, they classified themselves as second generation. A common trend among these participants is that they exhibited a firm understanding of their ethnic identity by providing solid answers that reflected their birthplace: "Mexican American. I was born here," and "I'm a second generation Mexican American. I was born here, that's why." Roberto Carlos, a senior chemical engineering major, spoke to this point when he said, "I am a Chicano, second generation because I was born here." As these seven Mexican American participants and the Chicano participant show, birthplace contributes to one's ethnic identification.

The remaining four participants defined their ethnicity according to their parents' birthplace and families' cultural traditions. Additionally, these four incorporated the American identity term because they were born in the United States. Rivaldo, a 
sophomore political science major, explained that he is a "Honduran American--I was born here, but my parents are very traditional; we follow our Honduran culture, traditions, everything." Neymar, a junior psychology major, defined his ethnicity as Peruvian American, saying, "We eat Peruvian food, listen to Peruvian music, and we visited Perú often.” Luis Enrique, a senior sociology major, stated, "My ethnicity, I would consider to be Mexican and Nicaraguan American. To me, well that's how I define it." Cienfuegos, a senior political science major, said, "I consider myself 100 percent Salvadoran and I guess Americanized because I grew up here, was born and raised in California. If anyone asks, I say, 'I'm Salvadoran American'." These participants defined their ethnicity based on birthplace, parents' ethnicities, and individual experiences. Table 5 summarizes their ethnic identification and birthplace. Table 5. Participants' Ethnic Identification by Parents' Heritage and Birthplace

\begin{tabular}{lll}
\hline Number of Participants & Ethnic Identification & Birthplace \\
\hline 1 & Honduran American & United States \\
1 & Peruvian American & United States \\
1 & Mexican and Nicaraguan & United States \\
& American & \\
1 & Salvadoran American & United States
\end{tabular}

In sum, these participants understood their racial and ethnic identity according to their birthplace, generation status, and personal experiences. Thus, using a one-size fits-all category will prevent us from comprehending how these participants understood their racial and ethnic identity. For example, some participants who were born in México attributed their comfort in incorporating the American term to time spent in this country and their abilities to manage both cultures. On the other hand, six participants who were born in México reported feeling uncomfortable integrating the American term. Five of 
them have continued to identify as Mexicans, and one of them as a Chicano. All have associated ethnic identification to birthplace, so none opted for integrating the American term which, they felt, would not represent who they really are. Contrary, to these six participants, Zague, a senior mechanical engineering major, was born in the United States but, due to spending his early childhood in México, identifies only as Mexican. He felt uncomfortable integrating the American term into his ethnic identity because he did not spend his early childhood in this country. From their narratives, it is evident that these participants' personal experiences are a key factor in their ethnic identification. More important is the fact that they value and feel comfortable about their ethnic identity. As a result, their ethnic identity continues to thrive in the college setting and even becomes a motivation since these participants are aware that Latino males overall struggle to attend college and earn degrees.

Racial and ethnic identity as a motivation. These 22 Latino male college students understand their racial and ethnic identity as a source of motivation to achieve a higher education degree. At the same time, this racial and ethnic identity plays a double role in their lives: on one hand it motivates their academic achievement; on the other hand, it impacts their psychological stress. Every single participant expressed that their racial and ethnic identity has empowered them to do well in college.

All 22 reported feeling a sense of privilege, having the opportunity to attend a fouryear-university. They recognize that many Latinos from their communities are unable to participate in higher education. Consequently, they feel responsible for representing and demonstrating that Latinos, males in particular, are capable of achieving a college degree. 
Giovanni, a Mexican American political science junior, captured how these participants perceived themselves as ambassadors representing Latino males in higher education, knowing that their comrades were left behind in their path to higher education.

I wanna be successful in academics and stuff, because I know a lot of people (males) in my community who end up in gangs or don't have the opportunity to go to college. I think I'm one of the few in my community who are lucky enough to go to college. Getting into this school has been really a good accomplishment, and that motivates me to do well and graduate.

Here, Giovanni has justified his enrollment in higher education as being "lucky enough." Such sentiment was shared among the 22 participants. The social science majors and the engineering majors alike reported a lack of Latino male representation within their majors. Therefore, they considered their own participation in higher education as an advantage that many other Latino males are deprived of experiencing. They felt, then, that they faced an additional burden to "be successful in academics" in order to honor those who were unable to make it into college. Such a burden positions these participants to strive to achieve academic success, as Zague, a Mexican mechanical engineering senior, expressed:

I have some friends that are like, "Oh, it's okay. We don't have to have the top score because we're Mexicans." I'd be like, "That just drives me more to beat everybody and show we're equal and we can do the same things as well." Being Latino motivates me. We are here and we can graduate and earn good grades.

In this narrative, Zague conveys two principles these participants are determined to establish about Latino males in higher education, academic competency and the right to participate. In essence, these participants feel responsible for proving that Latino males are capable of achieving academic excellence, which eventually results in attaining a 
college degree. Furthermore, they are conscious of changing Latino males' negative stereotypes by orchestrating and promoting an unfamiliar version of Latino males as higher education students.

Simultaneously, these participants are validating their very own participation in higher education by holding themselves accountable to succeed academically. Such a mindset impacts their psychological stress. For instance, Galindo, a Mexican economics major, stated, "At times, it is stressful to feel like I have to do well no matter what because I'm here. Like representing my people, more like my fellow high school friends, who didn't have this opportunity." Similarly, Rivaldo, a Honduran American political science major, explained, "It is a bit of pressure to do well because this is an opportunity not many people or people like me have." Luis Enrique, a Mexican Nicaraguan American sociology major, stated, "There is a lot of pressure on me to be very successful because of my identity," while Neymar, a Peruvian American psychology major, explained, "As a Latino I feel obligated to do well. I always worry about earning good grades because I want to change the Latino image, like I want Latinos to be seen as smart people." Luna, a Mexican electrical engineering major, shared, "As a Latino or because I'm Mexican, I always spent more time studying because I feel, I have, there is, I guess I worry about not doing well."

Whereas these participants' ethnic identity motivated them to be successful students, it also constituted a burden as they held themselves accountable for academic success. Essentially, they understand that there is no room for failure, which at times, as Galindo, a Mexican economics major, explained, "It is stressful to feel like I have to do well no 
matter what." Moreover, participants reported that feeling responsible for succeeding academically added greatly to their stress levels during exams, midterms, and finals. In short, these participants' racial and ethnic identity both motivated them to achieve academic success and impacted their psychological stress.

Research question number 1 overview of key findings. Again the first question guiding this study was, How Latino male college students understand their racial and ethnic identity? The findings suggest that these 22 participants are committed to their ethnic identity. However, it is important to mention that their ethnic identity is linked to their gender identity, as they assumed a sense of responsibility to represent Latino males in higher education, meanwhile validating their own participation. To contrast existing stereotypes that categorize Latino males as academically unfit, these 22 participants are determined to prove an unknown academic facet of Latino males. As a result, their racial and ethnic identity motivated them to achieve academic success while it also impacted their psychological stress. As these participants pressured themselves to demonstrate that Latino males are entitled to attend higher education, they struggled to manage their gender identities due to the important role gender plays within Latino culture. Therefore, it is important to inquire how these participants understand their gender identity.

\section{Research Question Number 2 Participants' Masculinity Constructs}

The second question guiding this research study was, How do Latino male college students understand their gender identity? These participants' narratives reveal a new version of Latino masculinity, which is neither machismo nor just caballerismo. This study frames Latino masculinity constructs under a new concept called un hombre de 
familia (a family man). Twenty-one participants' responses reflected ethnically grounded gender roles, which disclose avoidance to being associated with the machismo construct and unfamiliarity with the caballerismo construct. Only one participant described his gender identity as integrating machismo principles. The following section focuses on understanding his machismo identity, followed by the 21 participants' un hombre de familia gender identities.

This participant explained the important role machismo played in his upbringing. Cienfuegos, a Salvadoran American political science major, shared some of the expectations he learned to fulfill, which brought forth positive and negative outcomes:

I was taught in the machismo mentality that I can't invoke emotions. I wasn't really allowed to complain or cry or anything like that. I guess that's how I understood what it means to be a Latino man. It does kind of suck that I wasn't allowed to show my emotions, but for the most part, I'd say that it was more of a good thing for me. I learned to be more solutionoriented, and if anyone around me, like my mom or older sisters, are like crying or something for whatever reason, in my household, it would be my duty to make sure that I do something about it. It's never really about me. It's always about everyone else in my family, and especially the ones that can't necessarily protect themselves as well as I can protect myself.

Under the machismo construct, toughness is a male characteristic, which places the burden on males to be in control all the time. Cienfuegos admits to how difficult it was for him to withhold his emotions while fulfilling one of his main responsibilities, looking after his family. In effect, he was forbidden from exhibiting weakness and expected to be strong, not just physically, but emotionally, as well. Consequently, he endured maintaining a feeling of invincibility, which discouraged him from complaining, crying, or even displaying feelings. As he functioned within the parameters of machismo, he experienced psychological stress from suppressing all his emotions. In spite of this, he 
pointed out the positive features he experienced from machismo. For example, his work ethic benefited as he "learned to be more solution-oriented," which was a life skill that "came in handy" in his personal life and as a college student. More importantly, he concluded that machismo equipped him with the necessary tools to be a leader. "I know this is kind of controversial" he said, "that I shouldn't show emotion and I should just be strong, but in some ways I feel like that's beneficial because I'm expected to be a leader." This participant has definitely equated his ability to display courage and control as characteristics that leaders possess--machismo. The following section focuses on understanding how the remaining 21 participants understand their gender identity.

Un hombre de familia (a family man) familism values. As 21 participants endorsed functioning away from machismo and caballerismo constructs, they conceded that they would much rather share gender household responsibilities. These 21 described their sense of relief to move away from holding all the power or for being characterized as responsible for everything. As a result, they talked about gender equality. They felt comfortable displaying vulnerability, seeking help, and expressing their feelings. They understood their gender identity as functioning without adhering to performing only specific gender roles based on machismo and caballerismo constructs. Accordingly, they defined un hombre de familia by incorporating familism values.

The 21 participants emphasized collectivism by stressing that a family man must be able to ask for help, function as a follower, and feel comfortable helping out to the best of his abilities. Under family as referents, the participants established that a family man needs to be educated, a team player, and responsible. These traits are important 
components when it comes to representing one's family. According to the participants, a family man needs to fulfill familial obligations, such as participating in their children's extracurricular activities, assisting them with homework, and "cooking dinner and being a joint provider." In regard to perceived support from the family, these participants expect a family man to care for and display affection to every family member and to support family unification by expressing feelings and encouraging their wives to work or study. Basically, these participants understand that their ethnically grounded gender identities require them to fulfill familism values rather than restricting them to function solely within the machismo and caballerismo constructs. Hence, their gender decisions, actions, and responsibilities unfold from the important role Latino culture plays within gender role socialization.

The interview data may be interpreted as a distinct construct of Latino masculinity, which acknowledges that machismo and caballerismo unsuccessfully characterize Latino males' gender identities. Instead, these participants bring into view un hombre de familia (a family man), which enables them to exercise their ethnically grounded gender identity according to their familism cultural values, experiences, and views rather than imposed identities. Similar to un hombre de familia, which redefines Latino masculinity constructs, the future provider reveals that these participants are able to overcome specific gender responsibilities despite failing to authenticate their gender identity. Such actions demonstrate how Latino masculinity has progressed and adapted to current circumstances. 
Future provider. Under familism values, these Latino participants are expected to fulfill their role as providers (Lu \& Wong, 2014; Sáenz et al., 2013). The following two familism values trigger the "provider" responsibility from these participants: (1) "familial obligations" and (2) "perceived support from the family" (Sabogal et al., 1987, p. 397). According to Lu and Wong (2014), Latino males authenticate their gender identity to their family, society, and even themselves by successfully fulfilling their provider role. Conversely, failing to fulfill that responsibility threatens their gender identity. Twenty participants concluded that it is their obligation to fulfill this role, while two of them indicated that their families' economic situation does not require their help (see Table 6). Table 6. Participants' Masculinity Constructs

\begin{tabular}{ll}
\hline Number of Participants & Provider Familism Value \\
\hline 2 & Family Economic Stability \\
20 & Future Provider
\end{tabular}

Even though the provider role is a fundamental component of Latino masculine identity, those 20 participants who recognized themselves as providers have the strength to place that role on hold while they work on achieving a college degree.

Sáenz et al., (2013) found that Latino college students are expected to function as providers and that postsecondary education settings serve to measure Latino males' gender identities. Likewise, Figueroa's (2007) case study illustrates that certain gender identities, like that of provider, are extremely hard to overcome. For example, Figueroa's (2007) participants stated that, as Latino males, their main role is to be a provider. Twenty participants being presented in this study also understand that their ethnically grounded gender identity entails fulfilling the provider role. However, these 20 are 
focused on achieving a college degree, and such a goal overpowers the need to be a provider while attending college. Furthermore, they believe that placing the provider role on hold does not harm their gender identity because they are focused on a better future. For instance, Ramos, a Mexican American anthropology major, said, "My cousins give me a hard time about being home and going to school, because the idea's you're the man of the house, you work. But I'm still me." Though these participants experienced external pressures that reminded them about the significance of fulfilling their masculine role, the importance of achieving a college degree has permitted them to feel comfortable with simply focusing on their education.

Research question number 2 overview of key findings. The second question guiding this study was, How do Latino male college students understand their gender identity? The findings suggest that Latino male college students' familism values constructed these participants' gender identities. As a consequence, the following familism values positioned 21 participants (as previously mentioned only one participant's gender identity derived from machismo constructs) into functioning as un hombre de familia: (1) functioning as part of a collective unit (Fuligni et al., 1999), (2) "family as referents," (3) "familial obligations," and (4) "perceived support from the family" (Sabogal et al., 1987, p. 397). These four values encouraged participants to endorse gender equality, exhibit vulnerability, ask for help, express emotions, and be a joint provider.

Clearly, these 21 participants' gender identities illustrated the important role Latino culture plays within gender role socialization. What is more, these 21 participants' 
gender identities' development highlights the unimportant role machismo and caballerismo constructs play within Latino culture, as functioning as a collective unit overtakes gender role socialization. Although familism values guide Latino males into fulfilling their provider role, these participants have been able to overcome that requirement while attending college. Because they understand that a college degree has the potential to economically benefit their families, they have felt comfortable placing such a requirement on hold without compromising their gender identity. It was familism values that shaped their gender identities, and their narratives emphasize the important role collectivism, family, and un hombre de familia characteristics have played within their gender decisions, actions, and responsibilities. The following section focuses on addressing how these participants' ethnic gender principles impact their academic identities.

\section{Research Question Number 3 Ethnic Gender Identities and Academic Identities}

The third question guiding this research study was, How do Latino male college students understand their academic identity? Ethnically, Latino masculinity principles such as fear of failure, help affirmation, and lack of success (Lu \& Wong, 2014; Sáenz et al., 2013) challenge Latino male college students' academic identities. Since Latino males validate their masculinity by demonstrating confidence, functioning independently without help, and being successful, the college environment evaluates such principles (Lu \& Wong, 2014; Sáenz et al., 2013). That is, higher education challenges these participants to decide between fulfilling their ethnic masculinity principles or contradicting such concepts in exchange for academic achievement. Recognizing that it 
is acceptable to allow oneself to fail and to seek help leads to accessing higher education institutional assistance to achieve academic success (Sáenz et al., 2013). This study concludes that, once in higher education, Latino males have to reshape their ethnic gender identity principles to allow fulfillment of their academic identities. Although none of the participants referred to altering their ethnic masculinity principles as "reshaping," their narratives framed them as reshaping their ethnic gender identities. This study found that four participants struggled to reshape Latino masculinity principles, while the remaining 18 automatically favored reshaping them in order to accomplish academic achievement.

Struggling to reshape Latino masculinity principles. Four participants felt that their ethnic gender principles were in conflict with their academic identities. This caused Ramos, Alves, Zague, and Cienfuegos to be hesitant about seeking help. Although they understood that seeking help is an important component of being a college student, they disclosed how difficult it is for them to seek help. Consequently, they entered two different stages. Under stage one, they ventured into attempting to individually solve their academic challenges by adhering to their ethnic masculine principles, which restricted their academic identities (see Table 7). 
Table 7. Stage 1: Ethnically Masculinity Principles Restricting Academic Identities

\begin{tabular}{ll}
\hline Participant & Narratives \\
\hline $\begin{array}{l}\text { Ramos } \\
\text { anthropology major) }\end{array}$ & $\begin{array}{l}\text { I do a lot of things on my own. It's hard for me to ask for } \\
\text { help. It's hard and especially--I don't know where that } \\
\text { comes from. I don't know where. I guess I'm very } \\
\text { prideful. How much of that has to do with my ethnicity } \\
\text { or my gender, I don't know. I just have a lot of pride. }\end{array}$ \\
$\begin{array}{l}\text { Alves } \\
\text { (Chicano chemical } \\
\text { engineering major) }\end{array}$ & $\begin{array}{l}\text { I would try to figure things out myself, and I think going } \\
\text { and not need help from anybody else. }\end{array}$ \\
$\begin{array}{l}\text { Zague } \\
\text { (Mexican mechanical } \\
\text { engineering major) }\end{array}$ & $\begin{array}{l}\text { When I first came here, I had never been to professor's } \\
\text { office hours. I would just struggle on my own. I felt } \\
\text { unsuccessful. I tried to figure out things on my own or } \\
\text { go to YouTube, go online, use the books, but was not }\end{array}$ \\
successful.
\end{tabular}

In stage one, these participants discovered that academic achievement within higher education requires seeking help. Even so, in this stage they refrained from reshaping their ethnic masculinity principles and found themselves struggling academically. The above narratives illustrate how these participants' ethnic masculinity principles guided them into perceiving seeking help as a male weakness since they are expected to be selfsufficient. Thus, their ethnic-based gender principles conflicted with their academic identities. A case in point is Ramos, a Mexican American anthropology major. During the interview he was trying to figure out why he struggles so much with seeking help. He realized, "it's embarrassing to ask for help. I'm supposed to do it by myself." His realization indicates how firmly embedded are his ethnic masculinity principles. He tried 
to pinpoint if his behavior derived from his pride, ethnicity, or gender when, in actuality,

it is a combination of those three aspects. Ramos further shared this:

The expectation from the culture itself, from being a man, you work, and you do this, and you do that. I could've just continued to work, and everything would be fine. Here even after two years, it's difficult to go seek help. I can't get myself to just go in and be like "can you help me please," like other students without hesitation.

Similarly, Alves, a Chicano chemical engineering major, alludes to his ethnic masculine expectations:

Again, going back to some of the things my dad would teach me, as a man I'm supposed to be able to do it and not need help from anybody else. I learned to just figure things out myself and to try to do everything by myself.

These participants' techniques to figure things out on their own resulted in facing academic failures. Cienfuegos, the Salvadoran American political science major who admitted to how difficult it is for him to seek help, has tried to solve his struggles by concentrating more on those areas where he is struggling instead of modifying his ethnic masculinity principles to seek help.

When these four participants attempted to preserve their ethnic masculinity principles, they found themselves on the edge of academic distress. They reported enduring psychological stress, including feeling anxious, nervous, and worried. In addition, they felt frustrated and upset, which corresponds to behavioral stress for feeling unsuccessful. Since Latino masculinity constructs dictate that failure as a male is a deficiency, these participants were prone to seek other venues in which they could be more successful instead of suffering constant failure (Cerezo et al., 2013; Liang et al., 2011; Lu \& Wong, 2014; Sáenz et al., 2013). More precisely, fear of failure hinders 
Latino males' higher education attainment, as it forces them into a "fight or flight response" (Sáenz et al., 2013, p. 90). As these participants confronted academic failure and stress, they opted for employing a "fight" response, bringing them into stage two, where they negotiated their ethnic gender identities by reshaping their masculinity principles.

Under stage two, these four participants' academic identities took precedent, as their main goal was to achieve a college degree. They reshaped their ethnic masculinity principles by accessing institutional resources as they discontinued operating individually. The following narratives illustrate how they reshaped their ethnic masculinity principles (see Table 8).

Table 8. Stage 2: Academic Identities Reshaping Ethnic Masculinity Principles

\begin{tabular}{ll}
\hline Participant & Narratives \\
\hline $\begin{array}{l}\text { Ramos } \\
\text { (Mexican American } \\
\text { anthropology major) }\end{array}$ & $\begin{array}{l}\text { Asking questions is difficult, but I'm learning especially } \\
\text { in college because, if you don't ask questions, you're } \\
\text { gonna get lost. It's frustrating when you go down to the } \\
\text { office, and you have to ask questions. If not, you're } \\
\text { stuck. }\end{array}$ \\
$\begin{array}{l}\text { Alves } \\
\text { (Chicano chemical } \\
\text { engineering major) }\end{array}$ & $\begin{array}{l}\text { a lot easier to get help. Just noticing that I was really } \\
\text { struggling a lot, trying to do everything by myself, so } \\
\text { now I'm more open to seek help. }\end{array}$ \\
$\begin{array}{l}\text { Zague } \\
\text { (Mexican mechanical } \\
\text { engineering major) }\end{array}$ & $\begin{array}{l}\text { Now I'm more open to asking other people, asking my } \\
\text { friends, and using other resources like office hours that } \\
\text { has helped my grades. I just have to ask for help. }\end{array}$ \\
$\begin{array}{l}\text { Cienfuegos } \\
\text { (Salvadoran American } \\
\text { political science major) }\end{array}$ & $\begin{array}{l}\text { I have asked for help when I felt like it's a little too much } \\
\text { and if that affects my grades. }\end{array}$
\end{tabular}


These participants' determination to achieve a four-year college degree caused them to reshape their ethnic masculine principles. By the time they reached stage two, they had figured out that higher education requires them to be flexible in their ethnic gender principles. So, they set aside trying to accomplish everything on their own without asking for help. The following phrases verified that these participants understood that seeking help improves their academic achievement: (1) Ramos, "If not, you're stuck," (2) Alves, "I was really struggling a lot, trying to do everything by myself," (3) Zague, "Asking my friends, and using other resources like office hours, that has helped my grades." (4) Cienfuegos, "I have asked for help when I felt like it's a little too much and if that affects my grades." Under stage two, these participants understood that being college students requires them to adjust their ethnic gender practices by embracing their academic identities.

Reshaping Latino masculinity principles. The remaining 18 participants favored their academic identities and, in the process, reshaped their Latino masculinity principles. The academic identities of these 18 allowed them to feel comfortable in asking others for help sooner. They felt comfortable admitting and disclosing their academic limitations and failures. Such practices contradict Latino masculinity characteristics and expectations. As opposed to the previous four participants, these 18 replaced negotiating their ethnic masculinity principles with a focus on endorsing their academic identities. Foremost, they reshaped their Latino masculinity principles by accepting that, as college students, they are subject to possible failures, feeling powerless, and having to accept the idea that it is necessary to depend on other sources to be successful. They subsequently 
centered their efforts on overcoming academic failures by seeking help and refraining from operating individually. Those actions reshaped their ethnic masculinity principles. The following three narratives reflect how these 18 understand their own limitations and how they have overcome their academic struggles by embracing their academic identities. Galindo, a Mexican economist major:

When I struggle I would ask for resources or ask the professors what I can do to improve my academics. Just finding ways that I can help improve myself and improve my grades. Nothing wrong with asking for help. I don't feel like it makes me look bad that I need help. At the end of the day you gotta do what you gotta do to accomplish and get your degree. At least I know that I was able to ask, that I felt comfortable asking for help.

Giovanni, a Mexican American political science major:

In general, I definitely seek help, but if I can do it--I try it on my own first. Then if I feel like--I like to accept when I can't do something. Then I'd seek help, and then finish it that way. I'm not afraid to ask my professors for help. I emailed them, go to their office hours, contact other people in the class.

Hermosillo, a Mexican American aerospace engineering major:

Usually what I do is I ask students that are ahead of me, so I ask them for their help. If I can't then obviously the professor's a huge resource. I try to seek people that know more than I do. I mean, I know I can't understand it, so people that are more experienced than I am will probably help. I've been open-minded. I've been outgoing, I guess, so I've been able to reach out to people.

The above statements exemplify how these 18 reshaped their ethnic gender identities so they could achieve academic success. Their actions contradict Latino masculinity norms, which require them to be in control and to be successful at all times. A common trend among these 18 participants is that they understand that seeking help is acceptable behavior as college students even though it contradicts their own gender principles. For example, Galindo's statement demonstrates how he feels about seeking help: "Nothing 
wrong with asking for help. I don't feel like it makes me look bad that I need help.” As these participants come to feel comfortable seeking help, their masculinity is not questioned because they understand that their academic identities entail accepting academic support. Clearly, these participants are well aware of their own academic limitations. As Giovanni, a Mexican American political science major, explained, "I like to accept when I can't do something," while Hermosillo, a Mexican American aerospace engineering major, stated, "I try to seek people that know more than I do." Such confidence grants these participants the right to reshape their ethnic masculinity principles. Therefore, their academic identities drive them to employ academic resources such as professor's office hours, tutoring, classmates, and study groups to achieve academic success.

These participants explained that their academic behaviors do not hinder their masculinity. As Luis Enrique, a Mexican Nicaraguan American sociology major, said, "College is hard. Sometimes you fail, sometimes you're successful. Best thing, use all resources." Likewise, Rivaldo, a Honduran American political science major, concluded that struggling is a component of higher education. "It's okay to struggle," he said. "That's why not everyone has a college degree. There are so many resources here for us." In short, these 18 participants have a clear understanding that their academic behaviors do not hinder their masculinity, because seeking help verifies their masculinity more than failing classes. To summarize, these 18 participants' academic identities empowered them to perceive seeking help, experiencing failure, and depending on others as a natural educational process. 
It is crucial for Latino male college students to understand that higher education requires accessing resources to overcome academic struggles. This is made clear by the 18 participants who reshaped their ethnic gender principle to endorse their academic identities and who reported experiencing less academic struggles, while the four participants who struggled to reshape their ethnic masculinity principles reported psychological stress due to academic struggles. Ramos, Alves, Zague, and Cienfuegos engaged in attempting to achieve success on their own, by adhering to their ethnic masculinity principles. Such practices correlate with Figueroa's (2007) case study, which found that certain gender identities, such as achievers, are extremely hard to overcome. Nonetheless, these four participants eventually ended up reshaping their ethnic masculinity principles so that they could embrace their academic identities.

Research question number 3 overview of key findings. The third question guiding this study was, How do Latino male college students understand their academic identity? The findings suggest that ethnic Latino masculinity principles such as fear of failure, help affirmation, and lack of success are in conflict with their academic identities (Lu \& Wong, 2014). These ethnic masculinity principles guide Latino male college students toward demonstrating confidence and independent, successful functioning. As they face academic challenges they have two options: (1) continue to fulfill their ethnic masculinity principles, or (2) reshape their ethnic masculinity principles by embracing their academic identities.

Following option one conditions Latino males to fail to achieve academic success as they embark on operating individually, which triggers fear of failure and lack of success. 
Fear of failure causes them to implement a "fight or flight response" (Sáenz et al., 2013, p. 90). The findings suggest that Latino males' persistence to achieve a college degree leads them toward employing a "fight response" (Sáenz et al., 2013, p. 90), while owning a weak determination to achieve a college degree leads them toward a "flight response" (Sáenz et al., 2013, p. 90).

Following option two sets up Latino males to accept that, as college students, they are prone to experience possible academic failures, which they can address by depending on other sources and seeking help. Under option two, Latino males reshape their ethnic masculinity principles because, aware of the significance of achieving a college degree, they make their academic identities a priority.

This study concludes that Latino male college students must understand right away the importance of accessing higher education resources in order to counter academic challenges. To do this, they must be aware that their ethnic masculinity principles conflict with their academic identities. Such awareness will help them understand both why they struggle to seek help and the importance of utilizing higher education academic resources to be successful students. The following sections address participants' identities and psychological stress.

\section{Research Question Number 4 Latino Males' Racial and Ethnic Identity Psychological Stress}

The fourth research question guiding this study was, How do Latino male college students' various identities impact their psychological stress? Interview transcriptions were analyzed to identify commonalities and differences across participants. Racial profiling and microaggressions were two major themes attributed to racial and ethnic 
identity psychological stress. Eight participants reported that racial profiling and microaggressions from faculty influencing how they understand their racial and ethnic identity and how such identity impacts their psychological stress (see Table 9). Fourteen other participants did not report experiencing racial profiling and microaggressions from faculty.

Table 9. Racial and Ethnic Identity Participants' Experiences

\begin{tabular}{ll}
\hline Number of Participants & Experiences \\
\hline 8 & Racial Profiling \& Microaggressions \\
14 & Absence of Racial Profiling \& Microaggressions from \\
& Faculty
\end{tabular}

From these 14 participants, a total of four reported an absence of racial profiling and microaggressions from faculty (see Table 10). However, ten out of the 14 described nonverbal indirect singling out by classmates. The next section addresses some participants' racial profiling and microaggressions, followed by others' lack of racial profiling and microaggressions and nonverbal indirect singling out by classmates. Table 10. Fourteen Participants' Racial and Ethnic Identity Experiences

\begin{tabular}{ll}
\hline Number of Participants & Experiences \\
\hline 14 & $\begin{array}{l}\text { Absence of Racial Profiling \& Microaggressions from } \\
\text { Faculty } \\
\text { Absence of Racial Profiling \& Microaggressions from } \\
\text { Classmates } \\
\text { Nonverbal Indirect Singling out by Classmates }\end{array}$
\end{tabular}


Racial profiles and microaggressions. Eight out of 22 participants reported experiencing racial profiling and microaggresions related to their racial and ethnic identities. This specific sample includes four participants from the social sciences and four engineering majors. All of them reported experiencing racial profiling and microaggressions in two different domains: (1) academic spaces and (2) campus spaces. These students described being stereotyped by their racial and ethnic identities. As a result, they experienced psychological stress and racial battle fatigue. The following section addresses these participants' academic spaces and campus spaces racial profiling and microaggressions.

Social science and engineering Latino males in this study described enduring similar forms of racial profiling and microaggressions while attending classes and on campus. Their physical appearance was among the most frequently reported form of racial profiling against these eight. This type of racial profiling affected their academic achievement and created psychological stress. It is important to disclose that these eight were unable to understand why they were the recipients of racial profiling and microaggressions. Furthermore, none of them reported their encounters as racial profiling, microaggressions, or racial battle fatigue. Rather, they identified their experiences as individual incidents and struggled to understand such actions against them. This study determined that racial profiling and microaggresions directed at these males definitely do convey implications about these participants' racial, ethnic, and gender identities. 
Racial profiling from classmates. A frequent outcome from enduring racial profiling is the constant feeling of being left out in their academic spaces. Zague, a Mexican mechanical engineering major, illustrates how racial, ethnic, and gender identities pull classmates into racial profiling. He told about how he felt left out when he tried to find a study group. "I was trying to find a study group. Nobody wanted to study with me. I was like, "Oh the Middle Easterners ${ }^{3}$ [South Asians] are studying together and the Caucasians are studying together." I tried joining those groups, but nobody wanted me." He went on to explain how important his academic achievement is: "I'm super focused on my grades. I've been getting about just one B a semester. Hopefully, no B's this semester, just all A's." Zague's motivation to earn good grades and to make sure Latinos are perceived as intelligent inspired him to seek study groups. But he was rejected because his classmates perceived him as academically incompetent based on his racial, ethnic, and gender identity. This racial profiling eliminated his opportunity to work with other students. At the same time, it denied him access to learning spaces, as he was unable to join study groups. His only recourse was to study by himself, and he recalls studying diligently because he could not study with anyone else. He described the study group situation as, "I try to study with others because it makes it easier and we can learn from each other, but if they don't want me, then it's okay, I can just study by myself." As Zague reflected on his study group encounters, he recalled his high school. "I would say in high school, maybe a few times. Not the teachers, but the students would not look at me like I was smart.” Even though Zague refers to his classmates' rejection

${ }^{3}$ The Engineering participants referred to South Asian students and professors as Middle Easterners. 
as "okay, I can just study by myself," such incidents brought back memories from high school, where he also experienced rejection. As a higher education student, Zague came to feel academic confidence for two reasons: (1) “I really like my major and what I'm learning" and (2) "I'm here to earn good grades." He shared, "After the first exam, when the teacher said that I got the highest grade, then everybody wanted to study with me."

Common among these participants was that group work formation produced racial profiling. They talked about disliking the process of forming groups to complete class projects because of certain struggles when it comes to joining groups. The social science majors voiced that they usually just joined groups that were made up of students of color. They also said that Caucasian women avoided allowing them into their groups. The engineering participants explained that South Asian students were always a majority and that they have never been able to join their groups unless the professors assign groups. Most of the time, these Latino engineering majors ended up working with Vietnamese students--a minority just like them.

Galindo, a Mexican economics major, talked about his racial profiling encounters while forming groups to do class work.

Here in my major we do a lot of group projects. Every time I start a new semester I know that I would be left out when it comes to forming groups. I'm a tall Mexican guy, dark skin, and people, usually women, kind of feel uncomfortable when they don't' know me. People in general avoid me because of how I look. I guess. Once I'm in a group and they see my work ethic and how much work I dedicated to a project, then they change their opinions about me and want to work with me the rest of the semester, but it always happens when I start a new semester and no one in class knows me. Once I'm in a group, I have to show that I can do the work because they first see me as maybe lazy and not too smart. 
Galindo's narrative describes racial profiling that is grounded in stereotyping his racial, ethnic, and gender identity, in addition to his physical looks. He specifically points out that his physical looks, gender, and ethnicity cause his classmates to establish negative assumptions about him, which obstructs his likelihood of being recognized as a potential group member. As a consequence, he is well aware that he needs to work extra hard to validate his stance as a group member, while simultaneously defining himself as an outstanding future group member for the rest of the semester. Galindo's group work participation has entailed eradicating prejudices about his ethnicity, physical looks, work ethic, and academic abilities. When simply partaking in the process of joining a group, he finds himself juggling an array of assumptions that negatively impact his psychological stress. As he explained, "I get kind of nervous, anxious every time I start a new semester because I have to deal with the group issue, if that makes sense. It's just too much sometimes." He tries to justify his peers' actions by saying, "I know that my dress-up style, my clothes, plus I always wear caps with Mexican logos or Latino logos, kind of influence how others see me or think about me." In response, Galindo focuses on achieving academically so as to balance how others perceive him. He talked about his class work ethic by stating that,

It comes down to how much effort and work I put into my academics. There are no excuses as to why I can't pass my courses. I'm averaging a 3.3, and I've been very happy with everything that I've been learning and has been going well so far.

Like Zague, Galindo is inclined to achieve academic success so he can justify his higher education presence. Both are on a mission to affirm Latino males as academically proficient. Additionally, as these participants are determined to change how Latino males 
are perceived, they endure psychological stress that derives from the different ordeals they report experiencing.

A trend among all of the participants that stems from feeling left out is self-doubt. They explained that, when they have faced such circumstances, they questioned if they belonged in college, and that the feeling stayed with them for a while. At times they doubted their academic abilities, as well. Rivaldo, a Honduran America political science major, talked about feeling left out as a group member due to being perceived as academically incompetent.

It has happened like three times, like I ended up in an all-girls, women group and I'm the only guy. These ladies thought about me like I wasn't a serious student, like, we were dividing group work, and they were assigning the minimum to me. When I asked for more work, they questioned my schedule, my commitments and if I had enough time to collaborate. One of them said, "We need to earn a passing grade, so you just do what we said." I was like thinking, "Oh if I get to do more work that means we are going to get a bad grade." So, the first two times, I let it go, but the last time, I pushed for more work. I wanted to do more than just little things and I got to do more, but I was mad because what I did, what I was supposed to do, one of the girls went ahead and did it too. So, they, the girls got rid of my work, and used what the girl did instead of my work. I was mad, because they didn't value my work. Like, I'm part of the group, but not really, or maybe my work wasn't good enough.

Rivaldo felt marginalized within his own group, knowing that his group members were unable to fully trust his academic abilities. The first few times he decided just to go along; the third time he found himself in the situation, he demanded the right to contribute more to the group project. He became upset that his work was replaced. $\mathrm{He}$ had spent additional time to complete his part and shared it with his friends to make sure it was high quality. His work being replaced caused him to doubt his own academic abilities and feel that "maybe my work wasn't good enough.” Although he knew his 
work was good enough, his group members thought otherwise, since they had already classified him as academically unfit and a potential danger to everyone else's group grade.

Enduring marginalization damaged Rivaldo's academic confidence. The aggression caused him to internalize that he might not be academically competent. He did, though, report how important it is for him to achieve academic success. He said, "I can't let my guard down. That's why I'm so focused on studying and passing my classes. I'm the one earning my grades. Most classes I have earned B's, yeah just me."

Like Zague and Galindo, Rivaldo's racial and ethnic identity and gender led to his classmates' view of him as academically incompetent. That perception increased these participants' psychological stress. They reported anxiety, frustration, and feeling nervous. These three responded to their racial profiling by focusing on their academic achievement. Essentially, they validated their higher education enrollment. One way in which they did this was to share investing effort and time into their academics to demonstrate that Latino males are academically competent. Basically, all three have been working towards removing the negative stereotypes that are associated within their ethnic group (Arson, 2004). Still, during this process, they have had to deal with rejection, racial profiling, and psychological stress. Similarly, the following participants reported microaggressions due to being categorized as unintelligent, which led to their enduring psychological stress. 
Microaggressions from professors and classmates. These participants understand that their racial and ethnic identities guide classmates and professors into framing them as unintelligent. Such framing triggers microaggressions that target their academic abilities. As a result, these participants constantly work to prove their academic work ethic while navigating professors who have a hard time trusting their academic abilities. Along these lines, Guardado, a Mexican American mechanical engineering major, and Neymar, a Peruvian American psychology major, talked about professors questioning their academic intelligence during class lectures. Guardado reported that he currently has a 3.2 grade point average and works thirty hours per week. Yet, he said, "It's not my full, potential, right? I can do better." His life philosophy enables him to understand that the sky is the limit. "It's all mental, I think. I mean people have come from worse places, from worse situations than I have, personally, and they've gone on to become successful. It is about the effort we put into our grades." Further, Guardado shared how his racial and ethnic identity has been used to marginalize him when he participates during lectures by answering a question:

Most of my professors, they're Middle Easterners [South Asians]. Most of the students attending here in the Engineering Department are also Middle Easterners [South Asians]. As I said, there's very few Latinos in my class. Whenever I answered questions correctly, he looks at me and looks at his kind and says, "Come on, really? He answered this question before you guys?" He doesn't think that I'm capable of the same knowledge as the other people. Obviously, that has had a huge impact because it's not very encouraging to not have a professor who supports you.

This type of interpersonal microaggression targets Guardado's academic abilities, accomplishments, and worthiness as a higher education student. It simultaneously 
deteriorates his ethnic identity, which is perceived as unworthy of intelligence. The professor delivers verbal and nonverbal racial insults--verbal as he articulates, "Come on, really? He answered this question before you guys?" and nonverbal as he gestures, "he looks at me and looks at his kind." The verbal and nonverbal racial insults pinpoint Guardado as what Yosso et al. refers to as "the racial Other" (2009, p. 667). Guardado finds himself enduring a microaggression that questions his intelligence: "He doesn't think that I'm capable of the same knowledge as the other people." The professor holds low expectations of him because he is a Latino and a minority. The professor's microaggression towards him indicates that South Asian engineering students are expected to be more academically intelligent and prepared. His remarks disturb Guardado’s academic confidence as his professor undermines his academic participation and contributions. All this, as Guardado reports, creates stress, as he is seen as academically unqualified due to his racial and ethnic identity. He explained that his South Asian classmates “do undermine my potential to succeed, right.” Guardado ends up finding himself dealing with academic biases just because of his racial and ethnic identity. Yet, he was able to continue displaying his knowledge and to ratify his academic abilities through his first exam performance. "Like when I took that first test we had," he said, "I got the highest score on that class right." His highest score reinforced his academic identity among his South Asian peers,

Before the exam they wouldn't talk to me. They wouldn't approach me. After that, they all wanted to study with me. In the beginning, they just thought I was just some other guy or some random dude. I guess that's a stereotype. They didn't think I was smart enough to be in the class.

Guardado has acknowledged that his racial and ethnic identity prompted his 
classmates to regard him as unintelligent and to stereotype him. Instead of fitting in just as a student, his racial and ethnic identity has positioned him to be perceived by his classmates and professors as an impostor. Guardado encountered a hostile academic environment, but his academic application granted him the right to integrate himself as a student among his classmates. His struggle to be accepted as a student illustrates the racial profiling and microaggression he suffered due to his ethnic identity.

Neymar, a junior social science major with an emphasis in psychology, talked about a like situation in which his racial and ethnic identity steered one of his professors into characterizing him as academically unprepared. He attributes his good grades, which are mainly B's, to the fact that he has learned to focus on his studies rather than going out. He described himself as “a boring guy, don't go out because it takes time away from studying." He defined his ethnicity as Peruvian American, which prompts him to achieve academically. "As a Latino I feel obligated to do well," he explained. "I always worry about earning good grades because I want to change the Latino image, like I want Latinos to be seen as smart people." This drive to achieve academically focuses him on his academics outside and inside the classroom.

In my major the majority of students are Caucasian women. In one of my classes, I really like the material, I tried and tried to participate, but the professor only called on women. I kept on switching seating places to make myself noticeable to him. When he finally called on me, he was like, "I'm not too sure you were able to read all assigned readings." He didn't even let me answer, he moved on. I lost interest.

The professor had concluded immediately that Neymar was incapable of participating, perceiving him as an irresponsible student who lacks the capacity to digest a heavy load of reading assignments. In that particular class there were only two Latino 
males enrolled. It is clear that the professor's judgment on his racial and ethnic, along with his gender, identity led him to subordinate Neymar to his classmates and dismiss him from participating in class. The professor's verbal microaggression towards Neymar interfered with his academic performance because it affected his enthusiasm, made him feel rejected and stereotyped, and caused him to "lose interest." Prior to the microaggression, Neymar was focused on participating by physically making himself noticeable to capture his professor's attention. But his ethnicity and gender automatically disqualified him, as shown by the professor's calling on him, then verbally acknowledging him as an incompetent student.

Guardado's and Neymar's professors' microaggressions verbally humiliated them by questioning their intellectual abilities and, at same time, acknowledging their belief that these two students' racial and ethnic identity is inferior (Sue et al., 2007). This is in line with Pizarro's (2005) participants, who acknowledged that race played a major role in how they were treated and their racial discrimination experiences. Moreover, the racial and ethnic identities of these participants impacted how they have been perceived and treated not only inside their classroom but also outside classroom spaces.

Microaggressions and racial profiling outside the classrooms. Outside classroom spaces, participants Campos, Borgetti, Galindo, and Cienfuegos recounted stories of microaggressions and racial profiling, noting that their physical appearance caused others to perceive them as outsiders. For instance, the three of the four agreed that other students have questioned their student identities when coming onto campus, in the library, and while accessing major designated study spaces. They reported that they have 
been accused of being dishonest when confirming their higher education student identities. Campos, a Mexican aerospace engineering major, describes being questioned about his student identity on campus:

Oh, sometimes some students don't think that I'm a student. I remember one time when I was coming to school here I was carrying a book. I was getting off the bus and then these girls were like, "What are you doing?" I'm like, "Oh, I'm going to school." She's like, "You go to school here?" I'm like, "Yeah." She's like, "You don't got to lie to me. You don't look like a student. You don't have to pretend." Then, I said, "I'm not pretending, I'm a student." They were like, "Everyone can carry a book around." Yeah, they don't expect some of us to be students. I guess it's more like the internalized kind of thing.

This interpersonal microaggression framed Campos as an intruder who was pretending to be a student. Despite his efforts to establish himself as a student by stating, "I'm not pretending, I'm a student," the girls ignored his student identity and inferred that he was dishonest. Campos understood these girls' racial profiling and microaggression towards him, knowing that they automatically discarded Latinos as potential college students.

Like Campos, Borgetti, a Mexican American mechanical engineering major, reported feeling unwelcome outside the classrooms because of his ethnicity and physical appearance.

I always see people trying to...they feel intimidated by me because of my size and because I'm Latino. I feel a lot of people try to avoid me, like when walking in the hallways and study areas. Girls keep a close eye on me. Sometimes guys they feel like they have to act tough around me. People don't see me as a student. They wonder what I'm doing here because we are outnumbered, I guess, so not many Latinos in engineering. That's why people here don't think I'm a student and how I look makes people uncomfortable around me.

Outside the classroom Borgetti encounters racial profiling and nonverbal racial microaggressions. As a result, he walks through the engineering building quite aware 
that other students perceive him as an outsider. He knows that his physical appearance encourages males to feel the need to manifest roughness and females to assume a vigilant attitude towards him. He associates his height, skin color, and physical characteristics with how others perceive him. For males, part of that perception is viewing him as an aggressive threat, which impacts his emotional well-being. For example, he explained, "I mean, sometimes I don't want to act. I don't want to have to react, but at the same time I feel that if I don't, then they're gonna push me over. I'm just here to study. That's why I just mind my own business." Basically, Borgetti focuses on maintaining a "low profile" to avoid confrontations and to focus on his academics. In addition, while monitoring his behavior and actions around males, Borgetti is fully aware that females feel insecure around him and "keep a close eye" on him. During his narrative he explicitly states that his ethnicity adds to his being stereotyped as an impostor, which contributes to having to tolerate negative stereotypes from males and females alike because he is not classified as a student. Because Borgetti continuously feels out of place and endures rejection while navigating campus, he experiences stress, anxiety, and, at times, feeling upset.

All four participants conveyed both feeling confused as to why other individuals perceived them as outsiders and feeling unwanted. For example, Galindo, a Mexican economics major, described how he was questioned about his student identity at the library.

Usually I studied at home, but one time during finals I tried the library late study hours. I was just quietly studying. I wasn't bothering anyone, and I had to show my student card two times. Like, they didn't believe I was a student. The first time I didn't mind showing my ID, but I had to show it a second time. After that, I just study at home, in the living room when everyone is asleep during midterms or finals. 
He and the others understand that, in order to enter academic designated study spaces and allocated student study areas, they have to enter a code or use their student identification. Once they have entered those spaces, though, they should not be questioned about their student identity. Galindo was aware that, to take advantage of the library extended study hours, he could be asked to show his student identification. He was asked a second time to prove his student identity, which he felt was unnecessary. These participants struggled to understand why they encountered racial profiling and microaggressions even though they were attending a diverse and open campus that experiences a lot of public foot traffic.

Racial profiling and microaggressions related to academic abilities place these participants in a double bind. Not only do they feel like the "racial Other," (Yosso et al., 2009 p. 667) but they also feel responsible for changing classmates', professors', and other students' attitudes towards them. This makes them mindful about their actions, expressions, and how they carry themselves. Racial profiling and microaggressions pressured these Latino male students into justifying "their identity and presence" on their own campus (Franklin, 2016, p. 45; Yosso et al., 2009). Cienfuegos and Galindo offer insight into how these participants automatically allocated their energies to counteract imposed stereotypes. Cienfuegos, a Salvadoran American political science major, explained,

Right away, I'm prepared to flip their thinking. My work ethic speaks for me. For the most part, I just do my best to make sure that they understand that the prejudices that they have against me aren't real. It's always interesting because I never really thought that the way I look would even matter. You know?

In other words, he, along with the other three participants, is consciously working on 
proving wrong the imposed stereotypes he is faced with within academic and campus spaces. He navigates higher education knowing that he needs to justify his presence on campus via academic achievement and leadership. Academically, Cienfuegos is scheduled to graduate Spring 2017 and reported his grades are mostly B's. When it comes to leadership involvement, he is part of the board of directors and a vice president and chair for student campus organizations which focus on improving student campus experiences. He is also the public relations chair for his fraternity. He recognizes that the way he looks leads others to treat him differently. That is why, as a habit, he takes action to address biases, often thinking, "Okay, I need to make sure that this person doesn't keep doubting me." His approach has been very successful in changing people's perceptions.

I think for the most part, they're taken aback when they hear that I'm doing well in school, and then they hear me speak, and then they see that I'm very involved. At first, it seems like they treat me as if I may not know as much or as if I'm some naïve student, but as soon as they get to know me, then they start saying, "Oh, I didn't know you were so involved." That sort of thing.

Likewise, Galindo, a Mexican economics major, navigates higher education by consciously monitoring his actions and expressions.

I know that how I look and my height and being Mexican, usually people, especially women, kind of feel uncomfortable. So I'm mindful about holding the door, giving my seat or greeting them respectfully like, "good morning," stuff like that, so they don't feel I'm a threat. I'm more mindful about how I present myself, how I come across and I guess, how I carry myself, if that makes sense. I can't let my guard down.

He, like the other participants, works on a daily basis to justify his right to attend higher education, all the while feeling like a foreigner on his own campus. 
The effort to succeed academically and to overcome racial profiling and microaggressions have come with a price tag for these participants. On the surface, the impact of racial profiling and microaggressions propels them to demonstrate their worth. Accordingly, they work on achieving academic success. Meanwhile, they feel responsible for changing imposed negative identities about Latino males. Internally, these participants suffer psychological, behavioral, and physical stress. These three types of stressors correspond to racial battle fatigue (Franklin et al., 2014; Smith et al., 2007). As mentioned in Chapter 2, the racial battle fatigue (RBF) framework addresses the wellbeing consequences of experiencing "racialized stress" (Franklin et al., 2014 p. 304). These eight participants reported enduring the following psychological stress symptoms: anxiety, frustration, anger and feeling nervous. They talked about such stressors impacting their physical health as they experienced behavioral stress, which had affected their eating, sleeping, and time management actions (Franklin et al., 2014; Smith et al., 2007). They reported feeling tired by always being mindful about how they are being perceived and by working on changing others' perceptions towards them.

These participants' psychological and behavioral stress definitely had a negative effect on their academic achievement and well-being. For one thing, because they have internalized that they could be perceived as "outsiders," they have felt anxious when required to interact with their peers during small group discussions and group projects. They explained that feeling anxiety affects their efficiency to "think straight," that "it's challenging to concentrate," and that it decreases their participation until they feel more 
acceptable and comfortable around their classmates. Rivaldo, a Honduran American

political science major, summarizes their all-too familiar classroom interactions:

At the beginning of the semester, I have a hard time participating, like during group discussions or lectures, because I feel like a pressure to be right. Like, I don't wanna not fit in. Oh, I don't want my classmates to think that I'm not part of the class. Always in the beginning, I just feel like that, nervous. It goes away once I feel like I'm part of the class.

While these participants endured racial profiling and microaggressions, they internalized an obligation to manifest their belongingness, which is not guaranteed by their enrollment. Feeling left out and having to bear biases not only carries them into doubting their intellectual identities and college integration, but also increases their psychological and behavioral stress. To illustrate, Zague, a Mexican mechanical engineering major shared this:

In the beginning of the semester I always freak out. I don't know why. I always get good grades, but I always feel like I'm going to fail. The teacher's like, "Oh, this is a hard class." I don't know; I always do good, but, for some reason, I always feel like it's me, the one they're talking to like, "Oh, you're going to fail." I feel like I overstress about proving to them that I can do the work. I overstress about doing good in class and my grades, so I feel anxious.

Zague's narrative illuminates the outcomes of being classified as the "racial Other"

(Yosso et al., p. 667).

To this point, six participants talked about feeling frustrated when their classmates demonstrated that they were unwilling to interact or collaborate. Such frustration interfered with three participants' ability to sleep. As Rivaldo explained, "It's hard to sleep, to fall asleep right away, because you think about why they don't want to work with you." The other three participants acknowledged that they tend to eat unhealthily 
when they encounter such situations. Zague, Guardado, Galindo, Neymar, Cienfuegos, and Rivaldo recognized that it is frustrating and wearisome to have to validate their higher education membership, while Borgetti and Campos expressed feeling tired and irritated by others who have a hard time seeing them as students. These feelings of being mentally and physically tired triggered these participants into procrastinating, which only increased their psychological and behavioral stress. Galindo, a Mexican economics major, explained this process:

Like I said before, for the first time I'm being a successful student. I really like college. Sometimes I'm just too tired and frustrated. Yeah, like I have to kind of watch carefully what I'm doing. Sometimes I'm just tired of that. And that makes me lose focus, and then I avoided class assignments. Until I get mad for wasting time because I have to get it done. Then I'm more stressed out because I wasted my time.

In this way, Galindo illustrates these participants' physical and psychological stress outcomes as they continued to work on proving themselves academically worthy. Furthermore, behavioral stress from racial profiling and microaggressions disturbed their academic achievement by interfering with their ability to focus on and address assignments. These participants have been dealing with what Yosso et al's study documents refer to as a "troubling amount of stress" $(2009$, p. 674$)$ as they engage in "resisting and fighting against racialized stressors" (as cited in Franklin et al., 2014, p. 306). Overall, they have endured the following symptoms: anxiety, anger, frustration, and nervousness. Besides feeling confused and tired, experiencing doubt, and having poor concentration, sleep disturbance, and an inability to think straight, they have eaten unhealthily, procrastinated, and "freaked out." And they have suffered racial battle fatigue, which has the potential to encourage Latino males to abandon higher education 
(Franklin et al., 2014). Despite all these symptoms, the commitment to attaining a college degree has helped these participants to thrive academically regardless of racial profiling and microaggressions. As a consequence, at times they have felt physically and emotionally drained, since they have been holding themselves accountable for performing academically while consciously monitoring every move they make, from speaking, to walking, to interacting with others. That is why these participants' stressors have impacted their health, which, in turn, has affected their "educational, social and interpersonal well-being" (Franklin et al., 2014, p. 307). On the other hand, 14 participants revealed an absence of racial profiling and microaggressions from faculty.

Acceptability and being treated with respect by faculty. Unlike the eight participants who reported experiencing racial profiling and microaggressions (8 of 22), 14 felt accepted and were treated with respect by faculty (14 of 22). This sample is composed of four social science majors and ten engineering majors. The four social science majors expressed feelings of being accepted and treated with respect by classmates (see Table 11), while the remaining ten engineering students addressed what they referred to as "indirect" instances of feeling singled out by classmates.

Table 11. Fourteen Participants' Positive and Negative Racial and Ethnic Identity Experiences

\begin{tabular}{ll}
\hline Number of Participants & Experiences \\
\hline 14 & Acceptable and Being Treated with Respect by Faculty \\
4 & $\begin{array}{l}\text { Acceptable and Being Treated with Respect by } \\
\text { Classmates }\end{array}$ \\
& Nonverbal Indirect Singling out by Classmates
\end{tabular}


Although, these ten minimized the importance of such instances and claimed a lack of psychological stress from feeling singled out, their narratives suggest otherwise. The following section addresses 14 participants' positive interactions with faculty and four participants' positive interactions with classmates, followed by the ten engineering participants' nonverbal indirect singling out by classmates.

Four social science and ten engineering Latino male participants described similar positive interactions with faculty within both academic and campus spaces. These 14 told about respectful encounters when interacting with Asian, Native American, South Asian, Latina/o, and White faculty. They described positive outcomes when interacting and communicating with professors during classes, via email, in person, or during office hours. They attributed positive interactions between students and professors to the fact that "this is a diverse campus." Wondo, a Mexican American computer engineering major, typifies these participants' observations.

The professors seem to be very aware of how diverse the school is. Each and every one of them have said that the staff is here to help us be better students, and so they wanna see us succeed. They are easily approachable and are easy to talk to, yeah.

A shared understanding among these participants is that faculty is always eager to help them with academics. Unlike the aforementioned participants who endured racial profiling and microaggressions from professors, these participants explained feeling supported academically and encouraged to participate in class. As an illustration, Hermosillo, a Mexican American aerospace major explained, "Not once have I received any...I don't think I've ever received any kind of undermining or behavior. I feel they've been there when I need 'em." Here Hermosillo reflects on what none of these 14 
participants recalled--experiencing negative interactions with faculty. Equally important, in terms of interacting with classmates, four of these participants cited positive outcomes; however, the ten engineering participants reported feeling singled out at times by classmates when entering classrooms. Regardless of feeling singled out, though, these ten had positive interactions with classmates and a lack of psychological stress.

Acceptability and being treated with respect by classmates. A total of four social science majors and ten engineering majors reported feeling comfortable when interacting with classmates inside and outside the classroom to accomplish classwork and projects. None of them reported facing verbal racial profiling or microaggressions. However, 11 out of these 14 mentioned being a minority within their major because of Latina/os' low enrollment. This sample consisted of one social science major and the aforementioned ten engineering majors who reported feeling singled out. Ramos, a Mexican American anthropology major, exemplifies these 11 participants' minority statuses. He said, "I wish sometimes that more students that I would...that I could relate to, ethnically, I guess, were in the department. There's maybe only two or three students." These 11 participants acknowledged feeling lonely and having a desire for more Latina/os to be in their major, whereas the other three participants (social science majors) did not talk about feeling like a minority within their major. The minority status greatly affected the ten engineering majors. It is important to state that every single engineering participant in this study mentioned being a minority within their major. The following ten engineering participants expressed enduring uncomfortable feelings due to their minority status. 
Nonverbal indirect singling out by classmates. These ten engineering majors reported feeling nonverbal indirect singling out, sometimes when walking into their classrooms. They felt their classmates "stare" at them as they walked in. A Mexican American aerospace engineering major, Hermosillo sums up these ten participants' reported experiences.

I think it's a bittersweet feeling to know that you are one of the few Latinos here. I don't think I have ever been singled out, at least directly. I do feel sometimes, like when I walk into a classroom, I do feel people look at me. Yeah. Or I feel like I don't belong here kinda thing. I don't think anybody's ever said anything to me. It's just they stared and feeling and knowing that there's very few of us. And to walk into a classroom it feels a little lonely. Everybody has their group. You just come in and it's scary. Again, I don't think I've ever been singled out directly by a student in words, but I'm sure maybe...I feel like I have sometimes when I walk into a classroom.

Hermosillo's narrative illustrates that these ten participants are perceived as the "racial Other" (Yosso et al., 2009, p. 667) within the engineering classroom walls, just like the above participants who endured racial profiling and microaggressions. The staring from other ethnic groups affected their psychological stress in that it translated as questioning their belongingness. Further, as soon as these participants walked into their classrooms they were already feeling stressed. Adding to their stress levels, they said they felt conscious about eradicating stereotypes and demonstrating an unfamiliar Latino academic facet. Pelé, a Mexican mechanical engineering major, clarifies these participants' struggles and intentions,

In my classes, I have to be careful about what I do or what I say because there's just a few of us. I feel like people are too judgmental. They created opinions just based on my ethnicity that aren't true or positive. I really don't care about what they think. But, I feel responsible for showing them who we really are. We are capable of being smart and good 
students like anyone else. We have the same potential, but they don't see us like that.

These participants acknowledged feeling responsible for monitoring their actions and interactions as a way to validate their enrollment. Because they represent a small Latino male sample in the engineering department, they are mindful that "every word may reaffirm racialized assumptions and cast doubt on their academic merit" (Yosso et al., 2009, p. 669). Consequently, they are focused on demonstrating their academic potential, just like Pelé explained. The staring is considered a nonverbal statement that confirms to these participants that their attendance as engineering majors is questionable, since the majority of students are South Asians, Asians, and White. Nonetheless, these participants interpreted the staring as "not in a bad way, but maybe neither in a good way" and "for some reason they stared at you." A common understanding among these participants is that they attributed their small enrollment to a justification for why others stared at them. Additionally, as these participants reported just feeling "stared at," without verbally expressed bias, they considered such a practice as an "indirect" act of being singled out. And they were unable to relate their racial and ethnic identity to producing psychological stress.

Feeling lonely, scared, and at times uncomfortable when entering a classroom are factors that produce psychological stress. In accord with Yosso et al. (2009), as these participants endured nonverbal interpersonal microaggressions their stress intensified. It is important to point out that these ten participants dismissed experiencing psychological stress from being stared at. They considered the staring length of time as momentary and 
classified it as minor occurrences. That is why they reported feeling acceptable and being treated with respect by classmates whenever they interacted.

There is a pattern between these ten participants and the participants who endured racial profiling and microaggressions. That is, they struggled to interpret such actions towards them as racial insults (Fergus, 2016; Pizarro, 2005; Suárez-Orozco \& Qin, Sue et al., 2007; Yosso et al., 2009). They also considered their experiences as individual incidents and were under the impression that none of the other Latino males confronted such experiences. As this study totals the number of participants that reported experiencing racial profiling, microaggressions, and indirect singling out, it adds up to 18 out of 22 . Eighteen account for $82 \%$ of the sample. This outcome offers a point of departure for future research about diverse higher education campuses and Latino males' psychological stress (18 of 22). These participants responded to their racial and ethnic identities' psychological stress by applying themselves academically in their efforts to eradicate imposed stereotypes. In their effort to overcome such stereotypes, they withstood an array of psychological, behavioral, and physiological stressors that impacted their well-being. It is important, then, to understand how these participants' gender identities affected their psychological stress.

\section{Latino Males' Gender Identity Psychological Stress}

Being required to function as students while feeling responsible for fulfilling their familism values causes Latino male college students psychological stress. Fourteen out of 22 participants reported struggling to balance their academic responsibilities and fulfilling the following familism values: (1) functioning as a collective unit (Fuligni et al., 
1999), (2) familial obligations, and (3) perceived support from the family (Sabogal et al., 1987). It is important to note that these participants' gender role responsibilities at this moment do not encompass financial contributions to their families. These 14 reported experiencing the following emotional psychological stress symptoms: anxiety, nervousness, and feelings of worry, depression, irritability, and anger. They found themselves tolerating constant psychological stress that derived from their gender and academic responsibilities until they learned to cope with these two constructs.

Contrary to the 14 participants, eight participants reported feeling a lack of responsibility to fulfill familism values while attending higher education (see Table 12).

Table 12. Struggling to Balance Academic Responsibilities and Familism Values

\begin{tabular}{ll}
\hline Number of Participants & Familism Values \\
\hline 14 & $\begin{array}{l}\text { (1) Functioning as a Collective Unit } \\
\text { (2) Familial Obligations } \\
\text { (3) Perceived Support from the Family }\end{array}$ \\
8 & Lack of Responsibility to Fulfill Familism Values
\end{tabular}

These eight reasoned that, at the current moment, their main responsibility was to achieve a college degree. As a result, their families perceived higher education as the only responsibility for which these participants would be held accountable. Under the concept of man of the house, these participants knew that they were just expected to "set a good example" by "doing well in school." As Borgetti, a Mexican American mechanical engineering major, put it,

Yeah, my responsibilities right now. I feel like a role model to my family, cousins and my younger brother. I think that's one of the biggest roles that I play or the only role right now because I'm here to earn my degree. 
Since these eight participants have been concentrating on being good role models by achieving academic success, their gender identity has not been a source of psychological stress. Conversely, the remaining 14 participants did undergo psychological stress due to their gender identity. The following section focuses on their gender identities and psychological stress.

Prior to arriving at a four-year university, these 14 participants were able to fulfill their familism gender role expectations. The following narrative from Guardado, a Mexican American mechanical engineering major, highlights the important role these males played prior to pursuing higher education,

Family plays a huge role in me as a Latino male. One of the main reasons I went to a community college was because my dad, he has horrible eyesight. Mainly, I stayed there to keep helping them out, either it was financially or just taking them around wherever they needed to go, so aside from my school, I had my home obligations. It's a responsibility because, obviously, they are your parents. They raised you, taught you morals, so, it's my duty to them.

Here, Guardado exhibits the familism values these participants were complying with and emphasizes their commitment to their families. These participants reported that higher education academic demands restrict their abilities to live up to their gender role responsibilities. Therefore, they underwent a transition period in which higher education academic requirements challenged their gender identity roles. At this point, individually, without any help or support, they embarked on figuring out how to manage higher education responsibilities and their very own gender expectations. Navigating alone, this transition period resulted in detrimental psychological stress consequences and low academic performance. 
Having been socialized to comply with familism values, these participants have automatically responded to family needs without pausing to question how such actions could affect their academic achievement. Some of them attempted to fulfill their familism values only during their first two college semesters, while others tried longer, for about three to four semesters. This study refers to these two-to-four semesters as a transitioning period. During this transitioning period, participants began to realize that spending time fulfilling familism values decreases study time and intensifies psychological stress. The tendency among these 14 was to play a crucial role within their families. However, as they attempted to combine higher education and familism gender role expectations, they encountered psychological stress plus a negative impact on their academic achievement. The experience of Alves, a Chicano chemical engineering major, exemplifies these participants' difficulties.

In my family I have to be the stable pillar. I guess you could call it a burden to always just be that stable person and being, "Okay we're gonna make it through because I said we're gonna make it through." It's pretty stressful with school and everything, and it does build up, so there's certain moments where that responsibility starts to weigh a lot.

These participants were highly involved in safeguarding family unification by providing emotional support and sacrificing personal needs for the good of the family (Fuligni et al., 1999; Sabogal et al., 1987), finding such actions hard to maintain while they tried to focus on their academic achievement. That led them into what this study calls a negotiating detachment period (see Table 13). 
Table 13. Negotiating Detachment Period

\begin{tabular}{|l|l|l|l|}
\hline Stage & \multicolumn{1}{|c|}{ Reaction } & \multicolumn{1}{|c|}{ Outcome } & Psychology Stress \\
\hline One & $\begin{array}{l}\text { Combining Family } \\
\text { Functions and } \\
\text { Academic } \\
\text { Responsibilities }\end{array}$ & $\begin{array}{l}\text { Decreasing Study } \\
\text { Time }\end{array}$ & Intensifies \\
\hline Two & $\begin{array}{l}\text { Impossible to Equally } \\
\text { Carry Role } \\
\text { Expectations and } \\
\text { Academic } \\
\text { Responsibilities }\end{array}$ & $\begin{array}{l}\text { Prioritizing } \\
\text { Academic } \\
\text { Achievement } \\
\text { Severely Reducing } \\
\text { Family Involvement }\end{array}$ & Highest Stress \\
\hline Three & $\begin{array}{l}\text { Higher Education } \\
\text { Commitments no } \\
\text { Longer Conflicting } \\
\text { with Gender Role } \\
\text { Expectations }\end{array}$ & $\begin{array}{l}\text { Family Flexibility } \\
\text { Males Functioning } \\
\text { Independently }\end{array}$ & Least Stress \\
\hline
\end{tabular}

During the first stage of the negotiating detachment period, participants tried to keep up with their family functions and academic responsibilities at the same time. Then they realized that they were stretching themselves too thin, as higher education academic responsibilities consumed most of their time. This reflection by Ochoa, a Mexican American mechanical engineering major, echoes these participants' constraints:

I have to make sure my family is okay. It is kind of stressful because sometimes I don't know what to do. Like, I'm literally busy from the time I wake up until the time I go to bed. Overall, I feel like I've taken some stuff off my plate with my family. I feel like I'm not helping enough, but I really can't, I tried. But, I can't, because of work and school.

Ochoa's narrative illustrates these participants' busy schedules, psychological stress, and how unrealistic it is to fulfill familism values and academic achievement simultaneously. It is important to point out that ten participants work, which has restricted their schedules 
even more. In the midst of striving to keep up with their family functions and academic responsibilities, these participants reported experiencing anxiety and irritability. Despite their efforts, they have discovered that higher education responsibilities and Latino males' gender role principles are worlds apart, and they have come to feel anxious and easily irritable as they fail to merge these two worlds into one that is much more manageable.

From here, participants moved into the second stage of the negotiating detachment period. This is when they acknowledged that it is impossible to carry on their gender role expectations and academic responsibilities equally. At this juncture, prioritizing takes center stage, as they have come to realize that their academic achievement must take precedence. Campos, a Mexican sophomore aerospace engineering major, spells out this realization:

I feel like there's a lot of pressure to help out family, too. That's also been a struggle with trying to focus on myself, because I need to get my degree if I really want to make a meaningful change. Yeah, it is expected that I help my family. That's not the best thing to do when I'm in school.

During this stage, the participants disclosed experiencing higher levels of psychological stress due to severely reducing their involvement, contributions, and attendance within their families. Such detaching increased their psychological stress levels, because their families questioned and challenged their family disengagement and, to a certain point, their disappearance. At this stage, participants began to function much more independently, which contradicts familism values. The result was, as participants described it, feeling a sense of guilt when they declined to participate in family-related activities so they could focus on academic achievement. Besides feeling guilty, some 
participants explained feeling a sense of anger, and four of them referred to their psychological stress as depression. The four mentioning depression talked about feeling extremely sad and guilty, particularly when they had to decline their mother's requests and postpone helping out until their student schedule permitted. Ochoa, a Mexican American mechanical engineering major, illustrates how these participants have negotiated detachment.

They're always like, "Oh, are you gonna come to this party? Are you going to be here? I need you to do this for me." I'm, like, "No, I have homework assignments and projects. I can't go home." "Oh, but your niece is going to be here." You know, they tug on my heartstrings, and it's so hard. It makes me so sad. The other day I made my sister move my niece's birthday party. Because I was, like, "I can't come home. I have stuff to do." She moved it, so that was good. It's also harder. That makes it that much more rewarding when you succeed.

It is important that these 14 participants were able to negotiate their family disengagement so they could face academic struggles. Not doing so has consequences. For example, three participants lost their academic scholarships after failing to maintain a specific grade point average, while two others were placed on academic probation. Four participants acknowledged feeling overwhelmed and disappointed about their academic performance. Eight concluded that driving home almost every weekend to visit their families kept them from studying. Three spoke about spending from six to eight hours on the road and recognized that those hours were better spent studying, since their major required intense study time. Realizing the importance of academic achievement, these participants were able to negotiate and prioritize in order to balance their gender and student identities. 
By the third and final stage of the negotiating detachment period participants described enduring the least psychological stress. By now, they and their families had a clear understanding that higher education commitments require balancing familism values with achieving a college degree. At this stage, the participants who had figured out how to keep higher education commitments from conflicting with their gender role responsibilities felt comfortable failing to fulfill such roles. According to Ronaldo, a Mexican electrical engineering major, this is how these participants were able to function independently and guilt-free:

Being away from home and no longer visiting every weekend, cuz I'm four hours away, and living close by, it makes me focus. I do call home and they call me, but now it's rare. I try not to do that so I don't get distracted. Sometimes I do need to talk to my family, but sometimes I need to stay away. Yeah, so I can focus on my studies.

During this stage, participants are no longer stretching themselves too thin, as they have learned to manage their academic responsibilities. More important is the fact that they have noticed that prioritizing their academics has resulted in earning better grades. At this point in time, their families' flexibility and support toward their education prevents them from pressuring them to attend and participate in family-related activities or needs. In other words, these participants' families have come to a consensus that achieving a higher education demands that these males, at the moment, function independently and away from meeting cultural-based gender role expectations.

It is important to acknowledge that these families adapted to permitting their Latino male college students to function independently after undergoing an adaptation process. During the adaptation process, these Latino families learned via negotiation that higher 
education requirements must be fulfilled first in order to support academic achievement and degree completion. Also during the process, these families became aware that their males' class schedules, study hours, group projects time requirements, and work hours prevented them from fulfilling familism gender role expectations. When these families continued to seek their males' help and family participation, their students became capable of voicing their inability to help or participate due to their busy schedules. At this point, these students and their families underwent a negotiation process in which higher education commitments dictated when these males could help out and participate in family events. In short, these Latino families adapted their needs and family gatherings to their male college students' higher education commitments, scheduling or rescheduling family gatherings to honor their males' availability. Furthermore, these families' adaptations have brought them to a reliance on other family members to help. More importantly, these families have adapted to their males' higher education commitments and become better at holding off familism gender role expectations because they are aware that a college degree has the potential to provide a more stable economic future. Even though these families eventually adapted and understood how their males' higher education commitments prevent them from fulfilling familism gender role expectations, these males underwent psychological stress.

It is important to understand that during the three stages of the negotiating detachment period these participants endured psychological stress. They were quick to point out that they experienced much more psychological stress during the first two stages. During stage three, though, participants shared that they sought spending time 
with their families as a way to reenergize themselves. Cienfuegos, a Salvadoran American political science major, highlights why these participants have sought spending time with family.

Even though I don't get to see them every weekend like before, like I would love to or how they would love me to, whenever I do go home, we always eat together. We catch up. We crack jokes. We talk about what I've been doing, what they've been up to, any plans for the future, that sort of thing. I drive my mom to the grocery store, carry the groceries, and get more water for the family, that sort of thing. I can say my family ties are very strong. Every time I go home, it feels rejuvenating cuz when I'm here, it's very exhausting to be away from my family. There's class work, work in general, assignments, and everything else I'm involved in, so when I go home, it feels like a little retreat.

This study concludes that behind the reenergizing concept is an unconscious drive to exercise gender role responsibilities. For example, like Cienfuegos, other participants spoke about how good it feels to be there for their families and to place family first, even if is just for one whole day or a few hours. Those actions correlate to the following familism values: functioning as a collective unit and perceived support from the family. A commonality among these 14 participants is that when they spent time with their families they reported helping out by engaging in different errands.

Although these participants claimed that they had learned to balance their gender role responsibilities, it is evident from stage three that they are inclined to exercise their gender roles familism values. This means that the institutions of higher education need to be aware of the important role family values play within Latino males' gender identities. Needing to figure out on their own how to manage higher education responsibilities and their own gender expectations, these participants were prone to "vanishing" from higher education (Sáenz \& Ponjuan, 2009, p. 54). Placing Latino male students in such 
situations without any kind of support or guidance sets them up to suffer psychological stress in response to having been socialized to comply with familism values. Spending up to four semesters trying to fulfill gender role expectations and complying with higher education demands not only negatively impacts these males' academic achievement, it also drains them physically and mentally. Bottom line, when it comes to Latino males, higher education must take into consideration these students' gender role expectations if it is to provide them with the appropriate tools to manage both ends of the spectrum.

\section{Latino Males' Academic Identity Psychological Stress First-Generation College Student Status}

Thirteen participants reported enduring academic stress due to their first-generation college student status. They explained that, as first-generation college students, they have internalized that they are completely responsible for achieving a college degree (see Table 14).

Table 14. Causes of Academic Stress

\begin{tabular}{ll}
\hline Number of Participants & Reason \\
\hline 13 & First-Generation College Student Status \\
6 & Balancing Academics and Finances \\
4 & Major Academic Demands
\end{tabular}

Adding to their ordeal is the fact that their economic situations pressured them into attaining their degree without delay. As they strived to meet the objective of fulfilling their academic identity responsibilities, they placed themselves in harm's way without even realizing it, until they suffered major side effects. These 13 participants spoke about how important it is to obtain passing grades for two reasons: (1) it keeps them on track to 
graduate, and (2) it saves money by not adding additional semesters to their budget. Consequently, the pressure to fulfill their first-generation college status expectations created in these participants both physiological and psychological stress.

In their effort to avoid graduation delays, these participants pushed themselves to the limit by making their academic achievement a priority at all times. A common stance among these 13 participants has been that studying and working are non-negotiable. Meanwhile, eating and sleeping are considered luxuries, especially during project deadlines, midterms, and finals. Such a mentality has increased their physiological stress. They expressed having the following physiological stress symptoms: headaches, grinding teeth, body aches, low energy levels, insomnia, and stomach aches. These symptoms originated from their efforts to succeed academically. They were well aware that eating and sleeping are essential to maintain physical health and to prevent physical stress, but they justified their negotiable methods as necessary sacrifices in order to achieve a college degree. In fact, six participants categorized sacrificing as a workable practice, saying, "It's not like it will last forever" and "What can you do? I need to graduate." Similarly, eight participants described manipulating their sleep hours into additional study time in order to keep on track academically. This creates the physical stress and necessary strategies that Guardado, a Mexican American mechanical engineering major, describes:

I haven't slept much this week. I just have so much to do, you know. I can't miss work; I need the money. If I sleep a few hours that will do it. I can't worry about having enough time to sleep, but I worry about my grades. This week has been too stressful. It is what it is. 
Operating under pressure to graduate, these participants are not equipped to pursue other methods since they are navigating and finding solutions as they go on their own. For instance, six participants admitted drinking great amounts of coffee, as the caffeine keeps them "going and awake." However, they admitted that drinking too much coffee affects their mood, making them easily irritable and "shaky," which affects their concentration and tolerance levels. Additionally, they explained that over-drinking coffee interferes with trying to fall asleep and causes stomachaches. Intrinsically, these participants are cognizant that their actions and choices impact their physical stress. Nonetheless, achieving a college degree is more important than their own health at the moment. Essentially, their first-generation college status commands them to succeed.

First-generation college students are expected to succeed because they "have made it so far." Such a principle compels them to put up with psychological stress, as they are forbidden to fail. Neymar, a Peruvian American psychology major's narrative demonstrates these participants' academic achievement pressures and psychological stressors.

I'm the first one to attend college. They're expecting me to graduate. That stresses me because I don't, I can't fail. Sometimes, when I don't do well in class, I feel a lot of anxiety, and that affects my ability to study and to concentrate. There isn't any room for failure, you know.

Because these participants stress about obtaining a low grade on a given assignment, quiz, midterm, or final, their anxiety affects their study habits. A common trend among these 13 participants is that their families equate their college student status with having already earned a college degree. This assumption produces an additional weight on these participants, as they feel an obligation they must fulfill in order to meet their families' 
expectations. Alves, a Chicano chemical engineering major, tells about such family expectations:

Well, I mean, it's pretty stressful with school and everything, and it does build up, so there's certain moments where that responsibility starts to weigh a lot and I feel anxious, anxious most of the time. Definitely just because the family's expecting, "We expect you to graduate." It's a feeling where, "I need to come through for them."

As these participants coped with meeting their first-generation status families' expectations, they experienced psychological stress. They explained that such family expectations originated from witnessing their struggles to attend a four-year university. Their families automatically considered their mere higher education attendance as a guarantee of a college degree. Such embedded notions augmented these participants' psychological stress, leaving them with the only option being to achieve a college degree. Figueroa et al. (2016) explains that parents of first-generation Latino college students view higher education as the path to become "someone in life," whereas failing to earn a college degree corresponds to "being a nobody" (p. 66). While these participants avoided disappointing their families and diverted from becoming "a nobody," they experienced the following psychological stress symptoms: anxiety, anger, worry, frustration, depression, and keeping to themselves. The narrative of Luis Enrique, a Mexican Nicaraguan American sociology major, presents these participants' first-generation stresses and side effects as they went through the motions of earning a college degree without pausing to assess their well-being.

I feel like I'm catching up. Part of my academic challenge has come from being spread thin. I can't even count the amount of all-nighters that I've had, just to catch up. I'm just overworking myself overall due to work and academics. I feel stress, I get mood swings, I also lose a lot of sleep 
because I stress out so much that it paralyzes me. I will start feeling grumpy, anxious and depressed too.

Luis Enrique recognized that he was "overworking” and knew that it was affecting his health. These other participants, just like Luis Enrique, were constantly enduring mental and physical stress in their effort to graduate. As they faced physical and psychological stress, they were vulnerable to "hit the wall," as Hernández, a Mexican American aerospace engineering major calls it when stress overtakes academics and personal health.

Adding to their psychological and physical stress is that fact that a higher education degree holds the key to a prosperous economic future. These participants and their families perceived a college degree as a guarantee to financial stability. Blanco, a Mexican American psychology major, brings to light the economic perspective that stems from achieving a college degree: "One of my biggest fears is not getting to graduation. That makes me anxious because my family is counting on me to graduate. Once I graduate we will have a better economic situation." These participants' first-generation status already signified a major accomplishment, plus it correlated to "being somebody" and predicted a stable financial future. To conclude, because these participants prevail in achieving a college degree while enduring physical and psychological stress, it is important for higher education institutions and first-generation Latino families and their students to learn about how first-generation stress impacts students. 
Balancing academics and finances. Six other participants reported physiological and psychological stress from balancing academics and finances. They described their headaches, lack of sleep, and anxiety. For example, Ochoa, a Mexican American mechanical engineering major, explained,

My weeks and weekends are typically stressed. There's always an assignment, paper or project that is due. I just feel like I can't catch my breath. Still, I'm trying to work some hours because I need the money. I don't know if the socioeconomic aspect has to do with it, but I'm definitely stressed about work and school to the point that I panic. My boss is very lenient. He is like, "School first," which I would take more time off. If I could have it right now, I wouldn't be working at all. That would be ideal, but I need to eat and pay rent, so I'm sleeping less.

Here, Ochoa reports physical and psychological stress as he tries to sustain both his academic achievement and basic needs.

Just like Ochoa, the other five participants reported stressing about paying for food and rent, since their academics required them to work fewer hours, which is a luxury these participants were unable to afford. All six explained that their family's economic situations prevented them from providing additional funds. Hence, they reported sacrificing sleep hours in order to fulfill their academic requirements. Cienfuegos, a Salvadoran American political science major, summarizes these participants' tensions: "I have to work more, and so I worry about having enough time to study, having enough to pay everything, and just making sure that I'm fed well." These six participants' economic situations and academic commitments generated stress, which affected them physically and mentally. 
Major academic demands. The remaining three participants, as well, revealed psychological and physical stress from major academic demands. These three engineering majors reported feeling stress from doubting if they could accomplish their major academic requirements. They explained that their major academic workload was "very heavy," plus they stressed about performing well on exams, which is crucial to their overall class grade. James, a Mexican American electrical engineering major, spoke to this point: "You do bad on one exam and there goes your A, so you're playing catchup the whole time. Sometimes it's more about having enough time to study. If you are working, that's really hard." These three participants understood that their graduation depended on their grades. In addition, they stressed about their academics because they feared being "dropped out" or "kicked out of the program for failing classes." Another reason they worried about performing well academically was their desire to graduate as soon as possible. As a result, these three participants reported enduring anxiety, feeling pressured and continuously worried about their academic performance. Physically, they experienced headaches and stomach aches, especially during midterms and exams.

To summarize, these 22 participants have reported enduring psychological, physical, and behavioral stress as their academic identities guided them toward achieving a college degree. Their effort to graduate impacted their well-being because they focused mainly on thriving academically. Overall, the college experiences of these 22 were nested in balancing academic demands, their first-generation status, and, for some of them, working to finance their basic necessities. The narratives cited above clarify the different types of stress these participants endured from their academic identities. Even more 
important is the fact that these participants committed themselves to do whatever it takes to graduate and, in the process, unconsciously harmed themselves mentally and physically.

Research question number 4 overview of key findings. The fourth question guiding this study was, How do Latino male college students' various identities impact their psychological stress? The findings suggest that these Latino males experienced not only psychological stress but also physical and behavioral stress. Their racial and ethnic identities prompted faculty, classmates, and the student body to negatively stereotype Latino males as unintelligent, as a threat, as outsiders, and as the "racial Other" (Yosso et al., 2009, p. 667). In other words, the majority of the participants faced racial profiling, microaggressions, and nonverbal indirect singling out. This impacted their well-being in major ways; not only did they endure racial aggressions, but at the same time, they had to work on counteracting negative perceptions toward them while focusing on validating their higher education participation. Unlike other college students, Latino males' racialand ethnic-imposed stereotypes prevented them from just concentrating on their academic achievement.

Likewise, Latino males' gender identities positioned them to endure psychological stress. Prior to arriving at a four-year college, these participants were fulfilling the following familism values: (1) functioning as a collective unit, (2) "familial obligations," and (3) "perceived support from the family" (Fuligni et al., 1999; Sabogal et al., 1987, p. 397). Then higher education academic demands impinged on their abilities to fulfill gender role expectations. Therefore, these participants underwent a transitioning period 
in which they figured out how to manage academic responsibilities and familism values individually, without any guidance.

To recap, under stage one, participants combined family functions and academic responsibilities, which decreased study time, therefore intensifying psychological stress. Under stage two, participants figured out that it is impossible to succeed equally at fulfilling familism gender role expectations and academics. At this point, participants prioritized academic achievement, which severely reduced family involvement, which produced the highest levels of psychological stress. Participants reported enduring anxiety, irritability, sadness, and even depression. At the final stage, higher education commitments were no longer conflicting with familism gender role expectations; by now, Latino families understood that higher education requires their males to function independently. These participants were capable of negotiating their family disengagement so they could commit themselves to achieving a college degree. As they faced academic struggles they realized that committing to meeting both spectrums was just impossible. It is crucial for institutions of higher education to address the important role familism values play within Latino males' gender identities in order to provide them with the appropriate tools to navigate their negotiating detachment period. It must be acknowledged that seeking to fulfill familism values, gender role expectations, and higher education all at once has the potential to derail Latino males from achieving a college degree. 
Latino males' academic identities, such as first-generation college student status, balancing academics and finances, and major academic demands all positioned these participants to endure psychological, physical, and behavioral stress. First-generation college student status prompted participants to focus solely on their academic achievement by setting aside their well-being. The following family beliefs contributed to their ignoring their well-being in favor of academic achievement: (1) enrollment guarantees a college degree, (2) college degree equals financial stability, and (3) "become someone in life" by achieving a college degree (Figueroa et al., 2016, p. 66). Due to these family beliefs, participants reported enduring the following psychological stresses: anxiety, anger, worrying, frustration, depression, and keeping to themselves. Physically, they complained of headaches, grinding teeth, body aches, low energy levels, insomnia, and stomach aches. Similarly, balancing academics and finances resulted in participants experiencing physical and psychological stress as they struggled to fulfill their academic expectations while needing to work to pay for their expenses. To achieve this, they divided their time between work and study, which restricted their sleep hours. Major academic demands impacted their well-being because they understood that their graduation depended on their academic achievement. Therefore, at times, they doubted if they had what it takes to perform appropriately on exams in order to maintain their enrollment. In brief, these participants endured enormous amounts of stress due to suffering racial aggressions, managing their cultural expectations and higher education, and committing to achieving a college degree, knowing that their families expected nothing less. Findings from this study have the potential to indicate why Latino males 
are in danger of "vanishing" from higher education (Sáenz \& Ponjuan, 2011, p. 54). To be proactive and support these students, it is important to understand which coping mechanisms Latino male college students employ to manage their physical and psychological stress.

\section{Research Question Number 5 Latino Males' Coping Mechanisms}

The last question guiding this research study was, What coping mechanisms do Latino male college students employ to manage their various identities and associated psychological stress? Twenty students employed informal coping mechanisms while only two participants lacked a specific arrangement to cope with stress. A mutual inclination among these 20 was, as they reported, first to use informal coping mechanisms to manage their various identities psychological stress, then to seek formal coping mechanisms.

Various informal coping mechanisms. As shown in Table 15 (see below), the most frequently reported informal coping mechanism for these participants was exercise. A total of seven engineering majors reported exercising to manage their stress. They played soccer, ran, swam, and used the college gym to manage their stress.

Table 15. Types of Informal Coping Mechanisms

\begin{tabular}{ll}
\hline Number of Participants & \multicolumn{1}{c}{ Types of Informal Coping Mechanisms } \\
\hline 7 & Exercise \\
5 & Talking to Family or Friends \\
4 & Talking to Parents Only \\
2 & Talking to Friends Only \\
2 & None (Isolation Keeping to Self) \\
1 & Eating \\
1 & Faith and Prayer
\end{tabular}


It was usual among these seven to prefer keeping their stress to themselves rather than talking to their families or friends. In addition, these seven participants said that, once they exercised, they were capable of overcoming their stress because they were prepared to confront what was causing stress. For example, James, a Mexican American electrical engineering major, explained,

When I'm stressing, I know it's time to exercise, and to go to the gym here on campus. I can control my stress if I exercise because I know I don't really have time to dwell on it too long. Once I exercise, I'm ready. Just gotta start working, tackling what was causing my stress, like academics, money, or work, whatever it is, right, or else you're just gonna face more, more stress.

These seven participants reported noticing when stress interferes with their daily lives and responsibilities. They used exercise to reenergize themselves and empower them to face their stress in their effort to eradicate it.

Five social science majors coped with stress by talking to family members or friends. This is consistent with Chiang et al.'s (2004) findings that Latina/o students managed their stress by seeking friends and family. In fact, Chiang et al. (2004), found that seeking family and friends was ranked as the highest option to cope with stress. Study participants reported turning to their families as their first option, then to friends. Luis Enrique, a Mexican Nicaraguan American sociology major, tells why he decided to first seek their families' support.

Sometimes, the main reason I'll cope with stress by talking to my parents is because I'll tell my parents, "Tell me that it's gonna be okay," because if someone that you trust or that you love tells you that it's gonna be okay, then you feel it's gonna be okay. 
Just like Luis Enrique, the other four participants indicated that talking to their families induces a feeling that "no matter what it's, gonna be okay," or "this negative experience will soon be gone." Further, these four elected to cope with stress by talking to their families because they understood that "family will always be there." In regard to friends, five participants reported seeking their friends' assistance to manage their stress "for minor issues" or for something that they considered workable, like "sometimes you just need to tell someone and then you feel much better," as Galindo stated. The remaining participants coped with stress by talking to their parents only, talking to their friends only, by isolating themselves, by eating, or by praying.

Four social science majors, responding to the crucial role family plays in the Latino culture, coped by talking only to their parents. These four talked about having a great relationship with both parents and feeling comfortable seeking their guidance during stressful times. Two other participants, both engineering majors, said that they cope with stress only by talking to their friends. They intentionally avoided talking to their parents in an effort to keep them from worrying. Also, they perceived their "inner circle of friends" as having the capacity to help them cope with stress because they were experiencing similar situations.

Conversely, two engineering majors reported an inability to apply informal coping mechanisms to manage their stress. Instead, they isolated themselves whenever they felt stress. These two, Guardado and Zague, concurred on the following: "I'd rather not bother people. I just try and solve whatever's causing the stress." They understood their stress as being basically their own problem, one that they needed to be proactive to figure 
out how to eliminate it. They explained that if they were feeling stress about a test, they would study, and if it was work-related they would find a solution. On the other hand, they did recognize that when they felt "anxious" or "worried" they lacked strategies and procedures to manage such feelings. Ochoa, one of the last two engineering major participants, copes with stress by eating.

For my stress, I usually will have food, which affects my health. Then I used to be able to go to the gym when I slept more. Now that I'm sleeping less due to work and studying I can't wake up on time for the gym. I guess I've been eating comfort food, something that I don't have to use my brain for.

Ochoa understood that eating comfort food is not the most efficient coping mechanism, but, with his busy schedule, he felt that this was his only option at the moment. The last engineering major participant, Luna, coped with stress by exercising his religion. He described himself as an active church-goer and someone for whom praying is helpful in coping with stress.

In summary, 11 out of 22 participants elected family members and friends as their main way to cope with stress. These 11 employed what Chiang et al. (2004) refers to as cultural link coping mechanisms. Talking to family members and friends derives from functioning as a collective unit within the Latino culture (Fuligni et al., 1999; Sabogal et al., 1987). The remaining 11 participants coped with stress by employing individualistic practices, which contradict functioning as a collective unit. Such an approach is consistent with enforcing their masculinity roles as operating independently rather than seeking help (Figueroa 2007; Sáenz et al., 2013). 
The two participants who managed their stress by isolating themselves classified stress as a "problem" for which they are solely responsible for finding a solution without seeking any assistance. Actually, their plan affected their well-being, as Guardado, a Mexican American mechanical engineering major, reported:

Yeah, I think it's just too much, too much things happening at once. It got to me, right. I didn't know how to cope with it. I was just nervous throughout the week. I didn't know how to handle stress right. Yeah, I didn't know how to relax myself. I didn't know how to stop it.

These two participants keeping everything to themselves and their lack of an informal outlet to release their stress is cause for great concern. By applying individualistic approaches, they place themselves in harm's way mentally and physically. The remaining nine participants coped with stress individually, albeit with specific methods to respond to stress, as previously stated: seven managed their stress by exercising, one by practicing his faith, and one by eating. In order to support these participants' coping mechanisms it is important to report their formal professional coping responses to stress.

Formal coping mechanisms. A total of 21 participants reported being aware that the campus health center offers free counseling and psychological sessions to cope with stress. They learned about counseling through the health center's advertising efforts via flyers, information tables during campus events, and website. Only one engineering participant reported unfamiliarity with the health center offering such services. Findings revealed that 19 participants were open to formal counseling to cope with stress, while three engineer participants were completely opposed to coping with stress by seeking professional help. It is important to understand their postures. 
Opposed to formal coping mechanisms. These three participants reported having friends that have sought professional help to cope with stress, so they were familiar with the process and different resources available. Yet, they felt uncomfortable seeking professional advice for three reasons: (1) struggling to express feelings, (2) difficulty sharing personal information with a stranger, and (3) uneasiness at asking for emotional help. Guardado, a Mexican American mechanical engineering major, is typical of these three participants' discomfort with seeking professional help.

But to say that I would reach out for help, I don't think that's manly of us to do. They do have the Wellness Center. They do have therapy to help relieve...to teach you how not to be so stressful. I'm not used to really expressing my feelings, and much less to people I don't know.

James and Zague, just like Guardado, saw seeking professional help as contradicting masculinity standards. This is consistent with Lu and Wong's (2014) study that found that Latino males perceived holding back emotions as meeting masculinity standards, even though they reported suffering stress when they faced such principles.

It is important to mention that two of these participants are the ones that reported a lack of informal coping mechanisms and would rather manage stress by isolating themselves. As they feel uncomfortable expressing emotions and seeking help, their stress levels intensify, which affects them physically and mentally. Therefore, it is vital to understand why other Latino males were capable of seeking and accessing professional help to manage their stress. 
Formal coping mechanisms counseling. A total of ten participants disclosed having had or were currently undergoing formal counseling sessions to manage their various identities' psychological stress (see Table 16).

Table 16. Formal Counseling Participation

\begin{tabular}{ll}
\hline Number of Participants & Time Period \\
\hline 5 & Presently Receiving Counseling Sessions \\
5 & Previously Received Counseling Sessions
\end{tabular}

These ten admitted to seeking counseling once they reached the point where their physical, behavioral, and psychological health had deteriorated and they were unable to help themselves. This sample includes four social science majors and six engineering majors. Since only ten participants out of 22 had utilized professional help to manage their stress, it is important to understand how difficult it was for them to reach such a decision.

Seeking professional help, a difficult decision. Out of ten participants, only two of them (Blanco and Rivaldo) indicated that seeking professional counseling "was probably one of the most difficult decisions" they had to make. These two said that they used to perceive professional counseling as taboo. First of all, they were under the impression that "if you go for professional counseling, then something is wrong with you." Second of all, by attending counseling it acknowledges "there's something wrong with me, like I'm not normal. I guess." Adding to their attitude about professional counseling is that fact that sharing personal matters with a stranger is not a common cultural practice. This derives from functioning as a collective unit (Fuligni et al., 1999) and the following 
familism standards: "family as referents" and "perceived support from the family" (Sabogal et al., 1987, p. 397). Blanco, a Mexican America psychology major, illustrates these cultural practices:

Going for counseling was so difficult because I didn't feel comfortable sharing my things with a stranger. In my family, when we have problems we fixed them together. We count on each other for everything. Going for counseling was like maybe going against my family, if that makes sense. That was so hard, yeah.

Both of these participants struggled to set aside their collectivistic practices, because professional counseling involves an individualistic approach. By accessing professional counseling, they felt they were contradicting their family's cultural principles. As a consequence, they contemplated such a decision for a while before they committed themselves to counseling. For example, Blanco explained, "I'm good at knowing when I have to do something or not, but for this, it took me a while to decide. I was debating, like thinking too much about it." Rivaldo, a Honduran America political science major, also thought deeply about seeking professional help. It is important to examine why eight out of ten participants were more comfortable opting to seek professional help to cope with stress.

Seeking professional help, an uncomplicated decision. Eight out of ten participants reported deciding to seek professional help as an uncomplicated decision. These eight were more inclined to seek professional counseling for various reasons. One participant, Alves, a Chicano chemical engineering major, knew about such a resource and was curious to find out more about it. As a result, when he felt over-stressed, he decided to seek help. Meantime, Neymar, a Peruvian American psychology major, 
accessed professional counseling because he knew other students that had benefited from counseling sessions. And, since Pelé, Campos, Ronaldo, Luis Enrique, Hernandez, and Wondo felt comfortable talking to others about their stress, counseling was an obvious outlet for them. Unlike the two previously mentioned participants who felt uncomfortable sharing personal matters with a stranger, these six participants viewed such a practice as a healthy and natural process to cope with stress. For example, Campos, a Mexican aerospace engineering major explained, "I think it's good to be able to express yourself," and Ronaldo shared, "I think it's good to talk to others when I'm not okay with myself." Wondo, a Mexican American computer engineering major, had a similar explanation:

I think everyone once in a while has to talk to someone else that they might not know and have someone actually listen to you and give you perhaps some positive feedback or tools to handle stress. Besides your friends and family, someone from the outside.

Contrary to the two participants who perceived professional counseling as taboo, these eight considered professional counseling as a resource to improve their health.

Furthermore, these eight felt that, if they were to be a healthy student, they needed to take care of their "minds," as well. Pelé, a Mexican mechanical engineering major, exemplifies this perspective:

It's important to take care of our minds. Sometimes we think that it will cure through time or we'll forget about it. Being a student is hard because we have so many responsibilities. If we don't take care of our minds, then our problems affect everything--grades, health, work, everything. We need someone to guide us, to help us feel better, to help us clear our vision. 
All of these participants understood that taking care of themselves necessitated attending to their mental health. Such an attitude empowered them to feel comfortable sharing their emotions and seeking help. This contradicts Figueroa's (2007) investigation that found that Latino males authenticate their gender identity by refraining from acknowledging needing help or seeking help. Because this study's participants were focused on accessing institutional resources, it is important to review the types of psychological symptoms they reported experiencing.

\section{Emotional Stress Symptoms}

The various stressors caused by these ten participants' various identities caused them to seek professional counseling because their symptoms were affecting their daily lives. They reported attending counseling sessions to cope with the following emotional stress symptoms: depression, anxiety, anger, sadness, and loneliness (see Table 17).

Table 17. Formal Counseling Psychological Stress Symptoms

\begin{tabular}{ll}
\hline Number of Participants & Symptoms \\
\hline 4 & Depression \\
3 & Depression and Anxiety \\
2 & Anxiety \\
1 & Anger and Sadness
\end{tabular}

Three of the participants talked about coping with two different symptoms, while seven reported coping with only one symptom. Wondo, a Mexican American computer engineering major, illustrates why these participants seek professional counseling.

The difficult part has to be that I've been worn out physically and mentally. It's been a long journey. I fell into depression. That hindered it a lot. That was the most difficult part of my career because I was debating whether coming back or not, but I continue to push on. Counseling has 
helped. This semester has not been so depressed. I'm actually continuing, doing counseling sessions. The more help or the more resources I can use to help me out is better.

Wondo's narrative characterizes the severity of emotional and physical stress symptoms these participants reported experiencing. The other participants, like Wondo, discussed benefiting from attending counseling sessions. Prior to counseling, they were unable to control emotional stress symptoms on their own. At the same time, they felt "hopeless," “despair," and "down." Counseling has empowered them to feel "much better," and, more importantly, it has provided them with the necessary tools to continue thriving in their effort to heal. For instance, Rivaldo, a Honduran American political science major, said,

Seeing a counselor has been very helpful. I'm making a lot of progress and feel much better. I'm learning to feel better about myself and to avoid negativity. Just talking about it, setting healthy goals for myself, it has made a difference on how I feel. I'm glad I'm doing it.

Professional coping guides these participants toward regaining the mental and physical health that was negatively impacted by their higher education journey. As their racial and ethnic, gender, and academic identities caused them to endure stress, professional counseling allowed them to speak about their difficult situations. In addition, it provided them with "a safe space" to work out their difficulties. Ronaldo, a Mexican electrical engineering major, reported learning how to cope with anger by admitting feeling sadness instead. He was struggling to manage his anger to the point that he recognized being a threat to himself and others. Through counseling, he and the other participants have learned to work on specific goals in order to improve their health. 
Common among these participants is that the severity of their emotional stress has prompted them to seek professional coping mechanisms. These ten participants' professional counseling preferences correlate with Chiang et al. (2004) study findings that Latino males in particular had a much more positive attitude about professional counseling. Yet, it contradicts Gloria et al.'s (2009) quantitative study in which the 100 participants ranked seeking professional advice from doctors, psychologists, or counselors as their least-favored coping method. The study that is the subject of this paper concludes that the severity of these ten participants' emotional stress symptoms pushed them toward seeking professional help. This finding correlates with Gloria et al.'s (2009) study that found "emotional focus coping was the largest predicting variable of psychological well-being" (p. 332). This educational institution provides an emotional avenue for students to cope with stress, which these ten participants have utilized. However, due to the severity of these participants' psychological, behavioral, and physical stress, more participants can benefit from accessing formal counseling. Thus, it is important to figure out a way to reach more Latino male students, such as sharing their stressors within a group, which correlates to functioning as a collective unit.

\section{Research Question Number 5 Overview of Key Findings}

The fifth question guiding this study was, What coping mechanisms do Latino male college students employ to manage their various identities and associated psychological stress? The findings suggest that Latino males prefer to cope with stress by implementing informal coping mechanisms. These participants managed their stress by exercising, talking to family or friends, eating, and religious faith. It is evident that 
talking to family or friends derives from functioning as a collective unit (Fuligni et al., 1999; Sabogal et al., 1987). When it comes to formal stress-coping mechanisms, a total of 19 participants expressed openness to access formal counseling, while the three others were completely opposed to seeking formal counseling due to feeling uncomfortable about sharing personal matters. Five participants reported previously receiving counseling, and five more were presently attending counseling sessions. These participants sought professional counseling after reaching a point at which their wellbeing had deteriorated from psychological, physical, and behavioral stress. Hence, they sought formal counseling to cope with depression, anxiety, anger, and sadness. The findings suggest that participants' various identities and associated psychological stress majorly impacted their well-being. Clearly, more participants could benefit from accessing formal counseling. By tapping into Latino culture, higher education should provide collectivism counseling sessions to increase Latino males' participation.

\section{Latino Males' Identity Development, Negotiation, and the Impacts on Academics}

As these 22 Latino male college students are determined to achieve a college degree, they have experienced what this study calls an identity development. They underwent an identity development so they could adapt to higher education academic requirements. This process is necessary in the college environment, which challenges Latino males' racial and ethnic, gender, and academic identities. Some of these males immediately underwent an identity development, while others engaged in a negotiation period to reach this point. Eventually, these Latino male college students figured out that they must adjust their identities, and they negotiated cultural gender expectations and practices in 
order to comply with higher education requirements. They engaged in an identity development while negotiating their racial and ethnic, gender, and academic identities in order to achieve a college degree.

In regard to their racial and ethnic identity, a lack of Latino males' higher education enrollment has influenced them to take it upon themselves to represent Latino males in higher education. These participants were aware that many Latino male students are unable to attend a four-year university. As a result, these males held themselves accountable for succeeding academically. Similarly, racial profiling, microaggressions, and nonverbal indirect singling out propelled these Latino males toward demonstrating that Latino males are, indeed, capable of succeeding academically. Therefore, external factors such as Latino males' low enrollment and racial aggressions positioned these males to undergo an identity development. For example, Alves, a Chicano chemical engineering major, had this to say about his commitment to succeed:

As a Chicano student, more than anything being a first-generation makes me strive to be a little bit more, and push through and pursue a higher education degree. In this case I want to prove that we can do it. Then, of course, there's always that spiteful thing, too, "I want to prove certain people wrong." Because we are Latinos, others don't think we can get this done. I'm here and it is possible.

Fundamentally, for these 22 Latino males, racial and ethnic identity stimulated an identity development in which their academic identities benefitted, because they wanted to prove their academic achievement. Simultaneously, their racial and ethnic identity altered as they felt pressured to represent Latino males as academically competent. Internally, they negotiated their very own academic expectations by deciding to identify themselves as academically successful. When it came to gender identity, these Latino 
males underwent an identity development resulting from familism gender role expectations and ethnic masculinity principles.

Prior to arriving at a four-year college, these males were able to fulfill familism gender role expectations. Then higher education academic requirements restricted their availability to function as a collective unit, to fulfill familial obligations, and to reassure perceived support from the family. Consequently, they went through gender identity development and engaged in negotiating familism gender role expectations and academic requirements. The following two narratives illustrate these males' familism gender role responsibilities:

Blanco explained,

In my culture I have to be a good son. I have to care for my family, like it is my duty to make sure they have what they need, not just economically, but emotionally. I have to help around the house, from chores to like making appointments, to even figuring out the mail and what needs to be done. Overall, I have a lot of responsibilities. That's like my main role.

\section{Neymar stated,}

As a male, I have to always place my family first. Like if I have something that I need to do for myself, I can't until I have already done anything my mom, dad or family needs from me. It sounds weird, but I'm responsible for making sure everything is working right at home. Like if we are running out of water, I must go get it, if my mom needs to fill forms or paperwork she counts on me for that. If my dad is going to do an oil change, I have to help him. I have learned just to do things without asking if they need help. Yeah, I always just do things without even asking. That's how I grew up.

These Latino males automatically focused on fulfilling familism gender role expectations even when no one asked them to do so. Higher education requirements altered their male gender identities, though, giving them two options: (1) continue fulfilling familism 
gender role expectations and experience academic struggles or (2) negotiate fulfilling familism gender role expectations by prioritizing academic achievement. This study data revealed that $64 \%$ of participants were required to fulfill familism gender role expectations by their families. As stated earlier in this chapter, these $64 \%$ endured high levels of psychological stress and experienced major academic struggles while trying to fulfill familism gender role expectations and academic requirements. The importance of academic achievement eventually guided the $64 \%$ to negotiate fulfilling familism gender expectations. At this point, these $64 \%$ achieved an identity development in which they figured out that academics was, at the moment, their first priority. The following narratives by Blanco and Neymar illustrate these males' identity development and negotiation.

Blanco:

As a college student I have learned that my first priority is to pass all my classes, so I can graduate. My family depends on me for many things, but I learned that it is impossible to continue helping them like before I got here. My parents and I kind of figured out when I can help and when I need to just focus on my academics. They have been very good just letting me focus on my education. But, it took a while for us to figure this system, I guess. Now my mom knows that if I call on Thursdays it means I will be home for the weekend and I can do some stuff. But if I don't call on a Thursday it means I'm super busy and need to stay to study and complete assignments.

Neymar:

When I first started here I was helping my family like I did before when I was in high school. Adjusting to this university and trying to continue helping my family was very challenging because I needed more time to do school stuff. I was struggling to complete all my assignments and didn't have enough time to study. I realized that I couldn't do it. Because I really want to graduate and my family wants me to graduate we find out 
that I needed to do my school stuff first. Now is much easier because my parents gave me the green light to just focus on my studies. If I have time, then I can help, but if I don't is okay. Now, I don't feel as bad for not helping. Before it was just hard, you know, not to be there for them.

These $64 \%$ of participants' familism gender role expectations and higher education academic achievement positioned them to undergo an identity development which helped them figure out that, to graduate, academics needed to be a priority. As Blanco's and Neymar's narratives illustrate, these males realized that trying to fulfill familism expectations hindered their academic achievement. They came to realize that they needed to focus on their academics first. After prioritizing academic achievement, they felt comfortable negotiating when they could help out and stating when it was necessary to be left alone to focus on academics. These participants were capable of undergoing an identity development and negotiating gender role expectations because they were determined to achieve a college degree. That goal facilitated prioritizing academic achievement over fulfilling familism expectations not just for these males, but also for their families.

The remaining $36 \%$ of participants were not required to fulfill familism gender role expectations by their families. As Giovanni, a Mexican American political science major, states,

Right now my role is just to set a good example and to do good in school. My parents made it clear that all I need to do is study. Right now my only responsibilities are my academics. That's been very helpful.

It is important to mention that these $36 \%$ of participants reported feeling comfortable with experiencing a lack of responsibility to fulfill familism gender role expectations. 
However, it is critical to note that, unlike the $64 \%$ of participants, these $36 \%$ reported not playing a key role in helping family. In essence, family expectations played a vital role in regard to why some of them were able to successfully negotiate their familial obligations while others struggled to reach this point. Contrary to familism gender role expectations, when it comes to ethnic masculinity principles, these Latino males individually could either shift or continue to adhere to their masculinity principles.

Latino males individually can decide whether or not they will shift their masculinity principles to access higher education academic supports. The following ethnic masculinity principles have the potential to lead them into academic failure: fear of failure, needing help, and lack of success (Lu \& Wong, 2014; Sáenz et al., 2013). Since Latino males are expected to demonstrate confidence, to function independently, and to be successful, facing academic failures and continuing to operate individually impacts academic achievement (Lu \& Wong, 2014; Sáenz et al., 2013). At this juncture, Latino males undergo an identity development in which they shift their ethnic masculinity principles. Shifting ethnic masculinity principles entails demonstrating uncertainty, being prone to failure as college students, and depending on other sources and seeking help to overcome academic struggles. This study's data revealed that $82 \%$ of participants right away shifted their ethnic masculinity principles to access academic support. These $82 \%$ (18 of 22 ) felt comfortable shifting their ethnic masculinity principles because they knew that, as college students, they would face academic struggles. Further, they knew that, as college students, they would need help. Accordingly, their identity development brought them into embracing their academic identities and spending their energies 
seeking help to overcome academic challenges. The remaining 18\% (4 of 22) at first opted for functioning according to their ethnic masculinity principles. Once their academic struggles impacted their academic achievement, they shifted their ethnic masculinity principles. This study concludes that these $18 \%$ struggled to shift their ethnic masculinity principles at first because they had not yet endorsed their academic identities. Instead, these four males initially adhered to functioning within the margins of their ethnic masculinity principles. Again, the importance of achieving a college degree defined whether or not these Latino males could shift their ethnic masculinity principles and negotiate their familism gender role expectations. The following section focuses on participants' ethnicities as well as the similarities and differences in the academic majors.

\section{Participants' Ethnicities and Academic Majors Overview of Key Findings}

This study included a total of 18 participants who self-identify as Mexicans by birthplace or ancestry. From these 18, ten utilized the American term to describe their ethnic identity, while two identified as Chicanos and six just as Mexicans (18 of 22). The remaining sample includes three non-Mexican participants who identified as Latinos by ancestry from Central América and South América. These three incorporated their parents' birthplace and the American term to describe their ethnic identities (3 of 22). The remaining participant identified as a Mexican Nicaraguan American (1 of 22). In terms of academic majors, 14 participants are engineering majors and eight are social science majors. Data findings revealed similarities between academic majors and participants' ethnicities in regard to their racial and ethnic, gender, and academic identities. 
All 22 participants defined their ethnic identities according to their life experiences. Likewise, all 22 considered their racial and ethnic identities as a motivation to achieve a higher education degree. All 22 participants felt responsible for demonstrating that Latino males are capable of achieving academic success. In terms of gender identities, the data results revealed that these participants' gender role socialization derived from familism cultural values. Their gender identities exposed an unknown portrayal of Latino masculinity. A total of 21 participants described their gender identities as operating away from machismo and caballerismo (21 of 22). Rather, they endorsed gender equality, expressing vulnerability and feelings about managing their gender identities via familism values. This resulted in their identifying as un hombre de familia (a family man). Although familism values required these Latino males to fulfill their role as providers, both social science and engineering majors were able to place the role on hold, understanding that such action does not impact their masculinity and that their main goal was to achieve a college degree.

Continuing with participants' gender identities, specific ethnic masculinity principles, such as fear of failure, helped affirmation, and lack of success (Lu \& Wong, 2014; Sáenz et al., 2013) were in conflict with their academic identities. To illustrate, two social science and two engineering majors struggled to reshape their ethnic masculinity principles. These four opted to function within the margins of their ethnic masculinity principles, making them struggle academically. Once their academic achievement declined, they joined the other 18 participants by focusing on fulfilling their academic identities. But, during this process, these four experienced psychological stress for two 
reasons: 1) struggling academically on their own and 2) feeling uncomfortable fulfilling their academic identities by seeking help, depending on other sources, and being exposed to failure as college students. These 22 participants had the capacity to flex their ethnic masculinity principles because they were committed to graduating from college.

Due to the important role familism values play within Latino males' gender identities, social science and engineering majors alike struggled to manage higher education responsibilities. The 14 who played a key role within their families prior to arriving at the university (eight other participants' families required these males to just focus on their academics) felt responsible for continuing to function as part of a collective unit by fulfilling the following familism values: "family as referents," "familial obligations," and "perceived support from the family" (Sabogal et al., 1987, p. 397). These 14 went through a negotiating detachment period before they and their families understood that, as college students, it is impossible to fulfill familism values and higher education responsibilities equally. Throughout this detachment period, participants endured high levels of psychological stress, since they had to focus on their academics and declined to participate and help out their families. As their academic achievement declined, their expectation to graduate from college decreased, as well. As a result, they negotiated their family disengagement, which had a greater consequence to the point that some participants underwent depression, anxiety and irritability.

These participants' academic identities played a crucial role in their pursuit of a college degree. The social science and engineering majors' academic identities created stress as a result of their first-generation college student status, balancing academics and 
finances, or from major academic demands. For one thing, these first-generation college student status participants reported physiological stress such as headaches, grinding teeth, body aches, low energy levels, insomnia, and stomach aches. They described their behavioral stress in terms of feeling easily irritable and "shaky" and feeling psychological stresses such as anxiety, anger, worrying, frustration, depression, and keeping to themselves. Along these same lines, balancing academics and finances brought these participants physiological and psychological stress. Physically, they reported the following symptoms: headaches and lack of sleep. Psychologically, they talked about anxiety over paying for food and rent while managing their academic responsibilities and work schedules. Major academic demands further positioned them to suffer behavioral stress, which manifested in headaches and stomachaches, especially during midterms and exams. They felt worried about performing well academically due to the importance of earning good grades in order to graduate. The findings suggest that social science and engineering majors prioritized their academic identities over their own health. Throughout the process leading to graduation, their determination has made them forget to pause to assess and attend to their well-being. This is due to the external pressures of families expecting a college degree and avoiding graduation delays because of economic situations. In like manner, imposed stereotypes of participants' racial and ethnic identities impacted their well-being.

Four social science and four engineering majors reported experiencing racial profiling and microaggressions. From this sample, participants identified their ethnicity as follows: three as Mexican, two as Mexican American, one as Peruvian American, one as 
Honduran American, and the last one as Salvadoran American. These eight reported suffering psychological stress, physical stress, and behavioral stress, all of which had a major impact on their well-being. Up to this point, the data revealed similar findings between participants' ethnicities and academic majors. On the other hand, this study documented a precise outcome within the doors of the engineering department--a specific difference between the social science majors and engineering majors. It must be noted that ten engineering majors experienced nonverbal indirect singling out by classmates (10 of 22). As opposed to the social science majors, as a minority, the Latino engineering majors endured psychological, behavioral, and physical stress over being classified within their college as the "racial Other" (Yosso et al., 2009, p. 667). This study found a common trend among the 22 participants, that their racial and ethnic, gender, and academic identities positioned them to endure typical college student stress along with specific identity-related stressors that impacted their well-being.

\section{Conclusion}

This study illustrates the crucial role Latino male college students' identities play in their effort to achieve a college degree. According to Sáenz and Ponjuan $(2009,2011)$, "Latino male college students are effectively vanishing from our postsecondary institutions" (p. 82, as cited in Sáenz et al., 2013). Based on the findings of this study, specific factors from participants' identities have the potential to steer Latino male college students into abandoning higher education. For example, participants' racial and ethnic identities influenced faculty, classmates, and the student body to deliver racial profiling, microaggressions, and nonverbal singling out. Experiencing such hostile 
treatment and environment not only affects Latino males' well-being, it also has the potential to encourage them to drop out of college, as their academic opportunities are impacted and they are negatively stereotyped (see Table 18 and 19).

Table 18. Impacts of Racial Profiling, Microaggressions, and Nonverbal Indirect Singling Out

\section{Latino Males Experiences}

Rejection from joining study groups and class projects

Minimal group participation

Academic biases

Professors hold low expectations

Professors discourage Latino males' class participation

Professors and classmates undermine Latino males' academic participation and contributions

Table 19. Racial Profiling, Microaggressions, and Nonverbal Indirect Singling Out Stereotypes

Latino Males Stereotyped as:

Academically incompetent

Racial other

Intruders or outsiders

Irresponsible

Dishonest

A Threat

In regard to gender, Latino male gender identities, specifically ethnic gender principles such as fear of failure, help affirmation, and lack of success, have the potential to trigger males leaving higher education behind (Lu \& Wong, 2014; Sáenz et al., 2013).

If Latino males refuse to shift ethnic gender principles, they will face academic failure while navigating college independently without institutional supports. That fear of failure contributes to Latino males dropping out of college. Participants' academic 
identities data revealed that familism gender role expectations produced enormous amounts of stress on them. For example, as they focused their energies on seeking to fulfill familism values and higher education responsibilities equally, they were prone to experience academic failure and personal disappointment resulting from inadequately meeting family expectations. If they are to keep Latino males' higher education enrollment, they and their families must realize and accept that higher education commitments restrict a complete fulfillment of familism values. Such realization and acceptance will keep Latino males focused on academic responsibilities without feeling familism pressure to satisfy their gender identities. Additionally, findings from participants' academic identities indicated that first-generation college student status, plus its external and internal pressures, have the strength to derail Latino males from graduating. External factors included (1) families' perception that higher education attendance equates to already earning a college degree, (2) families' understanding that a college degree secures financial stability, (3) expecting to succeed because they "made it so far," and (4) families' economic situations compelling them to avoid degree completion delays. All of these are factors that impact Latino males' psychological, behavioral, and physical stress. Internal factors include: (1) feeling responsible for meeting families' graduation expectations, (2) appointing academic achievement as a priority at all times, (3) ignoring health symptoms over academic achievement, and (4) "hitting the wall" after overworking and ignoring health symptoms. These factors pressure Latino males into "vanishing” from higher education (Sáenz \& Ponjuan, 2011, p. 54). As the data suggest, first-generation college student status and academic identities 
lead them to internalize complete responsibility for achieving a college degree. As these participants' external and internal factors pressured them into doing whatever it takes to graduate, they placed themselves in harm's way. Consequently, external and internal factors and detrimental psychological, physical, and behavioral health have the potential to terminate Latinos' higher education participation. This study data concludes that the aforementioned Latino male college students' identity factors can contribute to explaining why "Latino male college students are effectively vanishing from our postsecondary institutions" (p. 82, as cited in Sáenz et al., 2013). 


\section{Chapter 5}

\section{Key Findings, Conclusions, Discussions, and Recommendations}

As previously stated, the educational pipeline for Latina/o students illustrates the underrepresentation of Latino males in postsecondary education (Pérez Huber et al., 2015). For every 100 Latino elementary students, only 11 Latino males will graduate from college (Pérez Huber et al., 2015). For every 100 White elementary males, on the other hand, a total of 33 will attain a college degree (Pérez Huber et al., 2015). By combining 22 interviews with information from demographic surveys, this study begins to dissect Latino males' educational and personal experiences. Chapter 5 summarizes key findings, conclusions, and discussions that have the potential to impact Latino males' academic achievement. This chapter also focuses on informing policy and practice. Furthermore, it offers recommendations for further research. This study accomplished its purpose: the narratives shed light on the impact of identities, psychological stress, and coping mechanisms on both the academic achievement and personal experiences faced by Latino male college students as they work toward attaining a postsecondary degree. Thus, data findings authorize this study to inform policy and practice as to how higher education institutions can better meet the needs of Latino male college students.

A common pattern within the data illustrates that participants' identities are tied to academic achievement. It should be noted that none of these participants mentioned a lack of preparation coming into the university. Rather, they basically focused on their current academic achievement. Consequently, their decisions, behaviors, and responsibilities have been deeply tied to attaining a college degree. As evidenced by the 
interview data, participants' identities, alongside their commitment to achieving a college degree, have created psychological, behavioral, and physical stress. Further, racial profiling, microaggressions, and nonverbal indirect singling out have hampered most participants' educational experiences and well-being as they undergo racial battle fatigue.

Since the college experience operates under an individualistic system, attending college often conflicts with a student's culture, which, in turn, has an effect on his identity. The literature on first-generation college students concludes that Latino families see higher education admission as the path for males to "become someone in life," while neglecting to attain a college degree is viewed as comparable to "being a nobody" (Figueroa et al., 2016, p. 66). This perspective was evident in the participants' interview responses, which indicated that they felt pressured to accomplish this goal for their families. In actuality, they endured a range of psychological, behavioral, and physical symptoms as they worked to fulfill their "someone in life" status by over-valuing their academic achievement above their psychological, behavioral, and physical health (Figueroa et al., 2016, p. 66). At the same time, ethnic masculinity principles, which required them to navigate college independently and successfully, helped shape their academic identities. The following sections provide an overall discussion of findings that relate to participants' identities and well-being, leading to clarification of factors that impact Latino males' academic achievement. Following this discussion are recommendations and implications for policy and practice, as well as recommendations for further research. 


\section{Ethnic and Racial Identity, Academic Achievement, and Participants' Well-being}

Narrative data findings for this study revealed that $82 \%$ of participants (18 of 22 ) endured racial profiling, microaggressions, and nonverbal indirect singling out by classmates in academic and campus spaces due to racial and ethnic identity. Conversely, $18 \%$ (4 of 22) reported an absence of racial profiling, microaggressions, or nonverbal indirect singling out by classmates. The following section provides a discussion and conclusions regarding the relationships between academic achievement, racial and ethnic identities, and participants' well-being.

Latino males' experiences of racial profiling, microaggressions, and nonverbal indirect singling out impinge on both their academic achievement and their well-being. Interview data revealed that of the $82 \%$ of students who endured these kinds of treatment, $27 \%$ (6 of 22) experienced racial profiling from classmates and university personnel, $9 \%$ (2 of 22) reported microaggressions from professors, and 45\% (10 of 22) described nonverbal indirect singling out from classmates. A common trend among these 18 participants was that classmates, professors, and university personnel perceived the interviewees' ethnic identity as Mexican. In reality, according to the racial profiling and microaggressions sample, only three participants identified as Mexican. The remaining six identified themselves with their parents' ethnicities while viewing themselves as American, since they were born in the United States (see Table 20). 
Table 20. Racial Profiling and Microaggressions: Participants' Ethnic Identities and Major

\begin{tabular}{lll}
\hline Number of Participants & Ethnic Identification & Major \\
\hline 3 & Mexican & Engineering \\
2 & Mexican American & Engineering \\
& & Social Science \\
1 & Honduran American & Social Science \\
1 & Salvadoran American & Social Science \\
1 & Peruvian American & Social Science
\end{tabular}

The majority of the engineering participants who reported nonverbal indirect singling out by classmates identified as Mexican Americans, three as Mexican, and two as Chicano (see Table 21).

Table 21. Nonverbal Singling Out by Classmates: Participants' Ethnic Identities and Major

\begin{tabular}{lll}
\hline Number of Participants & Ethnic Identification & Major \\
\hline 3 & Mexican & Engineering \\
5 & Mexican American & Engineering \\
2 & Chicano & Engineering
\end{tabular}

Taken together, only six out of 18 participants identified themselves as Mexican.

Nonetheless, other people not only generalized all 18 participants as being Mexican but also, when mentioning or inquiring about their ethnic identity, consistently referred to them all as "Mexican." It is important to consider that, while all 22 felt proud of their racial and ethnic identity, these 18 participants' classification as Mexican by other people within higher education resulted in negative outcomes.

According to Yosso et al. (2009), society's endorsement of negative stereotypes and racial labels derives from the ways in which Mexicans are represented in forms of mass media. For example, when Donald Trump publicized that he was running for President, 
there was widespread reporting of his statement about Mexicans:

When Mexico sends its people, they're not sending their best. They're not sending you. They're sending people that have lots of problems, and they're bringing those problems with us. They're bringing drugs. They're bringing crime. They're rapists. And some, I assume, are good people. (Ross, October 20, 2016)

In Mr. Trump's speech, Mexicans were depicted as "people that have lots of problems," as criminals, and even as "rapists." On other occasions, the media repeatedly reported Mr. Trump's stereotype of Mexican males as "bad hombres” (Ross, October 20, 2016). These labels have the potential to negatively impact how others perceive Mexican males, particularly when vocalized by a future or current President of the United States. That is, such comments encourage others to generalize Mexican males as a threat to society. Besides bolstering perceptions that Mexican males are delinquents, identifying them as Mexican evokes assumptions such as having "language difficulties, disinterest in school, interest in working with one's hands" (Pizarro, 2005, p. 243). In short, such negative media-promoted generalizations make it hardly unusual that people equate being Mexican with lack of intelligence and not having the potential to achieve academically (Pizarro, 2005, p. 243).

Interview data in this study revealed that 18 participants experienced racial profiling, microaggressions, and nonverbal indirect singling out by classmates because they were stereotyped as Mexican. During the interviews, participants of non-Mexican descent reported being ignored and/or not believed whenever they tried to explain their real ethnic identity. Similarly, Mexican-American participants reported being “cut off” when describing their identity within the margins of being American. And the Mexican 
participants reported that classmates exhibited a disinterest in their ethnic identity. As supported by interview data, this study concludes that these 18 participants encountered racial profiling, microaggressions, and nonverbal indirect singling out due to being ethnically stereotyped as Mexican.

In contrast to the experience of those participants, $18 \%$ of the social science majors (4 of 22) reported an absence of racial profiling, microaggressions, and nonverbal indirect singling out by classmates. Common among these four participants was that others did not perceive them as Mexican. From this sample, three identified as Mexican American and one as Mexican Nicaraguan American. They explained that others are usually intrigued by their ethnic identity. For instance, Luis Enrique shared the following:

People have always asked me, "What's your ethnicity," you can't really tell. I've gotten like, "Are you White? Are you Asian? Are you Filipino and White? Are you Latino?" I've gotten it all. I think because of that, professors and faculty members and others, they see me as Latino, but I don't think they see me as a Mexican.

Like Luis Enrique, the other three participants had been identified as Latinos or other ethnicities, not as Mexicans. Giovanni, a political science major, was identified as a Filipino because the majority of his friends were Filipino. Blanco, a psychology major, was identified as White. They explained how others struggled to figure out what their ethnic identity was, thus illustrating those peoples' curiosity about the participants' ethnic backgrounds. Details about their birthplace revealed that these four were born in the United States. Of the other 18 participants who encountered racial profiling, microaggressions, and nonverbal indirect singling out, ten were born in México and eight in the United States. 
This study concluded that the four social science major participants discussed above experienced a lack of profiling, racial aggressions, and singling out as a result of their being perceived as Latino or other ethnicities, not as Mexicans. As a consequence, their academic achievement experiences and well-being differed from those of the 18 participants who were labeled as Mexicans. These four had positive experiences in academics in comparison to the participants who endured racial aggressions. Equally important, those who did not suffer from racial aggression did not suffer racial battle fatigue, either. The following section focuses on the academic experiences of the 18 participants who did face racial profiling, microaggressions, and nonverbal indirect singling out by classmates, who identified them as Mexican.

Academic achievement. Latino male participants in this study experienced limited opportunities, low expectations from others, and hostile learning environments resulting from being identified as Mexican (18 of 22). This ethnic categorization inhibited their academic achievement, as some classmates, professors, and school personnel stereotyped Mexicans as unqualified to attend higher education institutions. As mentioned in Chapter 2, it was found that Latinas'/os' perceived racial identity drove classmates, professors, and university personnel to see them as academically incompetent (Yosso et al., 2009). This study's participants endured the same types of aggressions that grew out of being viewed as academically incompetent and unworthy of higher education.

When these 18 were marginalized by the people around them, their academic achievement and success were significantly affected. The six participants who experienced racial profiling struggled to fit in during group work because they were 
thought to be academically unfit and at times were considered a threat based on their physical appearance. The two participants who experienced microaggressions from professors felt academically unacceptable, having experienced professors' low expectations and disapproval during class participation. Likewise, the ten engineering participants were perceived as the "racial Other," causing their academic abilities to be disputed by their classmates (Yosso et al., 2009, p. 667). In essence, these participants' ethnic identity was seen by others as excluding them from the possibility of academic achievement. Despite the participants' pride in their racial and ethnic identity, when they encountered these racial aggressions they contemplated whether or not they belonged within higher education. It is crucial to acknowledge, then, that racial profiling, microaggressions, and nonverbal indirect singling out by classmates generated academic achievement "doubt" for these 18 participants.

Academic achievement doubt. Interview data revealed that once participants encountered racial aggression their confidence in their identity as students diminished. They questioned whether or not they had what it takes to succeed academically and speculated about whether or not they belonged in college. In effect, aggression towards the participants caused them to believe that they were insignificant in their university environment (Yosso et al., 2009). As they came to feel unwelcome in their own learning spaces, their academic achievement doubt intensified. Essentially, enduring racial aggressions disturbed their processes of integrating into the higher education system. Moreover, academic achievement and enrollment doubt endangered these Latino males' higher education retention and graduation rates. Therefore, the cumulative effect of 
academic achievement doubt had the potential to steer these Latino males towards dropping out of college.

This study shows that the 18 participants were constantly looked at as intruders by classmates, professors, and school personnel, and, as targets of negative stereotypes (Steele, 1997), their academic identities deteriorated. The theory of domain identification states that in order for students to identify as academically successful they must be provided with "opportunities to prosper there, as well as [having the reassurance] that one belongs there, in the sense of being accepted and valued in the domain" (Steele, 1997, p. 613). Since these Latino males endured racial aggressions that derived from negative ethnic stereotypes, their ability to see their own potential to achieve academic success was severely damaged. What is more, as classmates' and professors' racial aggressions reminded these participants that they were viewed as academically unskilled, their capacity to associate themselves with academic success suffered. This put them in danger of internalizing what Steele (1997) refers to as stereotype threat, which he describes as

The event of a negative stereotype about a group to which one belongs becoming self-relevant, usually as a plausible interpretation for something one is doing, for an experience one is having, or for a situation one is in, that has relevance to one's self-definition. (p. 616)

The idea of stereotype threat indicates that aggressions against Latino male college students have the power to cause them to believe they are not qualified to continue pursuing higher education. Yet, these 18 participants were determined to become "someone in life" (Figueroa et al., 2016, p. 66) and so were able to mitigate the consequences of racial profiling, microaggressions, and nonverbal indirect singling out 
by focusing on academic achievement to justify their pursuit of higher education. It is significant that these participants had the potential to stop the stereotype threat through their own solid understanding of their racial and ethnic identity. As previously stated, all 22 participants in this study considered their racial and ethnic identity as a motivation to gain a college degree. Nevertheless, their well-being suffered as they underwent racial battle fatigue while balancing aggressions with striving to succeed in their education.

Participants' well-being. Participants reacted to racial profiling, microaggressions, and nonverbal indirect singling out by focusing on academic achievement as a strategy to validate to others their pursuit of higher education. As evidenced by the data in this study, participants held themselves accountable for proving that Latino males are equipped to succeed academically. To this end, participants prioritized academic achievement and counteracting the prejudice they experienced over their own well-being. Laser-focused on proving their academic worth, they were ever-mindful of how their actions and expressions would come across while they interacted with others. To illustrate, participants expressed the following to validate their higher education enrollment: (1) "Right away, I'm prepared to flip their thinking." (2) "I'm here to earn good grades." (3) "I want Latinos to be seen as smart people." (4) "I feel like a pressure to be right, I don't wanna to not fit in." (5) "I feel like I overstress about proving that I can do the work."

Principally, these interviewees spent high levels of energy on the following three major tasks: academic achievement, counteracting imposed identities, and monitoring their actions. Juggling these different tasks had an effect on their well-being. That is, as 
they managed these tasks, their ability to monitor their own well-being deteriorated to the point where they endured racial battle fatigue. Smith (2009) emphasizes this point when he says, "Due to constant preparation, coping, and defending against racial microaggressions, people of color are often physically and emotionally drained" (as cited in Franklin et al., 2014, p. 306). This study found that Latino male subjects endured the following psychological stress symptoms: anxiety, anger, frustration, and nervousness. In regard to behavioral stress, participants reported feeling confused, full of doubt, eating unhealthily, procrastinating, and having poor concentration. Physically, they reported feeling tiredness from sleep disturbance and at times struggling to think straight.

It is important to distinguish between racial battle fatigue and common "occupational or academic stress" (Franklin, 2016, p. 47). According to Smith (2004), racial battle fatigue is "a response to the distressing mental/emotional conditions that result from facing racism daily" (as cited in Franklin, 2016, p. 47). During our interviews, participants described the outcomes of enduring racial battle fatigue: "It's challenging to concentrate," "I get kind of nervous, anxious," "I lost interest," "It's hard to sleep," and "I'm just too tired and frustrated." Plainly, racial profiling, microaggressions and nonverbal indirect singling out majorly impacted these participants' health. Of course, these participants dealt with the typical stress that derives from being a college student on a daily basis. However, society's negative stereotypes towards Mexicans positioned them in such a way that they endured further stress while seeking to achieve a college degree, which led to deterioration of their psychological, behavioral, and physical strength. So racial battle fatigue, typical stress associated with higher education, and the 
energy required to counteract imposed identities were all factors that had the potential to impact and possibly end higher education enrollment for these Latino males. Based on participant data, this study concludes that the following circumstances impacted these Latino males' higher education experiences: “being treated with less respect, receiving poor service, being assumed to not be smart, people acting as if they are afraid of you, and people thinking you are dishonest because of your racial and/or ethnic background" (as cited in Franklin, 2016, p. 45).

Even more alarming is the fact that these participants understood the racial aggression they experienced during individual incidents. But they often kept these negative experiences to themselves while working towards their primary goal of a college degree. Basically, they felt exclusively and personally responsible for enduring and dealing with the outcomes of racial aggression since they were not aware that their experiences constituted racism. This lack of awareness of racism endangered their higher education attainment by negatively affecting their determination to thrive under such toxic circumstances. Obviously, these participants would have benefited from learning about racial profiling and microaggressions to help them cope with racial battle fatigue stressors.

In fact, the literature on racial battle fatigue and racial microaggressions highlights the importance of coping by providing students with opportunities to talk about their experiences (Franklin et al., 2016; Yosso et al., 2009). This study concludes that participants would have benefited from focus groups to talk about their encounters, responses, and personal outcomes. Focus groups would have provided them with space 
in which they could "build communities" to support one another (Yosso et al., 2009, p. 680). Latino organizations would likely be best suited to offer these types of focus groups.

\section{Ethnic Gender Identity, Academic Achievement, and Participants' Well-being}

Although racial and ethnic identities impact academic achievement and well-being, gender identities also play a key role in either attaining or failing to attain a college degree. Latino culture establishes certain ethnic gender masculinity principles that Latino males are expected to fulfill (Ojeda \& Piña-Watson, 2014; Sabogal et al., 1987; Stein et al., 2015). Those principles, which include fear of failure, help affirmation, and lack of success, all challenged these participants' academic identities (Lu \& Wong, 2014; Sáenz et al., 2013). Latino males are well aware that, in order to validate their masculinity, they need to operate by (1) demonstrating confidence, (2) functioning independently without help, and (3) being successful (Lu \& Wong, 2014; Sáenz et al., 2013). Higher education students, who are bound to face academic challenges, are encouraged to seek help, depend on support structures such as tutoring centers and professors' office hours, and come to understand that failure is part of the learning process. These common parts of the college experience conflict with Latino masculine ideals, causing them to struggle to balance their ethnic masculinity principles with the inevitable academic challenges they face. Accordingly, if Latino males depend on their ethnic masculinity principles when they face academic challenges, they are in danger of failing, which can interfere with their higher education retention and graduation goals.

Narrative data findings revealed that $18 \%$ of the study participants struggled to 
embrace their academic identities as they attempted to fulfill their Latino masculinity principles (4 of 22). Conversely, $82 \%$ opted to embrace their academic identities over their gender principles. As pointed out in Chapter 4, and as this study concludes, participants needed to reshape their ethnic masculinity principles in order to develop their academic identities. While none of the participants referred to shifting their ethnic masculinity principles as "reshaping," data showed that they did engage in reshaping their ethnic gender principles to allow them to succeed academically. The following section provides a discussion and conclusions about ethnic masculinity principles impacting academic achievement and participants' well-being.

\section{Ethnic Masculinity Principles Academic Achievement}

Even though all 22 participants recognized that their main goal was to achieve a higher education degree, $18 \%$ of them ( 4 of 22 ) strived to function by retaining their ethnic gender principles despite those principles conflicting with their academic identities. Although 18\% represents a small sample, the literature on ethnic gender principles maintains that Latino male college students experience constant fear of failure because they are expected to succeed and operate individually (Lu \& Wong, 2014; Sáenz et al., 2013). Furthermore, according to studies by Figueroa (2007) and Sáenz et al. (2013), the most difficult ethnic masculinity principle for Latino males to overcome is seeking help. Narrative data from this study supported those findings by revealing that seeking help was the most difficult ethnic masculinity principle for these subjects to face. Seeking help plays a key role in confronting academic challenges; therefore, this study 
determined that the ability to ask for assistance is pivotal in addressing ethnic masculinity principles and academic achievement.

It is crucial, then, to inform Latino males upfront that their ethnic masculinity principles will probably prevent them from seeking help. It is also imperative to build awareness about how seeking help can resolve academic challenges. Data revealed that the four participants who retained their ethnic gender principles avoided seeking help because doing so would acknowledge a lack of success and their own limitations, both of which contradict ethnic masculinity principles. The question must be asked, "Why did these four participants struggle with reshaping their ethnic masculinity principles?”

The conclusions from this study indicate that these four participants were culturally socialized to feel that they must operate independently, stay in control, and succeed. Three of them explained that they sometimes had to play the role of "man of the house" within their families. The fourth participant from this group said that his culture compelled him to prove his masculinity to others. All four admitted that they had a hard time seeking help since they were raised to be strong, to protect family members, and to solve any issues independently. These expectations transferred into their educational practices, and they reported achieving academic success in high school by operating individually. Once in higher education, their ethnic masculinity principles steered them toward figuring things out on their own, expecting success from themselves, and not needing or seeking help. This led them to try to overcome their academic challenges alone, opting to maintain their gender identities. At this juncture, these interviewees' academic struggles caused them to fear failure. Fear of failure leads Latino male college 
students to employ a "fight or flight response" (Sáenz et al., 2013, p. 90). These four participants opted to implement what Sáenz et al. (2013) call a "fight response" (p. 90).

This study determined that the fight response correlates to stage one of reshaping Latino masculinity principles. Under stage one, Latino males take on the challenge of overcoming academic struggles on their own, when they are still validating their ethnic masculinity principles by functioning independently without seeking help. The fight response guided these participants toward applying different individual methods to solve their academic challenges, e.g., reviewing class notes, using books, watching YouTube videos, and going online. None of these approaches, however, included seeking help from others or from institutions. In other words, these Latino males were fulfilling their ethnic masculinity principles, which satisfied their expectations for themselves. While attempting to navigate college alone, they experienced academic failure. Academic failures contradict the experience of being successful, which is one of the ethnic masculinity principles.

Not fulfilling such an ethnic principle resulted in academic, psychological, and behavioral stress among study participants. Academic stress corresponds to both misunderstanding class material and assignments and to struggling on exams. In terms of psychological stress, they reported experiencing anxiety, feeling nervous, and feeling worried. Regarding behavioral stress, they reported feeling frustrated and upset. When in this frame of mind, fear of failure causes Latino males to rethink whether to continue employing a "fight response" or to abort higher education by employing a "flight response” (Sáenz et al 2013, p. 90). 
The literature on ethnic masculinity principles posits that fear of failure is perceived as a male deficiency and that Latino male college students therefore tend to find other venues in which they can be more successful (Cerezo et al., 2013; Liang et al., 2011; Lu \& Wong, 2014; Sáenz et al., 2013). As explained in Chapter 2, when Latino males drop out of college they are likely to be more successful at fulfilling their gender identities ( $\mathrm{Lu}$ \& Wong, 2014; Sáenz et al., 2013). They can do so by entering the military, attending vocational schools (Cerezo et al., 2013), or, as these participants explained, "there are good paying jobs out there." What happens is that, as Latino males face academic distress and are unable to successfully fulfill their ethnic masculinity principles, they are prone to contemplate dropping out of college. Though, if they are determined to achieve a college degree, they will continue to engage in a fight response while rejecting a "flight response" (Sáenz et al., 2013, p. 90). With conviction, these Latino males in this study proceeded into stage two, where they negotiated their ethnic gender identities by reshaping their masculinity principles.

It is essential to disclose that the four participants under discussion have been determined to achieve a college degree since they started in higher education. This made them good candidates for reshaping their masculinity principles in order to prioritize their academic identities. Under stage two, Latino males' academic identities take precedence, as ethnic masculinity principles are reshaped through acceptance of possible failure, a feeling of powerlessness, and the need to depend on others. At this point in time, Latino males begin to access institutional resources such as professors' office hours and tutoring centers, in addition to help from classmates or other students within their major. 
Essentially, under stage two, Latino males understand that, as college students, they must reshape their ethnic masculinity principles if they are to achieve academic success. This realization shifts their focus to fulfilling their academic identities.

Along with academic achievement, the following factors facilitated our study participants' ethnic masculinity reshaping: (1) learning to function within higher education culture as students; (2) realizing that as males depending on others and not just oneself is acceptable; and (3) being exposed to other points of view. They reported experiences within higher education that facilitated reshaping their ethnic masculinity principles. For instance, they spoke about realizing that there are other ways of functioning as males that contradict how they were raised. They specifically stated that higher education experiences taught them to perceive both seeking help and sometimes failing as components that are nonthreatening to masculinity affirmation. In essence, they realized that functioning as students improved their academic achievement, and, at the same time, it kept their masculinity intact.

In contrast to these four participants, the remaining 18 (82\%) opted for reshaping their ethnic masculinity principles as soon as they arrived at college. These individuals possessed a solid understanding that higher education and academic achievement required seeking help, feeling lost, and struggling academically. They arrived already understanding that their ethnic masculinity principles had to be placed to the side, as their primary role within higher education was to function as students. A common trend among these 18 participants was that, feeling comfortable recognizing their limitations, they sought as much help as possible. 
Owning to the larger role academic identities play in achieving a college degree, these 22 participants were successful in reshaping their ethnic masculinity principles. Four tried to do so immediately and experienced additional academic, psychological, and physical stress. The other18, who engaged in accessing resources as soon as they faced academic challenges, encountered less stress. It is important to point out that the following factors guided those participants toward seeking help immediately: (1) opting to fulfill academic identities; (2) feeling comfortable admitting and disclosing academic limitations; (3) understanding that as college students they are subject to possible failures; and (4) understanding that their masculinity is not put into question when they seek help. It is clear that Latino male college students can benefit from learning how higher education requirements impact their ethnic masculinity principles instead of independently discovering that these principles endanger their academic achievement, which can, in turn, impede their retention and graduation goals.

\section{Recommendations for Further Research}

Latino males' gender and academic identities influence their personal experiences, academic achievement, and well-being. Specifically, their familism gender role expectations and ethnic masculinity principles play a key role in the pursuit of a college degree. When Latino males are determined to achieve a college degree, they are able to adjust their familism gender role expectations so they can fulfill their academic identities. A total of $90 \%$ (20 of 22) of participants placed their provider role on hold. Similarly, $64 \%$ (14 of 22) engaged in negotiating a detachment from being required to fulfill 
familism gender role expectations by their families to allow them to focus on academic responsibilities (as previously covered in Chapter 4 findings), while 36\% (8 of 22) were not required by their families to fulfill their gender role expectations. In regard to ethnic masculinity principles and academic identities, $82 \%$ (18 of 22 ) of the participants shifted their ethnic masculinity principles as soon as they struggled academically. Eventually the remaining 18\% (4 of 22) shifted their ethnic masculinity principles to ease academic achievement struggles. Adjusting familism gender role expectations and shifting ethnic masculinity principles positioned these Latino males to experience stress as they navigated this process on their own without any support. Once participants' stress levels were out of their control, a total of 45\% (10 of 22) opted to seek professional counseling sessions. These findings provide a baseline for other studies to answer specific questions that arose from this study, as well as questions that emerged after completion of this study. The findings suggest the following recommendations for further research:

1. Replicate the study with a larger sample size to further explore in depth Latino males' gender and academic identities.

2. Include participants from other disciplines.

3. Research the role of family context in regard to familism gender role expectations and ethnic masculinity principles.

4. Focus research on the following four questions: (a) Why do some Latino males feel comfortable placing their provider gender role on hold while attending higher education? (b) Why do some Latino males shift their ethnic masculinity principles--to access higher education academic support or to overcome academic challenges? (c) Why are some 
Latino males able to function independently from familism gender role expectations? (d) What happens to these identity adjustments and shifts two to four years down the line?

\section{Implications for Policy and Practice}

This study concludes that certain outcomes from Latino males' identities impact their academic identities and well-being. For example, racial profiling, microaggressions, and nonverbal indirect singling out from Latino males' racial and ethnic identities affect academic achievement and personal wellness. In addition, Latino males' ethnic masculinity principles have the potential to determine higher education degree attainment. If Latino males shift ethnic masculinity principles, they feel comfortable accessing higher education academic supports. Refusing to shift ethnic masculinity principles can lead into academic failure, as these males feel responsible for achieving success independently. Also, focusing on fulfilling familism gender role expectations and academic responsibilities obstructs degree completion. Both responsibilities are in conflict, since as one takes time away from the other it increases Latino males' psychological stress and decreases study time. Yet, negotiating a detachment period from fulfilling familism gender role expectations supports academic achievement and wellbeing because it gives Latino males the freedom to focus just on their academic identities. Consequently, in order to support Latino males' higher education degree completion goals, the administration, health center, admissions, faculty, and Latino organizations should provide specific workshops and campus changes. Another major factor is providing food or snacks, which would improve attendance at workshops, orientations, and group counseling sessions. 


\section{Administration}

1. Should provide workshops for faculty, staff, and students about microaggressions so as to improve the campus environment. Data from this study revealed that $82 \%$ of the participants experienced racial aggressions by classmates, professors, and university personnel.

2. Should provide workshops for Latino students to learn about factors that trigger academic doubt and offer resources to overcome such factors. The racial insults experienced by our study participants triggered academic doubt, leaving $82 \%$ of the participants to question their enrollment and participation in higher education. Academic doubt has the potential to cause Latino males to abandon higher education.

\section{Health center}

3. Counseling centers should advertise the benefits of counseling, keeping in mind and trying to reframe different ethnic groups' negative associations with counseling. Data from this study revealed that only $45 \%$ of participants (10 of 22 ) utilized formal counseling, even when experiencing major psychological, behavioral, and physical stress.

4. In order to be ready to support students that experience racial aggressions, counselors need to learn about how racial profiling, microaggressions, and racial battle fatigue interfere with students' well-being.

5. College counseling services must learn about how Latino culture and gender expectations impact Latino males' higher education experiences. For counselors to help Latino males cope with psychological, behavioral, and physical stress, they need to be aware that familism expectations and ethnic masculinity principles are in conflict with 
Latino males' academic identities.

6. For Latino students to perceive formal counseling as part of the campus culture and college experience, the health centers must deliver whole group counseling sessions or workshops once a month at Latino organizations, clubs, fraternities, or other areas frequently visited by Latinos. Equally important, counseling must cover culturally relevant topics to enable Latinos to be more open to accessing these services.

\section{Admissions}

7. Orientation staff should provide an orientation for Latino males with information on how ethnic masculinity principles can prevent them from accessing available academic supports. Latino males must be aware that academic challenges may necessitate their seeking help, which contradicts ethnic masculinity principles. During the orientation, students should be informed about different resources that are available to overcome academic challenges. It would be helpful to have current Latino male college students talk about their experiences with seeking help.

\section{Faculty}

8. To understand how to better support Latino males, faculty must learn about how central that Latino culture and gender role expectations are to Latino students' higher education experiences. It is crucial for faculty to understand that Latino males struggle with deciding to seek help and that it is incumbent upon faculty to make themselves available to them whenever they attempt to seek help. Otherwise, Latino males might not risk asking for help again. 


\section{Latino organizations}

9. Latino organizations should provide informative workshops for Latino students to learn about stereotypes, racial profiling, and microaggressions and help them understand that they make noteworthy contributions on campus. Such workshops would help Latino students to counteract perceiving themselves as the "racial Other" (Yosso et al., 2009, p. 667). They would benefit from understanding that they are just as entitled to participate in higher education as their classmates, negating their feelings of pressure to validate their enrollment and participation. These informative workshops should take place every other month to provide Latino males with a specific setting, one that facilitates students' sharing their experiences by having some kind of privacy and an inviting environment, like seating around a circle.

10. Latino organizations should provide workshops for incoming Latino students and their parents to help them understand how higher education requirements impact Latino males' familism gender role expectations and masculinity principles. Latino families would benefit from learning how Latino males must adjust familism gender role expectations if they are to be able to focus on academic achievement. This type of intervention would help Latino males and their families have a more positive detachment period. Too, these families and students would benefit from learning how Latino males must shift their ethnic masculinity principles to focus on their academic identities. The results would be that parents and students alike would be more prepared to shift family roles and gender responsibilities.

11. Latino organizations should identify first-generation Latino college students so they 
can provide interventions for students and parents, building awareness that achieving a college degree takes time and focusing on helping parents understand that pressure to achieve a college degree to meet their families' expectations has a bearing on students' psychological, physical, and behavioral stress. This type of intervention should occur whenever Latino males experience these types of stressors. Thus, Latino organizations must implement a system, possibly a monthly survey, to figure out who needs this type of intervention and must have designated personnel to deliver this intervention.

\section{Conclusion}

Findings from this study indicated that participants' racial and ethnic, gender, and academic identities play dual roles within academic achievement. Data revealed that the aforementioned identities both support and challenge Latino males' academic achievement. Figure 2 (below) provides a visual conceptual model overview of the research findings. Specific factors from participants' identities served as a support system that reinforced their academic achievement. Concurrently, specific outcomes and factors from participants' identities generated challenges that they had to address so they could sustain academic achievement. 


\begin{tabular}{|c|c|c|c|}
\hline & $\begin{array}{l}\text { Racial and Ethnic } \\
\text { Identity }\end{array}$ & Gender Identity & Academic Identity \\
\hline $\begin{array}{l}\text { Challenges } \\
\text { Impacting } \\
\text { Academic } \\
\text { Achievement }\end{array}$ & $\begin{array}{l}\text { A. Racial Profiling } \\
\text { B. Nonverbal Indirect } \\
\text { Singling Out by } \\
\text { Classmates } \\
\text { C. Stereotypes }\end{array}$ & $\begin{array}{l}\text { A. Ethnic Masculinity } \\
\text { Principles: fear of } \\
\text { failure, needing help, } \\
\text { and lack of success (Lu } \\
\text { \& Wong, 2014; Sáenz } \\
\text { et al., 2013) } \\
\text { B. Fulfilling Familism } \\
\text { Gender Role } \\
\text { Expectations: } \\
\text { functioning as a } \\
\text { collective unit, familial } \\
\text { obligations, and } \\
\text { perceived support from } \\
\text { family (Fuligni et al., } \\
\text { 1999; Sabogal et al., } \\
\text { 1987) }\end{array}$ & $\begin{array}{l}\text { A. First-Generation } \\
\text { Status Pressure to } \\
\text { Achieve a College } \\
\text { Degree to Meet } \\
\text { Families' } \\
\text { Expectations }\end{array}$ \\
\hline $\begin{array}{l}\text { Strategies } \\
\text { Supporting } \\
\text { Academic } \\
\text { Achievement }\end{array}$ & $\begin{array}{l}\text { A. Having a Solid Racial } \\
\text { and Ethnic Identity } \\
\text { B. Motivation to } \\
\text { Achieve a College } \\
\text { Degree } \\
\text { C. Representing Latino } \\
\text { Males as Successful } \\
\text { College Students }\end{array}$ & $\begin{array}{l}\text { A. Reshaping Ethnic } \\
\text { Masculinity Principles } \\
\text { B. Negotiating a } \\
\text { Detachment Period } \\
\text { from Fulfilling } \\
\text { Familism Gender Role } \\
\text { Expectations } \\
\text { C. Placing Gender Role } \\
\text { on Hold } \\
\text { D. Identifying as un } \\
\text { hombre de familia (a } \\
\text { family man) }\end{array}$ & $\begin{array}{l}\text { A. Prioritizing } \\
\text { Academic } \\
\text { Achievement }\end{array}$ \\
\hline Stress & \multicolumn{3}{|c|}{ Psychological, Physical, and Behavioral } \\
\hline $\begin{array}{l}\text { Coping } \\
\text { Mechanisms }\end{array}$ & \multicolumn{3}{|c|}{$\begin{array}{l}\text { First Choice: informal applying familism values } \\
\text { Formal Counseling Sessions: when unable to help own self }\end{array}$} \\
\hline
\end{tabular}

Figure 2. Latino male college students' findings conceptual model.

It should be emphasized that 18 participants were first-generation college students, two had an older sibling that graduated from a four-year university, and two had a parent who 
graduated from college in México. The following section addresses how these participants' identity factors supported academic achievement.

Data revealed that having a solid racial and ethnic identity supports academic achievement. These 22 participants felt proud of their racial and ethnic identity, which, in turn, prompted them to achieve academic success. They reported feeling accountable for earning good grades since they understood that they were representing Latino males in higher education. Along the same lines, participants' racial and ethnic identity served as a motivation to achieve a college degree. Participants reported a desire to demonstrate that Latinos have the potential to achieve academic success. More importantly, the 22 study participants were motivated to achieve academic success so that Latino males' graduation numbers would increase.

With regard to their gender identities, familism values guided 21 out of 22 participants to identify as un hombre de familia (a family man). Identifying as un hombre de familia entitled them to embrace academic achievement, because, as interview data indicated, they categorized un hombre de familia as a person who is educated and holds a college degree. Therefore, their identity as un hombre de familia helped them to focus on achieving academic success. These participants explained that, as Latino males, they wanted to portray Latino males as having the capacity to work with their brains. Being un hombre de familia encouraged them to achieve academic success.

Similarly, these participants' gender identities within familism values allowed them to put their provider gender role on hold. By seeing themselves as future providers, they were able to continue focusing on academic achievement instead of attempting to fulfill 
immediate financial responsibilities within their families. Undoubtedly, gender identity played a crucial role within their academic identities, which required these males to reshape their ethnic masculinity principles to allow them to address their academic challenges. Reshaping ethnic masculinity principles empowered them to access support to improve academic performance.

Negotiating a detachment from fulfilling familism values' gender role expectations while attending higher education permitted these participants to function independently. This allowed them to focus on fulfilling their academic responsibilities. The factors from their racial and ethnic, gender, and academic identities outlined above support academic achievement. And so it is important to address how certain outcomes and factors from participants' identities challenge academic achievement.

Professors, classmates, school personnel, and the student body negatively stereotype Latino males' racial and ethnic identities. Enduring racial profiling, microaggressions, and nonverbal indirect singling out by classmates, as well as living with imposed stereotypes, challenge Latino males' ability to achieve academically. When these participants experienced hostile learning environments and focused on counteracting racial aggressions, they underwent racial battle fatigue. Such racial battle fatigue negatively influenced their academic achievement due to the psychological, physical, and behavioral stress they suffered.

With regard to gender, masculinity principles, including fear of failure, needing help, and lack of success, challenge Latino males' academic identities (Lu \& Wong, 2014; Sáenz et al., 2013). These principles encourage them to think that they are solely 
responsible for their own success. Indeed, Latino males are socialized to believe that they, as Latino males, should display confidence, function independently without help, and attain success (Lu \& Wong, 2014; Sáenz et al., 2013). These principles prevent them from accessing academic resources to overcome academic challenges because they feel uncomfortable seeking help or being seen as failing.

In like manner, familism values such as functioning as a collective unit, fulfilling "familial obligations," and "perceived support from the family," (Fuligni et al., 1999; Sabogal et al., 1987, p. 397) all challenge academic achievement. As Latino males divide their time and energies between academic responsibilities and familism responsibilities, their academic achievement and well-being are inhibited. Findings illustrate that Latino males' academic identities, including first-generation status, challenge their well-being. When they are pressured to graduate from college to meet their families' expectations, psychological, physical, and behavioral stress are common. Such stressors challenge their academic achievement, since they ignore basic health necessities such as sleeping, eating, and relaxing. "While academics are at the main interest for higher education institutions, the health consequences for attending these institutions for Latina/o students should also be as great of an interest" (Franklin et al., 2014, p. 317). These participants' identities offer a significant perspective for higher education institutions to take a proactive role in responding to students' specific needs that impact their academics and well-being. 


\section{References}

Aguirre, F. P. (2005). Mendez v. westminster school district: How it affected brown v. board of education. Journal of Hispanic Higher Education, 4(4), 321-332. doi:10.1177/1538192705279406

Akers, R. L., Krohn, M. D., Lanza-Kaduce, L., \& Radosevich, M. (1979). Social learning and deviant behavior: A specific test of a general theory. American Sociological Review, 44(4), 636-655.

Aranda, M. P., Castaneda, I., Lee, P. J., \& Sobel, E. (2001). Stress, social support, and coping as predictors of depressive symptoms: Gender differences among Mexican Americans. Social Work Research, 25(1), 37-48. doi:10.1093/swr/25.1.37

Arciniega, G. M., Anderson, T. C., Tovar-Blank, Z., \& Terence, J. G. T. (2008). Toward a fuller conception of machismo: Development of a traditional machismo and caballerismo scale. Journal of Counseling Psychology, 55(1), 19-33. doi:10.1037/0022-0167.55.1.19

Aronson, J. (2004). The threat of stereotype. Educational Leadership, 62, 14-19.

Bem, S. L. (1981). Gender schema theory: A cognitive account of sex typing. Psychological Review, 88(4), 354-364.

Borrell, L. N. (2005). Racial identity among Hispanics: Implications for health and wellbeing. American Journal of Public Health, 95(3), 379-381. doi:10.2105/AJPH.2004.058172

Cammarota, J. (2004). The gendered and racialized pathways of Latina and Latino youth: Different struggles, different resistances in the urban context. Anthropology \& Education Quarterly, 35(1), 53-74.

Carroll Massey, G., Vaughn Scott, M., \& Dornbusch, S. M. (1975). Racism without racists: Institutional racism in urban schools. The Black Scholar, 7(3), 10-19.

Castellanos, J., \& Gloria, A. M. (2007). Research considerations and theoretical application for best practices in higher education: Latina/os achieving success. Journal of Hispanic Higher Education, 6(4), 378-396. doi:10.1177/11538192707305347

Castillo, L. G., Cano, M. A., Chen, S. W., Blucker, R. T., \& Olds, T. S. (2008). Family conflict and intragroup marginalization as predictors of acculturative stress in Latino college students. International Journal of Stress Management, 15(1), 4352. doi:10.1037/1072-5245.15.1.43 
Cerezo, A., Lyda, J., Beristianos, M., Enriquez, A., \& Connor, M. (2013). Latino men in college: Giving voice to their struggles and triumphs. Psychology of Men \& Masculinity, 14(4), 352-362. doi:10.1037/a0029646

Chapa, J., \& De La Rosa, B. (2004). Latino population growth, socioeconomic and demographic characteristics, and implications for educational attainment. Education and Urban Society, 36(2), 130-149. doi:10.1177/0013124503261320

Chiang, L., Hunter, C. D., \& Yeh, C. J. (2004). Coping attitudes, sources, and practices among Black and Latino college students. Adolescence, 39(156), 793-815.

Clandinin, D. J., \& Connelly, F. M. (2000). Narrative inquiry: Experience and story in qualitative research. San Francisco, CA: Jossey-Bass Publishers.

Connelly, F. M., \& Clandinin, D. J. (1990). Stories of experience and narrative inquiry. Educational Researcher, 19(5), 2-14.

Contreras, A. R., \& Valverde, L. A. (1994). The impact of Brown on the education of Latinos. The Journal of Negro Education, 63(3), 470-481.

Creswell, J. W. (2013). Qualitative inquiry and research design: Choosing among five approaches. Thousand Oaks, CA: Sage.

DiCicco-Bloom, B., \& Crabtree, B. F. (2006). The qualitative research interview. Medical Education, 40(4), 314-321. doi:10.1111/j.1365-2929.2006.02418.x

Entman, R. M. (2006). Young men of color in the media: Images and impacts. Washington, DC: Joint Center for Political and Economic Studies Health Policy Institute. Retrieved from http://jointcenter.org/docs/pdfs/YMOC\%20and\%20the\%20Media.pdf

Ethier, K. A., \& Deaux, K. (1994). Negotiating social identity when contexts change: Maintaining identification and responding to threat. Journal of Personality and Social Psychology, 67(2), 243-251.

Excelencia in Education \& ACT. (2015). The conditions of college and career readiness 2014: Hispanic students. Washington, DC: Excelencia in Education. Retrieved from http://www.edexcelencia.org/research/college-career-readiness-2014

Fergus, E. (2016). “Because I'm light skin... they think I'm Italian” Mexican students' experiences of racialization in predominantly White schools. Urban Education, 52(4), 460-490. doi:10.1177/0042085916666931 
Fergus, E., Noguera, P., \& Martin, M. (2014). Schooling for resilience: Improving the life trajectory of Black and Latino boys. Cambridge, MA: Harvard Education Publishing Group.

Figueroa, J. L. (2007). Building knowledge: Exploring the Chicano/Latino undergraduate narratives of academic success in higher education. Retrieved from California State University, Sacramento, Serna Center website: http://www.csus.edu/sernacenter/research/figueroa.htm.

Figueroa, J. L., Pérez, P. A., \& Vega, I. I. (2016). (Re)constructing masculinity understanding gender expectations among Latino male college-going students. In V. B. Sáenz, L. Ponjuan, \& J. L. Figueroa (Eds.), Ensuring the success of Latino males in higher education: A national imperative (pp. 60-74). Sterling, VA: Stylus Publishing.

Franklin, J. (2016). Racial microaggressions, racial battle fatigue, and racism-related stress in higher education. Journal of Student Affairs, 7(12), 44-55.

Franklin, J. D., Smith, W. A., \& Hung, M. (2014). Racial battle fatigue for Latina/o students a quantitative perspective. Journal of Hispanic Higher Education, 13(4), 303-322.

Fry, R., \& Gonzales, F. (2008). One-in-five and growing fast: A profile of Hispanic public school students. Washington, DC: Pew Hispanic Center. Retrieved from https://files.eric.ed.gov/fulltext/ED502556.pdf

Fry, R., \& Taylor, P. (2013). Hispanic high school graduates pass Whites in rate of college enrollment. Washington, DC: Pew Hispanic Center. Retrieved from http://www.pewhispanic.org/2013/05/09/hispanic-high-school-graduates-passwhites-in-rate-of-college-enrollment/

Fuligni, A. J., Tseng, V., \& Lam, M. (1999). Attitudes toward family obligations among American adolescents with Asian, Latin American, and European backgrounds. Child Development, 70(4), 1030-1044.

Galanti, G. A. (2003). The Hispanic family and male-female relationships: An overview. Journal of Transcultural Nursing, 14(3), 180-185.

Garcia-Preto, N. (1996). Latino families: An overview. In M. McGoldrick, J. Giordano, \& J. K. Pearce (Eds.), Ethnicity \& family therapy (pp. 141-154). New York: Guilford. 
Germán, M., Gonzales, N. A., \& Dumka, L. (2009). Familism values as a protective factor for Mexican-origin adolescents exposed to deviant peers. The Journal of Early Adolescence, 29(1), 16-42.

Ginorio, A., \& Huston, M. (2001). Si,se puede! Yes, we can: Latinas in school. Washington, DC: American Association of University Women Educational Foundation. Retrieved from https://files.eric.ed.gov/fulltext/ED452330.pdf

Gloria, A. M., Castellanos, J., Scull, N. C., \& Villegas, F. J. (2009). Psychological coping and well-being of male Latino undergraduates: Sobreviviendo la universidad. Hispanic Journal of Behavioral Sciences, 31(3), 317-339. doi:10.1177/0739986309336845

Gonzalez, J. C. (2007). The ordinary-ness of institutional racism: The effect of history and law in the segregation and integration of Latinas/os in schools. American Educational History Journal, 34(2), 331-345.

Hernandez, J. C., \& Lopez, M. A. (2004). Leaking pipeline: Issues impacting Latino/a college student retention. Journal of College Student Retention: Research, Theory \& Practice, 6(1), 37-60.

Huber, L. P., Huidor, O., Malagón, M. C., Sánchez, G., \& Solórzano, D. G. (2006). Falling through the cracks: Critical transitions in the Latina/o educational pipeline. (2006 Latina/o education summit report. CSRC research report. number 7). Retrieved from UCLA, Chicano Studies Research Center: http://libaccess.sjlibrary.org/login?url=http://search.ebscohost.com/login.aspx?dir ect $=$ true $\& \mathrm{db}=$ eric $\& A N=E D 493397 \&$ site $=$ ehost-live\&scope $=$ site

Hurtado, A., \& Sinha, M. (2008). More than men: Latino feminist masculinities and intersectionality. Sex Roles, 59(5-6), 337-349. doi: 10.1007/s11199-008-9405-7

Jacob, S. A., \& Furgerson, S. P. (2012). Writing interview protocols and conducting interviews: Tips for students new to the field of qualitative research. The Qualitative Report, 17(42), 1-10.

Kiang, L., Yip, T., Gonzales-Backen, M., Witkow, M., \& Fuligni, A. J. (2006). Ethnic identity and the daily psychological well-being of adolescents from Mexican and Chinese backgrounds. Child Development, 77(5), 1338-1350. doi:10.1111/j.1467-8624.2006.00938.x

Krogstad, J. M. (2016, July 28). 5 facts about Latinos and education. Retrieved from Pew Research Center: http://www.pewresearch.org/fact-tank/2016/07/28/5-factsabout-latinos-and-education/ 
Lazarus, R. S., \& Folkman, S. (1984). Coping and adaptation. In W.D. Gentry (Ed.), The handbook of behavioral medicine (pp. 282-325). New York: Guilford.

Lee J. M., \& Ransom, T. (2011). The educational experience of young men of color: A review of research, pathways and progress. New York: The College Board Advocacy and Policy Center. Retrieved from Lumina Foundation: https://www.luminafoundation.org/files/resources/educational-experienceymc.pdf

Liang, C. T. H., Salcedo, J., \& Miller, H. A. (2011). Perceived racism, masculinity ideologies, and gender role conflict among latino men. Psychology of Men \& Masculinity, 12(3), 201-215. doi:10.1037/a0020479

Lopez, J. D. (2005). Race-related stress and sociocultural orientation among Latino students during their transition into a predominately White, highly selective institution. Journal of Hispanic Higher Education, 4(4), 354-365. doi:10.1177/1538192705279594

López, N. (2002). Rewriting race and gender high school lessons: Second-generation Dominicans in New York City. Teachers College Record, 104(6), 1187-1203.

Lu, A., \& Wong, Y. J. (2014). Stressful experiences of masculinity among young USborn and immigrant Latino American men. Culture, Society and Masculinities, $6(2), 111-128$.

MacDonald, V. M. (2013). Demanding their rights: The Latino struggle for educational access and equity. American Latinos and the making of the United States: A theme study. Washington, DC: National Park Service. Retrieved from https://www.nps.gov/heritageinitiatives/latino/latinothemestudy/education.htm

Mahalik, J. R., Locke, B. D., Theodore, H., Cournoyer, R. J., \& Lloyd, B. F. (2001). A cross-national and cross-sectional comparison of men's gender role conflict and its relationship to social intimacy and self-esteem. Sex Roles, 45(1-2), 1-14. doi:10.1023/A:1013008800019

Mirandé, A. (1997). Hombres y machos: Masculinity and Latino culture. Boulder, CO: Westview Press.

Mishler, E. (1990). Validation in inquiry-guided research: The role of exemplars in narrative studies. Harvard Educational Review, 60(4), 415-443. doi:10.17763/haer.60.4.n4405243p6635752 
Muñoz, L. K. (2001). Separate but equal? A case study of Romo v. Laird and Mexican American education. Organization of American Historians Magazine of History, 15(2), 28-35.

Niemann, Y. F. (2001). Stereotypes about Chicanas and Chicanos: Implications for counseling. The Counseling Psychologist, 29(1), 55-90. doi:10.1177/0011000001291003

Ojeda, L., \& Piña-Watson, B. (2014). Caballerismo may protect against the role of machismo on Mexican day laborers' self-esteem. Psychology of Men \& Masculinity, 15(3), 288-295. doi:10.1037/a0033450

Omi, M., \& Winant, H. (1994). Racial formation in the United States: From the 1960s to the 1990s (2nd ed.). New York: Routledge.

Orfield, G., Losen, D., Wald, J., \& Swanson, C. B. (2004). Losing our future: How minority youth are being left behind by the graduation rate crisis. Cambridge, MA: Harvard University, Civil Rights Project. Retrieved June 5, 2017, from Escholarship: https://escholarship.org/content/qt4x44w1qh/qt4x44w1qh.pdf

Palinkas, L. A., Horwitz, S. M., Green, C. A., Wisdom, J. P., Duan, N., \& Hoagwood, K. (2015). Purposeful sampling for qualitative data collection and analysis in mixed method implementation research. Administration and Policy in Mental Health and Mental Health Services Research, 42(5), 533-544.

Palmer, R. T., \& Maramba, D. C. (2015). Racial microaggressions among Asian American and Latino/a students at a historically Black university. Journal of College Student Development, 56(7), 705-722.

Patton, M. Q. (2002). Two decades of developments in qualitative inquiry a personal, experiential perspective. Qualitative Social Work, 1(3), 261-283.

Peña-Talamantes, A. E. (2013). "Defining machismo, no es siempre lo mismo": Latino sexual minorities' macho flexible identities in higher education. Culture, Society and Masculinities, 5(2), 166-178. doi:10.3149/CSM.0502.166

Pérez Huber, L., Malagón, M. C., Ramirez, B., Camargo, L., Jimenez, A., \& Vélez, V. (2015). Still falling through the cracks: Revisiting the Latina/o educational pipeline. (2015 Latina/o education summit report. CSRC research report. number 19). Retrieved from UCLA, Chicano Studies Research Center: http://www.chicano.ucla.edu/files/RR19.pdf 
Perle, J., \& Waguespack, A. (2011). Gender schema theory. In S. Goldstein \& J. Naglieri (Eds.), Encyclopedia of child behavioral and development (pp. 690-691). NY: Springer.

Phinney, J. S. (1992). The multigroup ethnic identity measure: A new scale for use with diverse groups. Journal of Adolescent Research, 7(2), 156-176.

Phinney, J. S. (1996). When we talk about American ethnic groups, what do we mean? American Psychologist, 51(9), 918-927.

Phinney, J. S., \& Ong, A. D. (2007). Conceptualization and measurement of ethnic identity: Current status and future directions. Journal of Counseling Psychology, 54(3), 271-281. doi:10.1037/0022-067.54.3.271

Pino, N. W., Martinez-Ramos, G. P., \& Smith, W. L. (2012). Latinos, the academic ethic, and the transition to college. Journal of Latinos and Education, 11(1), 17-31.

Piña-Watson, B., Lorenzo-Blanco, E. I., Dornhecker, M., Martinez, A. J., \& Nagoshi, J. L. (2016). Moving away from a cultural deficit to a holistic perspective: Traditional gender role values, academic attitudes, and educational goals for Mexican descent adolescents. Journal of Counseling Psychology, 63(3), 307-318.

Pizarro, M. (2005). Chicanas and Chicanos in school: Racial profiling, identity battles and empowerment. Austin, TX: University of Texas Press.

Pizarro, M., \& Vera, E. M. (2001). Chicana/o ethnic identity research: Lessons for researchers and counselors. The Counseling Psychologist, 29(1), 91-117.

Quintana, S. M. (2007). Racial and ethnic identity: Developmental perspectives and research. Journal of Counseling Psychology, 54(3), 259-270. doi:10.1037/0022-0167.54.3.259

Raffaelli, M., \& Ontai, L. L. (2004). Gender socialization in Latino/a families: Results from two retrospective studies. Sex Roles, 50(5-6), 287-299.

Riessman, C. K. (2008). Narrative methods for the human sciences. Thousand Oaks, CA: Sage.

Rodriguez, C. E. (2000). Changing race: Latinos, the census, and the history of ethnicity in the United States. New York: NYU Press.

Rosenstock, I. M., Strecher, V. J., \& Becker, M. H. (1988). Social learning theory and the health belief model. Health Education Quarterly, 15(2), 175-183. 
Ross, J. (2016, October 20). From Mexican rapists to bad hombres, the Trump campaign in two moments. The Washington Post. Retrieved on May 5, 2017 from https://www.washingtonpost.com/news/the-fix/wp/2016/10/20/from-mexicanrapists-to-bad-hombres-the-trump-campaign-in-two moments/?utm_term $=.6772 \mathrm{a} 4 \mathrm{f} 3 \mathrm{da} 78$

Sabogal, F., Marín, G., Otero-Sabogal, R., Marín, B. V., \& Perez-Stable, E. J. (1987). Hispanic familism and acculturation: What changes and what doesn't? Hispanic Journal of Behavioral Sciences, 9(4), 397-412.

Sáenz, V. B., Bukoski, B. E., Lu, C., \& Rodriguez, S. (2013). Latino males in Texas community colleges: A phenomenological study of masculinity constructs and their effect on college experiences. Journal of African American Males in Education, 4(2), 82-102.

Sáenz, V. B., \& Ponjuan, L. (2009). The vanishing Latino male in higher education. Journal of Hispanic Higher Education, 8(1), 54-89. doi:10.1177/1538192708326995

Sáenz, V. B., \& Ponjuan, L. (2011). Men of color: Ensuring the academic success for Latino males in higher education. Washington, DC: Institute for Higher Education Policy.

Sáenz, V. B., Ponjuan, L., \& Figueroa, J. L. (2016). Current trends and future outlooks on the pervasive gender gap in educational attainment for Latino males. In V. B. Sáenz, L. Ponjuan, \& J. L. Figueroa (Eds.), Ensuring the success of Latino males in higher education: A national imperative (pp. 3-20). Sterling, VA: Stylus Publishing

Saez, P. A., Casado, A., \& Wade, J. C. (2010). Factors influencing masculinity ideology among Latino men. Journal of Men's Studies, 17(2), 116-128.

Sandelowski, M. (2000). Focus on research methods-whatever happened to qualitative description? Research in Nursing and Health, 23(4), 334-340.

San Miguel, G. Jr. (2005). The impact of Brown on Mexican American desegregation litigation, 1950s to 1980s. Journal of Latinos \& Education, 4(4), 221-236. doi:10.1207/s1532771xjle0404_2

Santos, S. J., Ortiz, A. M., Morales, A., \& Rosales, M. (2007). The relationship between campus diversity, students' ethnic identity and college adjustment: A qualitative study. Cultural Diversity and Ethnic Minority Psychology, 13(2), 104-114. doi:10.1037/1099-9809.13.2.104 
Schmader, T., \& Johns, M. (2003). Converging evidence that stereotype threat reduces working memory capacity. Journal of Personality and Social Psychology, 85(3), 440-452. doi: 10.1037/0022-3514.85.3.440

Seaton, E. K., Scottham, K. M., \& Sellers, R. M. (2006). The status model of racial identity development in African American adolescents: Evidence of structure, trajectories, and well-being. Child Development, 77(5), 1416-1426.

doi:10.1111/j.1467-8624.2006.00944.x

Smith, T. W. (1990). Ethnic images. (GSS topical report 19) Chicago, IL: The University of Chicago Press. Retrieved from http://citeseerx.ist.psu.edu/viewdoc/download? doi $=10.1 .1 .489 .3398 \&$ rep $=$ rep1\&type $=$ pdf

Smith, W. A., Allen, W. R., \& Danley, L. L. (2007). "Assume the position... you fit the description": Psychosocial experiences and racial battle fatigue among African American male college students. American Behavioral Scientist, 51(4), 551578.

Steele, C. M. (1997). A threat in the air: How stereotypes shape intellectual identity and performance. American Psychologist, 52(6), 613-629.

Stein, G. L., Gonzalez, L. M., Cupito, A. M., Kiang, L., \& Supple, A. J. (2015). The protective role of familism in the lives of Latino adolescents. Journal of Family Issues, 36(10), 1255-1273. doi:10.1177/0192513X13502480

Suárez-Orozco, C., \& Qin, D. B. (2006). Gendered perspectives in psychology: Immigrant origin youth. International Migration Review, 40(1), 165-198. doi:10.1111/j.1747-7379.2006.00007.x

Sue, D. W., Capodilupo, C. M., Torino, G. C., Bucceri, J. M., Holder, A., Nadal, K. L., \& Esquilin, M. (2007). Racial microaggressions in everyday life: implications for clinical practice. American Psychologist, 62(4), 271-286.

Syed, M., Azmitia, M., \& Phinney, J. S. (2007). Stability and change in ethnic identity among Latino emerging adults in two contexts. Identity: An International Journal of Theory and Research, 7(2), 155-178. doi:10.1080/15283480701326117

Tafoya, S. (2007). Shades of belonging: Latinos and racial identity. In P. S. Rothenberg (Ed.), Race, class, and gender in the United States and integrated study, $7^{\text {th }}$ edition (pp. 218-221). NY: Worth Publisher. 
Torres, J. B., Solberg, V. S. H., \& Carlstrom, A. H. (2002). The myth of sameness among Latino men and their machismo. American Journal of Orthopsychiatry, 72(2), 163-181. doi:10.1037//0002-9432.72.2.163

Torres, V. (2003). Influences on ethnic identity development of Latino college students in the first two years of college. Journal of College Student Development, 44(4), 532-547.

Wester, S. R. (2008). Male gender role conflict and multiculturalism: Implications for counseling psychology. The Counseling Psychologist, 36(2), 294-324. doi: $10.1177 / 0011000006286341$

Winant, H. (2000). Race and race theory. Annual Review of Sociology, 26(1), 169-185.

Yip, T., Seaton, E. K., \& Sellers, R. M. (2006). African American racial identity across the lifespan: Identity status, identity content, and depressive symptoms. Child Development, 77(5), 1504-1517. doi:10.1111/j.1467-8624.2006.00950.x

Yosso, T. J. (2005). Whose culture has capital? A critical race theory discussion of community cultural wealth. Race Ethnicity and Education, 8(1), 69-91.

Yosso, T. J., Smith, W. A., Ceja, M., \& Solórzano, D. G. (2009). Critical race theory, racial microaggressions, and campus racial climate for Latina/o undergraduates. Harvard Educational Review, 79(4), 659-691.

Zalaquett, C. P. (2005). Principals' perceptions of elementary school counselors' role and functions. Professional School Counseling, 8(5), 451-457. 


\section{Appendices}

\section{Appendix A: Potential Participant Questionnaire}

Looking for Latino Male Participants to Participate in my Dissertation Study. If you answer yes to the following questions, you qualify to be a participant:

1. Do you identify as a Male? Yes No

2. Do you identify as a Latino? Yes $\mathrm{No}$

3. Are you an engineering major or social science major? Yes No

4. Have you been a college student at this institution for one or more years? Yes No

The purpose of this study is to investigate how Latino male college students understand their racial and ethnic identity, gender identity, and academic identity. In addition, this study will investigate how Latino male college students' various identities impact their psychological stress and the coping mechanisms these students employ to mange their psychological stress. As a participant, you will be answering a demographic survey profile online, administered via Google Forms and participating in an individual interview, which will be audio-recorded and transcribed by a third party. If interested in participating, please email Ana Ramírez at ana.ramirez@sjsu.edu

See http://goo.gl/forms/3VavJIb990MWrsk12 
Appendix B: Demographic Survey Profile Consent Form

\section{Request for your Participation in Research Latino Male College Students' Identities}

Ana Ramírez, Graduate Student, Megan Thiele, \& Marcos Pizarro, Faculty Advisors

\section{PURPOSE}

You are being asked to participate in a qualitative research study examining how Latino male college students understand their racial and ethnic identity, gender identity, and academic identity. Further, it will investigate how Latino male college students' various identities impact their psychological stress and the coping mechanisms these students employ to manage their various identities' psychological stress.

\section{PROCEDURES}

The survey is available online at https://goo.gl/forms/UtAlfg86SNMpwI9k1. In this voluntary demographic survey profile (online, administered via Google Forms), you will be asked about your country of birth, parents' ethnicity, school major, current year in college, and your generation as a Latino male, in addition to other background questions. The survey will take less than one hour to complete. At the end of the survey, you will be asked if you are willing to participate in a one-on-one interview to discuss your individual experiences as a Latino male college student. Please read through the following information about your rights as a research participant. If you agree to take the survey, please hit the agree button on this page.

\section{POTENTIAL RISK}

The only foreseeable discomfort associated with this study is the invasion of your privacy. Measures will be taken to minimize that risk: responses will be confidential, and pseudonyms will be used when analyzing and disseminating our results in the final report.

\section{POTENTIAL BENEFITS}

There are no direct benefits from participation in the study. However, this study may benefit Latino male college students' educational experiences.

\section{CONFIDENTIALITY}

All research data collected will be stored securely and confidentially in a locked setting. Pseudonyms will be used throughout the study.

\section{PAYMENT/COMPENSATION FOR PARTICIPATION}

In appreciation of your time, you will receive a $\$ 10.00$ gift card of your choice from either Starbucks or Jamba Juice at the end of the one-on-one interview.

\section{PARTICIPANT RIGHTS}


Your participation in this study is completely voluntary. You can refuse to participate in the entire study or any part of the study without any negative effect on your relations with XXX XXX XXXX. You also have the right to skip any question you do not wish to answer. This is a written explanation of what will happen during the study if you decide to participate. You will not waive any rights if you choose not to participate, and there is no penalty for stopping your participation in the study.

\section{QUESTIONS OR PROBLEMS}

You are encouraged to ask questions at any time during the study.

- For further information about the study, please contact Ana Ramírez at XXXXXX-XXXX or ana.ramirez@sjsu.edu.

- Complaints about the research may be presented to Dr. Arnold Danzig, Director, EdD at San Jose State University, 408-924-3722.

- For questions about participants' rights or if you feel you have been harmed in any way by your participation in this study, please contact Dr. Pamela Stacks, Associate Vice President of the Office of Research, San Jose State University, at 408-924-2479.

\section{AGREEMENT TO PARTICIPATE}

Please select from the choices below. If you click agree, it is implied that you have read the information above about the research, understand your rights as a participant, and give your voluntary consent to participate. You should print a copy of this page and keep it for your records.
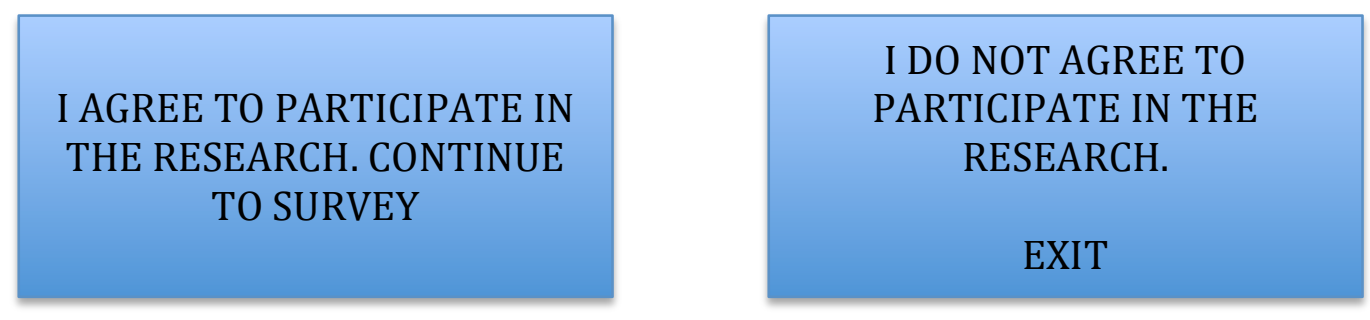

See https://goo.gl/forms/XF3PMQFW9JIBia4x2 


\section{Appendix C: Demographic Survey Profile}

Thank you for showing interest in participating in my dissertation study. As a participant you can expect to spend about two to three hours of you time. This time will include completing the following Demographic Survey Profile online (taking less than an hour) and participating in an individual interview (an hour to an hour and a half).

1. What is your first name?

2. Country of Birth . If you were born outside the United States of America (USA), how old were you when you arrived to this country?

3. What is your father's ethnicity?

4. What is your mother's ethnicity?

5. Check the generation that best applies to you: $1^{\text {st }}$ generation: you were born in a Spanish-speaking country (México, Nicaragua, Perú, etc.).

1.5 generation: you arrived to the USA as a child or as an adolescent.

$2^{\text {nd }}$ generation: you were born in the USA, either parent was born in any Spanishspeaking country.

$3^{\text {rd }}$ generation: you were born in the USA, both parents were born in the USA, and all grandparents were born in any Spanish-speaking country.

$4^{\text {th }}$ generation: you and your parents were born in the USA and at least one grandparent was born in any Spanish-speaking country with the remainder born in the USA.

$5^{\text {th }}$ generation: you and your parents were born in the USA.

I don't know what generation best fits.

6. What is your marital status? Single Married

7. Are you a father? Yes No

8. If you are a father how many children do you have?

9. Are you a full-time or part-time student (check one)? Full-time 12 units or more Part-time 6-11 units

10. Are you a transfer or non-transfer student (check one)? Transfer_ Non-transfer

11. What is your classification in college? Freshman/first year Sophomore Junior Senior Graduate Student

12. What is your major? You may indicate more than one, if applicable.

13. What have most of your grades been up to now at this institution? A's_B's C's D's F's

14. Do you work? Yes__ On campus__ Off campus _ 1-10 hours per week 11-20 hours per week 21-30 hours per week 31-40 hours per week More than 40 hours per week No, I don't work

15. Are you the first in your family to attend college? Yes No

16. Where do you now live during the school year? Dormitory or other campus housing __ Residence (apartment, house, etc.) within walking distance of the institution Residence (apartment, house, etc.) within driving distance Fraternity

17. Would you be willing to be contacted to participate in a one-on-one interview? Yes No 


\title{
Appendix D: Individual Interview Consent Form
}

\author{
Request for your Participation in Research \\ Latino Male College Students' Identities \\ Ana Ramírez, Graduate Student, Megan Thiele, \& Marcos Pizarro, Faculty Advisors
}

\section{PURPOSE}

You are being asked to participate in a qualitative research study examining how Latino male college students understand their racial and ethnic identity, gender identity, and academic identity. In addition, the study will investigate how Latino male college students' various identities impact their psychological stress and the coping mechanisms these students employ to mange their various identities' psychological stress.

\section{PROCEDURES}

In this voluntary individual interview you will be asked some questions that highlight your individual experiences as a Latino male college student. The interview questions will include details about your racial and ethnic identity, gender identity, and academic identity. Questions will also include how such identities impact your psychological stress and what coping mechanisms you employ to manage your psychological stress. The main goal of this study is to begin to address a significant research gap in regard to Latino male college students. The one-on-one interview will be audio-recorded. The audio-recorded interviews will be transcribed into text by a third party. The recordings are necessary and required for participating in this study. The interviews will be used as the data for this study. Ana Ramírez, doctoral candidate, will facilitate the interviews.

\section{POTENTIAL RISK}

The only foreseeable discomfort associated with this study is the invasion of your privacy. Measures will be taken to minimize that risk: responses will be confidential, and pseudonyms will be used when analyzing and disseminating our results in the final report.

\section{POTENTIAL BENEFITS}

There are no direct benefits from participation in the study. However, this study may benefit Latino male college students' educational experiences.

\section{CONFIDENTIALITY}

All research data collected will be stored securely and confidentially in a locked setting. Pseudonyms will be used throughout the study.

\section{PAYMENT/COMPENSATION FOR PARTICIPATION}

In appreciation of your time, you will receive a $\$ 10.00$ gift card of your choice from either Starbucks or Jamba Juice.

\section{PARTICIPANT RIGHTS}


Your participation in this study is completely voluntary. You can refuse to participate in the entire study or any part of the study without any negative effect on your relations with XXX XXX XXXX. You also have the right to skip any question you do not wish to answer. This is a written explanation of what will happen during the study if you decide to participate. You will not waive any rights if you choose not to participate, and there is no penalty for stopping your participation in the study.

\section{QUESTIONS OR PROBLEMS}

You are encouraged to ask questions at any time during the study.

- For further information about the study, please contact Ana Ramírez at XXXXXX-XXXX or ana.ramirez@sjsu.edu.

- Complaints about the research may be presented to Dr. Arnold Danzig, Director, EdD at San Jose State University, 408-924-3722.

- For questions about participants' rights or if you feel you have been harmed in any way by your participation in this study, please contact Dr. Pamela Stacks, Associate Vice President of the Office of Research, San Jose State University, at 408-924-2479.

\section{PARTICIPANT SIGNATURE}

Your signature indicates that you voluntarily agree to participate in the study, that the details of the study have been explained to you, that you have been given ample time to read this document, and that your questions have been satisfactorily answered. You may request a copy of this consent form for your records.

\section{Participant's Name (printed)}

\section{Participant's Signature}

\section{Date}

\section{Researcher Statement}

I certify that the participant has been given adequate time to read and learn about the study and all of his/her questions have been answered. It is my opinion that the participant understands the purpose, risk, benefits, and the procedures that will be followed in this study and has voluntarily agreed to participate. 


\section{Appendix E: Individual Interview Protocol}

\section{Opening Statement:}

Hello, thank you for participating in my dissertation study. The purpose of this individual interview is to ask you a series of questions that will focus on getting to know your racial and ethnic identity, gender identity, and academic identity. In addition, you will be asked how those identities impact your psychological stress and the coping mechanisms you employ to manage your psychological stress.

Date: Participant Pseudonym:

RSQ \#1 How do Latino male college students understand their racial and ethnic identity?

1. Tell me, what was the ethnic and racial composition of your neighborhood? Your high school?

2. Sometimes educational personnel have ideas about their students, whether positive or negative. Based on your personal experiences, has your race impacted how others perceive and treat you as a student? If yes, please explain: if no why not?

3. How has your racial and ethnic identity influenced your accomplishments and failures as a student? Please explain.

4. How would you define your ethnicity? How important is this identity to you? Please explain.

5. Has this university campus had an impact on your ethnic identification? How so or why not?

6. Have you ever been singled out at this institution because of your racial and ethnic identity? If yes, please explain and provide examples.

RSQ \#2 How do Latino male college students understand their gender identity?

7. How have you come to understand what it means to be a Latino man? Please explain.

8. Describe your gender role values? How do you feel about them?

9. How close do you feel to your family? Please explain.

10. Under the concept of "man of the house," describe your role within your family? (Tell me about your family responsibilities.).

11. Overall, does the college setting support or threaten your gender identity? How so or why not? Please explain. (Prompt: How do your familial responsibilities impact you as a college student?)

12. What has been the best part of being a Latino male for you in college?

13. What has been the most difficult part of being a Latino male for you in college?

14. In general, would you say you would rather figure out how to do things on your own or seek help? Please explain and give an example.

15. Do you feel you are expected to succeed because of your gender? Why or why not? (What happens if you fail? How do you feel? What do you do? Please explain.).

16. Has your understanding of what it means to be a man changed due to being a Latino college student? 
17. How would you define un hombre de familia (a family man)?

RSQ \#3 How do Latino male college students understand their academic identity?

18. Are their times when you feel academically unprepared for your studies at this school? How so or why not? Please explain.

19. Do you feel comfortable with the workload so far? How does it compare to your high school workload? Do you feel your high school prepared you well for your studies here? How so, or why not?

20. How are you doing grade-wise? Please explain.

21. If you struggle academically or need help with class assignments, what do you do? Please explain and give examples.

22. What university resources are you aware of? Would you feel comfortable going to these centers for help? Why or why not?

23. Do you participate in any extracurricular activities? If yes please explain: if no why not? What do you feel you receive from participating in organized activities?

24. Tell me about your interactions with White faculty? Faculty of color?

25. Tell me about your interactions with non-Latina/o peers? With Latina/o peers?

26. Have you taken any courses about your racial/ethnic identity? If yes why? Or why not?

RSQ \#4 How do Latino male college students' various identities impact their psychological stress?

27. Have you experienced stress due to your racial and ethnic, gender, and/or academic identities at this institution? If yes, please explain and provide examples. (If not, what causes you to stress at this institution?)

28. Describe the feelings you feel when you experience stress due to your identities at this institution. Prompt: What else do you experience when you are stressed? Do you ever feel sad? Depressed? What is usually the trigger for these feelings? (Note if participants are not experiencing stress due to their identities, then ask, Based on the things you previously mentioned that caused you to stress at this institution, describe what feelings you feel. Prompt: What else do you experience when you are stressed? Do you ever feel sad? Depressed? What is usually the trigger for these feelings?

29. At this institution, have you heard faculty, classmates, or others express stereotypes, racial jokes, and/or insults about your racial/ethnic group? If yes, please explain and give examples. How did that make you feel? (If not, how do faculty and classmates talk about your racial/ethnic group? Give examples. How did that make you feel?)

RSQ \#5 What coping mechanisms do Latino male college students employ to manage their various identities' psychological stress? 
30. Tell me of the ways you deal with stress. (Prompt for positive or negative means of coping, prompt for resources such as family, social support, etc.).

31. Are you aware of any university resources that are available for students to cope with stress? Would you feel comfortable going to these centers for help? Why or why not?

32. How do you feel about sharing your personal emotions, concerns and experiences with others?

33. Based on your experiences, would you rather cope with stress by seeking professional help or by using an informal coping mechanism?

34. Given the gender gap in achieving college degrees, particularly for Latino males, why do you think Latino male students struggle to achieve a college degree?

35. Ending question: Do you have anything else that you would like to share about your educational experience as a Latino male? Or anything else?

Closing:

This concludes the one-on-one individual interview of the study. If you have any questions, please email me at ana.ramirez@sjsu.edu or call me at XXX-XXX-XXXX Thank you for your time. 


\section{Appendix F: Recruitment Email to Stakeholders}

Greetings, My name is Ana Ramírez. I am a doctoral candidate in the Educational Leadership program at San José State University. I am conducting a research study as a part of the requirements for my degree. The purpose of this research study is to investigate how Latino male college students understand their racial and ethnic identity, gender identity, and academic identity. In addition, the study investigates how Latino male college students' various identities impact their psychological stress. I am also investigating the coping mechanisms these students employ to manage their psychological stress.

This study has been reviewed and approved by the SJSU Institutional Review Board. Currently, I am recruiting male volunteer participants from the Colleges of Engineering and Social Sciences (see Recruitment Flyer). Please let me know if you can help me announce this study and distribute recruitment flyers through one of the following options:

(1) Make an announcement to students about this research study by announcing the following: "A student from San José State Doctoral program is conducting a research study about Latino Male College Students' Identities and needs volunteer participants. Here are some flyers for more information." (I will deliver flyers to your department office.)

(2) Announce to your students, "Research study information" and display the attached flyer to your students for a few minutes so they can write down my contact information.

(3) Allow me to announce my study to your students at a time that is convenient for you. The brief announcement will be as follow: "My name is Ana Ramírez. I'm a student from San José State Doctoral program, and I'm conducting a research study about Latino Male College Students' Identities. I'm recruiting volunteer participants. Here are some flyers for more information. Please email me or call me if you have questions or want to participate. My email and phone number are on the flyer."

(4) Unable to help at this moment.

Please email me or call me to let me know which option works for you or if you have any questions ana.ramirez@sjsu.edu or XXX-XXX-XXXX

Thank you for your time,

Ana Ramírez

Doctoral Student SJSU 
Appendix G: Recruitment Flyer

\section{Volunteers Wanted for a Research Study Study Title: Latino Male College Students' Identities}

Be part of a Research Study

1. Do you identify as a Male?

2. Do you identify as a Latino?

3. Are you an engineering major or social science major?

4. Have you been a student at this institution for one or more years?

If you answered YES to all of these questions, you may be eligible to participate in this research study.

\section{PURPOSE}

The purpose of this research study is to investigate how Latino male college students understand their racial and ethnic identity, gender identity, and academic identity. In addition, it investigates how Latino male college students' various identities impact their psychological stress and the coping mechanisms these students employ to mange their psychological stress.

\section{PROCEDURES}

Participants will be invited to complete a Potential-Participant Questionnaire (online, administered via Google Forms, approximately five minutes). A follow-up email will be sent to those students that have been identified as potential participants, inviting them to complete a Demographic Survey Profile (online, administered via Google Forms, approximately one hour) and a One-on-One Interview, which will be audio-recorded and transcribed by a third party (approximately an hour to an hour and a half). After you have consented to participate by agreeing to the conditions outlined on the consent forms, Ana Ramírez, doctoral candidate, will facilitate the interviews.

\section{COMPENSATION}

In appreciation of your time, you will receive a $\$ 10.00$ gift card of your choice from either Starbucks or Jamba Juice.

If you have any questions or are interested in participating, please contact principal investigator Ana Ramírez, doctoral candidate student in the Educational Leadership program as SJSU, at ana.ramirez@sjsu.edu. 


\section{Appendix H: Participants Demographic Survey Profiles}

Participant 1: Galindo

Galindo is 23 years old and identifies as first generation since he was born in México and came to the United States when he was 11 years old. His father is from Nicaragua and his mother is from Guatemala. Galindo is single and has no children. He is a transfer student currently attending his junior year as a fulltime student. He is a social science major, with an emphasis in Economics. So far, most of his grades are Bs. He works 30 hours per week and is the first in his family to attend college.

Participant 2: Ramos

Ramos is 38 years old and a second generation Mexican American whose parents are both Mexican. He is married and has no children. He is a senior fulltime transfer student who will graduate Spring 2017 from the College of Social Sciences, with an emphasis in anthropology. He works 10 hours per week, and most of his grades have been As. He is the first in his family to attend college.

Participant 3: Rivaldo

Rivaldo is 20 years old and a second-generation Honduran American whose parents are both Honduran. He is single and has no children. He is a sophomore fulltime nontransfer student and social science major, with an emphasis in political science. He works 10 hours per week, and most of his grades are Bs. He is the first in his family to attend college.

Participant 4: Giovanni

Giovanni is 20 years old and a second-generation Mexican American whose parents are both Mexican. He is single and has no children. He is a junior fulltime non-transfer student and a social science major, with an emphasis in political science. He does not work, and most of his grades are As. He is the first in his family to attend college.

\section{Participant 5: Cienfuegos}

Cienfuegos is 23 years old and a second-generation Salvadoran American whose parents are both Salvadoran. He is single and has no children. Cienfuegos is a senior fulltime non-transfer student who will graduate Spring 2017 from the College of Social Sciences, with an emphasis in political science. He works 30 hours per week, and most of his grades are Bs. He lives in a fraternity house and he is the first in his family to attend college.

Participant 6: Luis Enrique

Luis Enrique is 21 years old and a second-generation Mexican Nicaraguan American whose parents are Mexican and Nicaraguan. He is single and has no children. He is a senior fulltime non-transfer student and a social science major, with an emphasis in sociology, concentrating in community change. He works 20 hours per week, and most of his grades are Bs. He has been highly involved in serving in leadership roles such as 
Residential Life and University Housing Services. Luis Enrique lives in a fraternity house and is the first in his family to attend college.

Participant 7: Neymar

Neymar is 20 years old and a second-generation Peruvian American whose parents are both Peruvian. He is single and has no children. He is a junior fulltime non-transfer student and social science major, with an emphasis in psychology. He works 20 hours per week, and most of his grades are Bs. He is the first in his family to attend college.

Participant 8: Blanco

Blanco is 21 years old and a second-generation Mexican American whose parents are both Mexican. He is single and has no children. Blanco is a junior fulltime non-transfer student and a social science major, with an emphasis in psychology. He works 20 hours a week, and most of his grades are Bs. He is the first in his family to attend college.

\section{Engineering Participants Demographic Survey Profiles}

Participant 9: Pelé

Pelé is 24 years old and identifies as a first-generation Mexican student since he was born in México and both parents are Mexican. He is single and has no children. Pelé is a junior fulltime transfer student and an engineering major, with an emphasis in mechanical engineering. He works 20 hours per week, and most of his grades are Bs. He is the second in his family to attend college.

Participant 10: Luna

Luna is 28 years old and identifies as a first-generation Mexican since he was born in México and both parents are Mexican. He is single and has no children. Luna is a junior fulltime transfer student and an engineering major, with an emphasis in electrical engineering. He works 20 hours per week, and most of his grades are Cs. He is the second in his family to attend college.

Participant 11: James

James is 20 years old and a second-generation Mexican American whose parents are both Hispanic. He is single and has no children. James is a senior-part time transfer student and an engineering major, with an emphasis in electrical engineering. He does not work, and most of his grades are Bs. He is the second in his family to attend college.

Participant 12: Borgetti

Borgetti is 27 years old and a second-generation Mexican American whose parents are both Mexican. He is single and has no children. Borgetti is a junior fulltime transfer student and an engineering major, with an emphasis in mechanical engineering. He does not work, and most of his grades are Cs. He is the second in his family to attend college.

Participant 13: Guardado 
Guardado is 23 years old and a second-generation Mexican American whose parents are both Mexican. He is single and has no children. He is a junior fulltime transfer student and an engineering major, with an emphasis in mechanical engineering. He works 30 hours per week, and most of his grades are Bs. He is the first in his family to attend college.

Participant 14: Zague

Zague is 21 years old, was born in the United States, and identifies as a Mexican. His parents are both Mexican. He is single and has no children. He is a senior fulltime transfer student and an engineering major, with an emphasis in mechanical engineering. He does not work, and most of his grades are As. He is the first in his family to attend college.

Participant 15: Roberto Carlos

Roberto Carlos is 22 years old and identifies as a Chicano student whose parents are both Mexican. He is single and has no children. Roberto Carlos is a senior fulltime transfer student and an engineering major, with an emphasis in chemical engineering. He works 40 hours per week, and most of his grades are B minuses. He is the first in his family to attend college.

Participant 16: Alves

Alves is 27 years old and a generation 1.5 who arrived in this country when he was two years old. He identifies as a Chicano, and both of his parents are Mexican. He is single and has no children. Alves is a junior fulltime transfer student and an engineering major, with an emphasis in chemical engineering. He works 20 hours per week, and most of his grades are Cs. He is the first in his family to attend college.

Participant 17: Ochoa

Ochoa is 23 years old and a generation 1.5 who arrived in this country when he was nine years old. He identifies as a Mexican American, and both of his parents are Mexican. He is single and has no children. Ochoa is a senior fulltime transfer student and an engineering major, with an emphasis in mechanical engineering. He works 30 hours per week, and most of his grades are Cs. He is the first in his family to attend college.

Participant 18: Ronaldo

Ronaldo is 21 years old and identifies as a first-generation Mexican who arrived in this country when he was eight years old. Both parents are Mexican. He is single and has no children. Ronaldo is a junior fulltime non-transfer student and an engineering major, with an emphasis in electrical engineering. He works 10 hours per week, and most of his grades are Bs. He is the first in his family to attend college.

Participant 19: Campos

Campos is 22 year old and identifies as a first-generation Mexican who arrived in this country when he was seven years old. Both parents are Mexican. He is single and has no 
children. Campos is a sophomore fulltime non-transfer student and an engineering major, with an emphasis in aerospace engineering. He works 30 hours per week, and most of his grades are Cs. He is the first in his family to attend college.

Participant 20: Hermosillo

Hermosillo is 22 years old and a generation 1.5 who arrived in this country when he was five years old. He identifies as Mexican, and both parents are Mexican. He is single and has no children. Hermosillo is a junior fulltime non-transfer student and an engineering major, with an emphasis in aerospace engineering. He works 20 hours per week, and most of his grades are Bs. He is the first in his family to attend college.

Participant 21: Hérnandez

Hernández is 20 years old and a generation 1.5 who arrived in this country when he was four years old. He identifies as a Mexican American, and both parents are Mexican. He is single and has no children. Hernández is a junior fulltime non-transfer student and an engineering major, with an emphasis in aerospace engineering and a minor in astronomy. He does not work, and most of his grades are Bs. He is the first in his family to attend college.

Participant 22: Wondo

Wondo is 24 years old and a second-generation Mexican American whose parents are both Mexican. He is single and has no children. Wondo is a senior part-time nontransfer student and an engineering major, with an emphasis in computer engineering. $\mathrm{He}$ works 30 hours per week, and most of his grades are Bs. He is the first in his family to attend college. 